Portland State University

PDXScholar

6-11-2019

\title{
Making Race Matter: Interrupting Racial Color- blindness in Education Through the Implementation of Anti-racist Curriculum
}

Kelly Deits Cutler

Portland State University

Follow this and additional works at: https://pdxscholar.library.pdx.edu/open_access_etds

Part of the Curriculum and Instruction Commons, and the Educational Leadership Commons Let us know how access to this document benefits you.

Recommended Citation

Cutler, Kelly Deits, "Making Race Matter: Interrupting Racial Color-blindness in Education Through the Implementation of Anti-racist Curriculum" (2019). Dissertations and Theses. Paper 5494.

https://doi.org/10.15760/etd.7368

This Dissertation is brought to you for free and open access. It has been accepted for inclusion in Dissertations and Theses by an authorized administrator of PDXScholar. Please contact us if we can make this document more accessible: pdxscholar@pdx.edu. 
Making Race Matter: Interrupting Racial Color-blindness in Education

Through the Implementation of Anti-racist Curriculum

by

Kelly Deits Cutler

A dissertation submitted in partial fulfillment of the requirements for the degree of

Doctor of Education

in

Educational Leadership: Curriculum and Instruction

\author{
Dissertation Committee: \\ Dot McElhone, Chair \\ Esperanza De La Vega \\ Anita Bright \\ Maude Hines
}

Portland State University

2019 
(C) 2019 Kelly Deits Cutler 


\begin{abstract}
The United States continues to be a highly racialized society. As a result, race remains a predictor of educational achievement for students in the PK-12 public education system. Concurrently, racial color-blindness continues to dominate educational institutions, as teachers_-particularly White teachers_-often feel uncomfortable and ill prepared to talk with students about race. One approach that educators have developed to combat color-blindness in schools is anti-racist curriculum. Such curriculum directly teaches students about race and intentionally interrupts the color-blind ideology.

This research study sought to understanding how teachers attending a series of collaborative professional development sessions experienced the process of designing and implementing anti-racist curriculum. The qualitative data collected for this research incorporated participant observations, semi-structured interviews, participant journal entries, and completed lesson plans. The data were transcribed, coded, analyzed through the theoretical framework of transformative curriculum as a means for answering the research questions and generating findings. The findings indicated that the collaborative experiences were beneficial for the participants, not only to construct curriculum but to foster new "anti-racist" lenses. Yet, the findings also spoke to the complexity and everpresent challenges faced by teachers attempting to implement such curriculum. This study calls for educational leaders, teacher educators, and teachers to challenge racial inequalities and color-blind ideology with anti-racist curriculum to actualize educational equity in schools.
\end{abstract}


Table of Contents

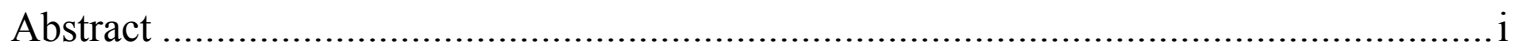

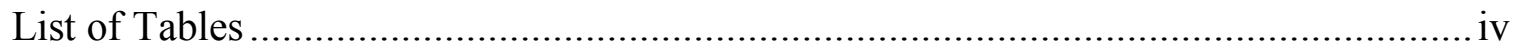

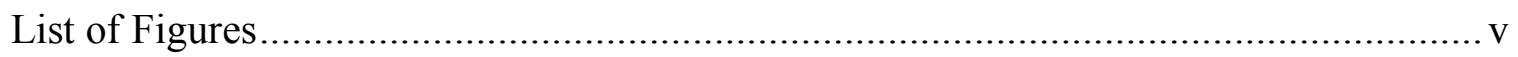

Chapter I: Problem of Practice ........................................................................... 1

Statement of the Problem of Practice....................................................................... 1

Society Founded on Systemic Racism............................................................... 4

The New Racism: Color-blindness ................................................................... 5

Color-blindness in Education .......................................................................... 7

Eurocentric Curriculum .......................................................................... 9

Talking about Race and Anti-racist Education........................................... 10

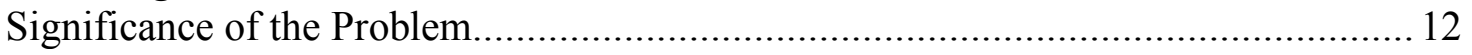

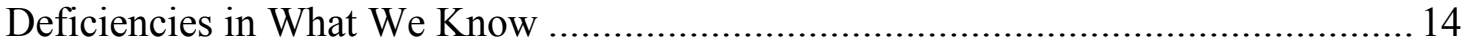

Research Purpose and Rationale ....................................................................... 15

Research Questions ................................................................................... 16

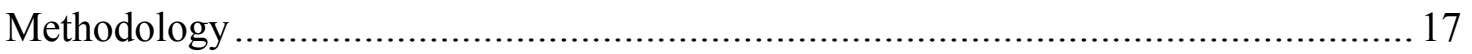

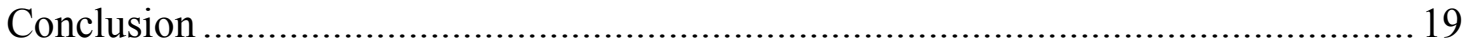

Chapter II: Review of the Literature ................................................................. 22

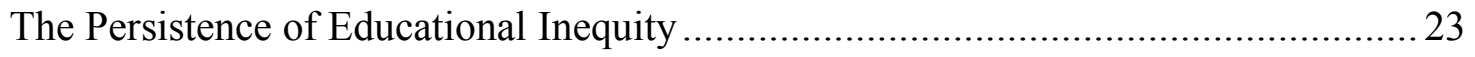

Color-blindness: The Silence around Race in Education ..................................... 25

Teachers Do Not Talk about Race ........................................................................ 26

Consequences of Not Talking about Race ........................................................ 31

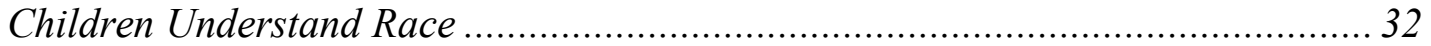

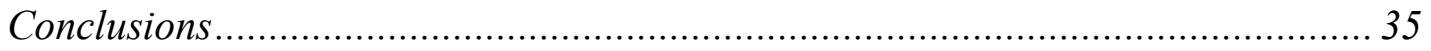

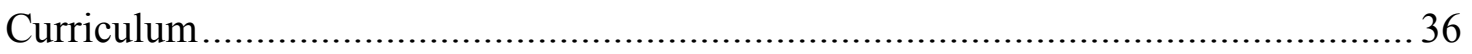

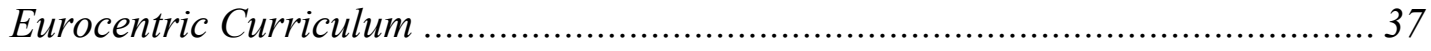

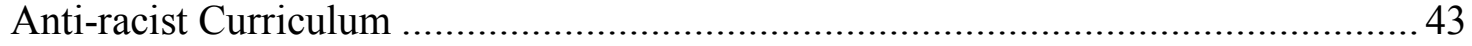

Defining Anti-racist Curriculum ....................................................................... 43

Research on Anti-racist Curriculum ............................................................. 47

Shortcomings of Anti-racist Curriculum ....................................................... 53

Theoretical Framework: Transformative Curriculum ......................................... 54

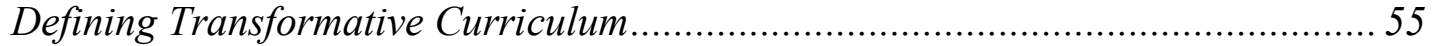

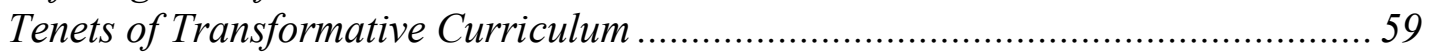

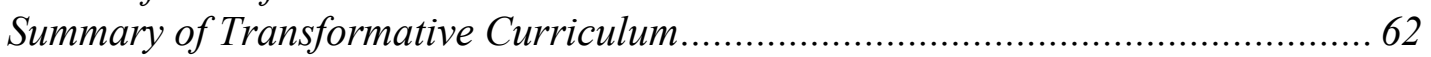

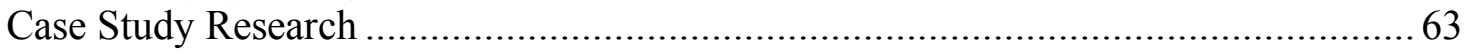

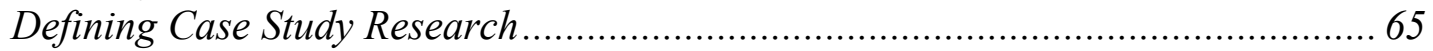

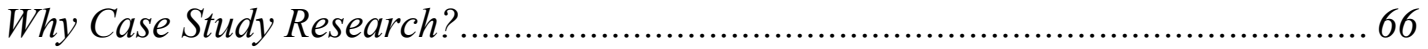

Research Studies Using Case Study Methodology......................................... 67

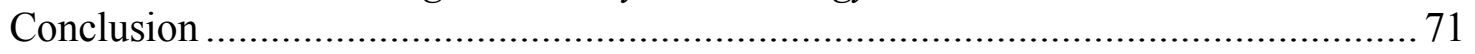




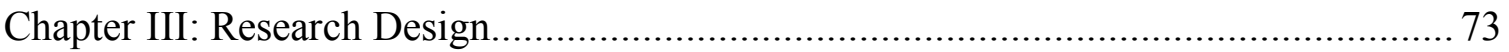

Case Study Research ................................................................................... 73

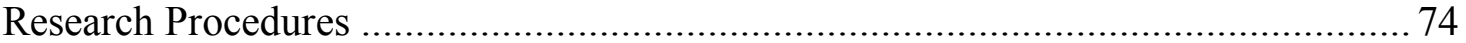

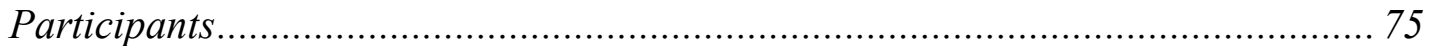

Collaborative Professional Development Sessions ............................................. 78

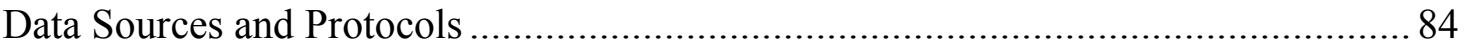

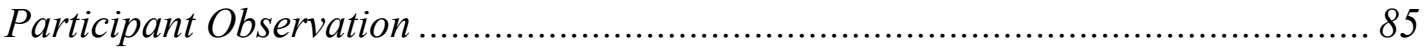

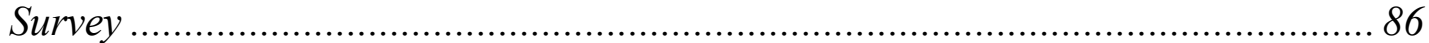

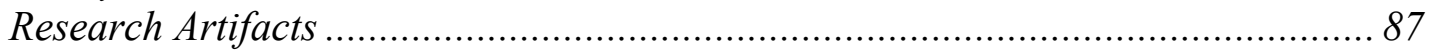

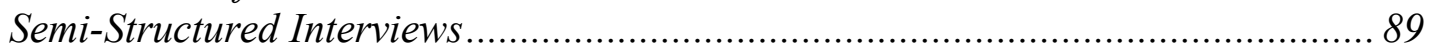

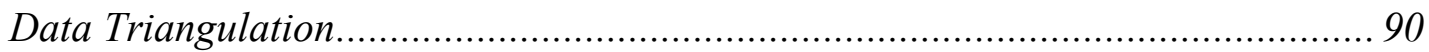

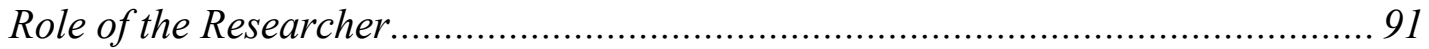

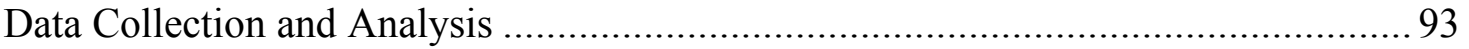

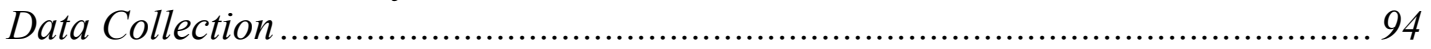

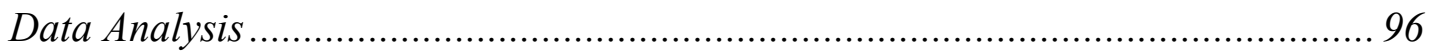

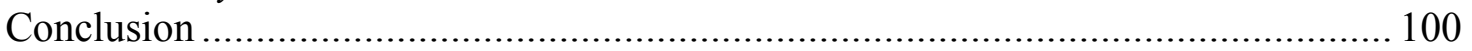

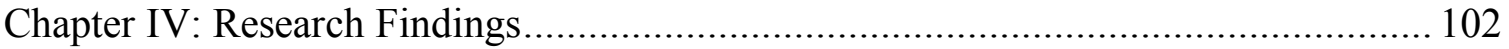

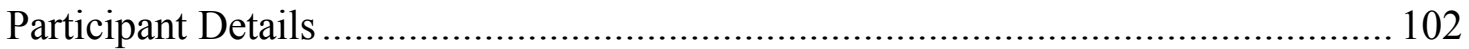

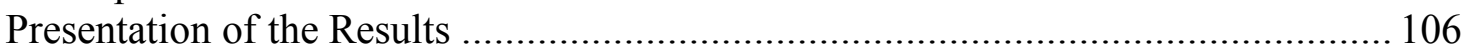

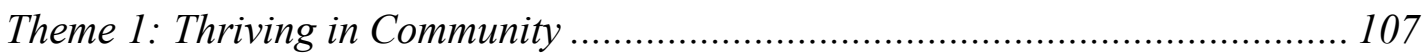

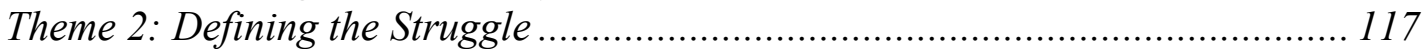

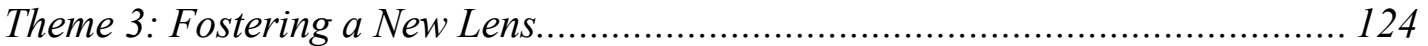

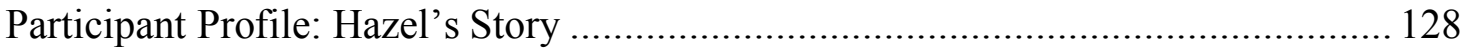

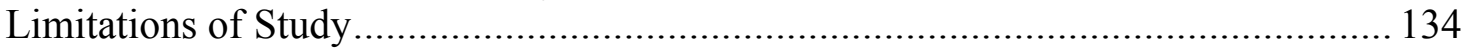

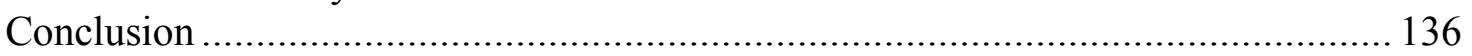

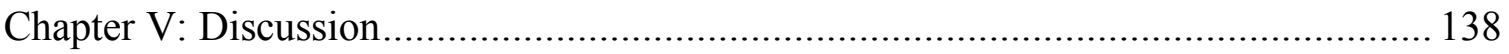

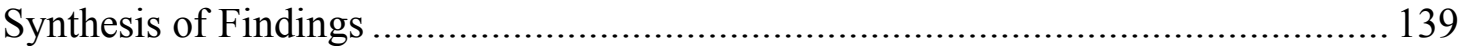

Positive Experiences with Collaborative Planning........................................... 139

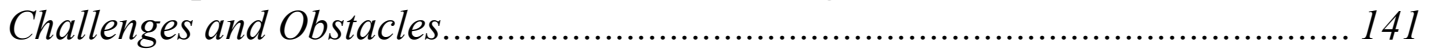

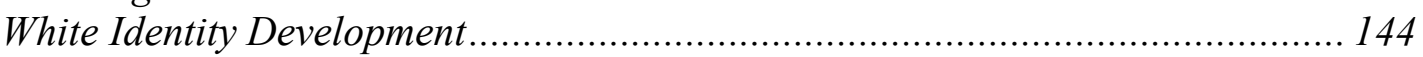

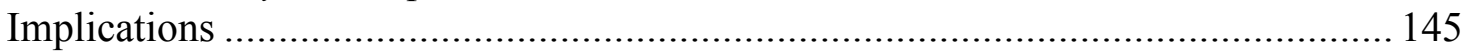

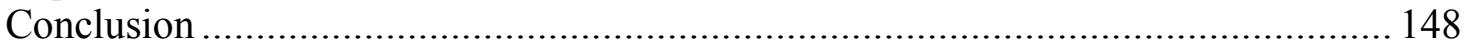

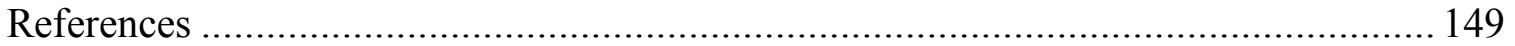

Appendix A: Written Informed Consent ............................................................. 166

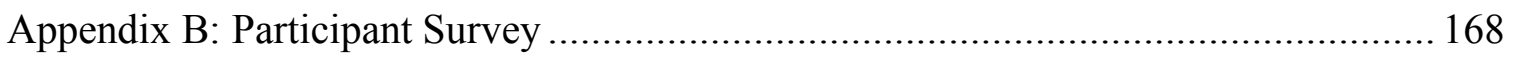

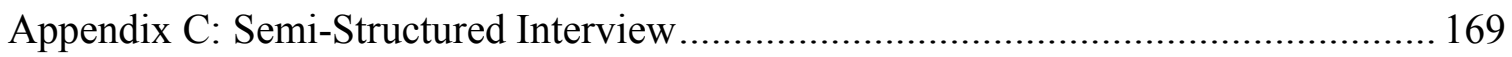

Appendix D: Participant Observation Protocol .................................................... 175

Appendix E: Participant Reflective Journal Prompts.................................................... 176 


\section{List of Tables}

Table 1. Research Questions \& Data Collection Sources ......................................... 18

Table 2. Tenets of Anti-racist Curriculum ............................................................... 58

Table 3. Overview Conceptual Framework of Culturally Responsive Pedagogy ............ 59

Table 4. Overview of Research Procedures \& Resources......................................... 75

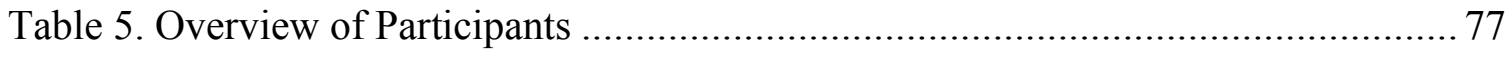

Table 6. Outline of Collaborative Professional Development Sessions ....................... 79

Table 7. Research Questions \& Data Collection Sources ......................................... 94

Table 8. Results of Study: Main Themes \& Subthemes .......................................... 107

Table 9. Research Theme $1 \&$ Connection to Theoretical Framework.......................... 109

Table 10. Research Theme $2 \&$ Connection to Theoretical Framework....................... 117

Table 11. Research Theme 3 \& Connection to Theoretical Framework....................... 125 


\section{List of Figures}

Figure 1. Transformative curriculum: Incorporating critical pedagogy, anti-racist

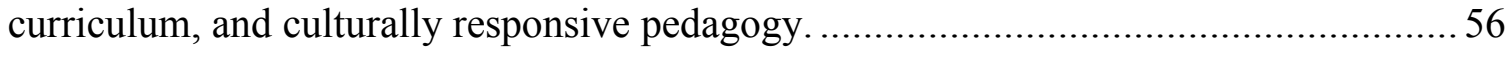

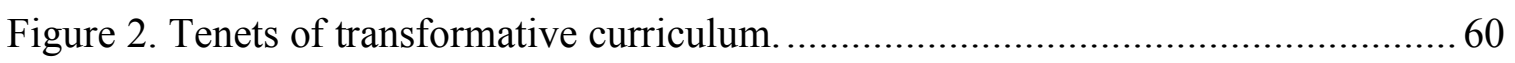

Figure 3. Overarching components of transformative curriculum. ............................... 63

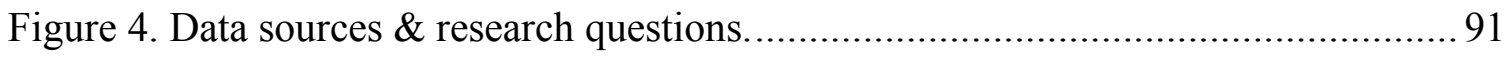

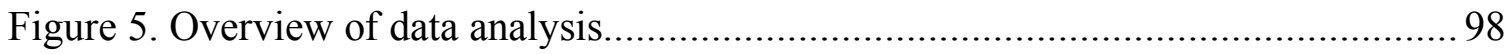

Figure 6. Generated themes and subthemes from data analysis.................................... 99 


\section{Chapter I \\ Problem of Practice}

If we are serious about democracy, if we are serious about providing equal opportunity for all citizens, if we are serious about equity and justice, then we have to undo any model that obliquely serves to replicate a racist past (Delpit, 2012, p. 119).

As a White woman raised in the suburbs surrounding a predominantly White metropolitan area, I was indoctrinated at a young age with the idea of meritocracy based on the notion that "we are all created equal" and carried such color-blind beliefs of equality into my professional career as an educator. It was not until I was confronted with the realities of a race-based society in my first teaching job in a racially, culturally, and linguistically rich school district that I began to dismantle those beliefs. Through students' experiences, I witnessed the perpetuation of the achievement gap, as many students - especially students of color — were academically left behind. Year after year, our staff discussed the standardized assessment scores and noted how students of color scored well below their White counterparts. In addition, I observed students of color being disproportionately disciplined, often with more severe consequences than those given to White students. Yet I encountered only silence about the topics of race and racial inequities in education. Despite the high racial diversity of my schools, the curriculum was devoid of instruction that directly addressed the topic of race. In my 12 years as a classroom teacher, during which time I used over 20 district-adopted curricular programs, I never encountered a single lesson about race, racism, or racial inequities. 
Racialized educational inequities persist in U.S. public schools despite their legal desegregation (Brown v. the Board of Education of Topeka in 1954) and federal legislation intended to address inequities, such as the Civil Rights Act of 1964, the Elementary and Secondary Education Act (ESEA) of 1965, and the No Child Left Behind Act (NCLB) of 2001(Mondale \& Patton, 2001). As a result of persistent opportunity inequality in schools, race remains a predictor of educational achievement for students in the PK-12 public education system in the United States (Conley, 1999; Kao \& Thompson, 2003; Solórzano, Villalpando, \& Oseguera, 2005). Educational inequity refers to systematic discrepancies in educational opportunities and services, which impacts individual students' abilities to enroll in, excel in, and graduate from educational programs (Kozol, 2012; Maslak, 2009). In the United States, educational opportunities for students of color are compromised because systematic preferences for Whites are often invisible and viewed as "normal" (McIntosh, 2010; Perry, 2002). For instance, predominant cultural norms and curricula used in education reflect White, Eurocentric, middle-class values and history, since the history of the United States has generally been written from the conquerors' points of view ( $\mathrm{Au}, 2009$; Banks, 1991; Ladson-Billings, 2001; Nieto \& Bode, 2012). Therefore, the standard version of history presented in schools is often sanitized and Whitewashed (Gillborn, 2009).

While nearly $84 \%$ of teaching professionals are educators with White, European American backgrounds (Feistritzer, 2011), 46\% of children in the United States identify as members of a racial minority group (Fowler, 2013). Ladson-Billings 
(1991) suggests that many White middle-class educators suffer from "multicultural illiteracy" and have limited experiences with and awareness of the perspectives of people beyond the dominant European American culture. Furthermore, as cultural transmitters, educators use their cultural power and Eurocentric educational philosophies in attempts to mold "other people's" children to the dominant cultural and linguistic norms (Delpit, 1988). Consequently, much of the curriculum and many of the normative expectations in U.S. schools are not reflective of a large portion of students and their lived experiences. As Banks (2001) states:

A curriculum that focuses on the experiences of mainstream Americans and largely ignores the experiences, cultures, and histories of other ethnic, racial, cultural, language, and religious groups has negative consequences for both mainstream students and students of color. A mainstream-centric curriculum is one major way in which racism and ethnocentrism are reinforced and perpetuated in the school (p. 242).

As a result, educational scholars have called for curricula that are rooted in the actual lives of students, reflecting racial, cultural, and linguistic diversity and historical representations incorporating multiple perspectives.

Critical race theory (CRT) has further urged moving beyond the mere representation of students of color in the curriculum, because racism is a permanent fixture in life in the United States that needs to be unmasked and exposed (Bell, 1992). CRT views mainstream curriculum as a set of cultural artifacts designed to maintain a White-supremacist master script (Ladson-Billings, 2009). CRT suggests that educational achievement gaps will not be closed unless educators take a serious look at race and the history of educational inequities in the United States (Horsford \& Grosland, 2013). 
Therefore, direct teachings about race, racism, and racial inequities must be embedded within the curricula.

\section{Society Founded on Systemic Racism}

Throughout U.S. history, laws, policies, and social norms have systematically reinforced a racial hierarchy, leaving many people disenfranchised and disadvantaged (Bonilla-Silva, 2014; Howard, 2010; Katz, 2003; Lewis, 2004; Marable, 2002; Nieto $\&$ Bode, 2012). The nation's Founding Fathers drew upon European scientist Carl Linnaeus' conceptions of scientific racism, which noted Europeans as the biologically superior race (Goodman, 2008; Kailin, 2002; Pollack, 2008). That myth of White racial superiority was used to justify the colonization of the Americas, the mass genocide of Native Americans (Duran, Duran, \& Brave Heart, 1998; Wolfe, 2006), the enslavement of Africans (Goodman, 2008; Hilliard, 2014; Pollack, 2008), and racial segregation during the Jim Crow era (Bonilla-Silva, 2014; Pilgrim, 2012).

Contemporary scientists have since refuted the claim that race is a biological category, as humans are genetically about $99.9 \%$ alike; therefore, racial categories are not biological realities but social constructions (Goodman, 2008; Mukhopadhyay \& Henze, 2003; Smedley \& Smedley, 2005).

Unfortunately, neither the dismantling of the Jim Crow laws nor the proof of biological similarity between all people has meant the end of racism in the United States. Rather, race relations have taken on new characteristics, featured as systemic racism, affecting educational opportunities, academic achievement, employment, housing, and involvement with the justice system for people of color. Systemic racism 
can be defined as, "attitudes, actions, or practices by an individual or institution, backed up by societal power, that undermine human and legal rights, economic opportunities, and cultural expressions of people because of their racial or ethnic identity" (Derman-Sparks \& Ramsey, 2011, p. 310). As an example, the Center for American Progress (2015) reported that, during the 2012-13 school year, nearly 1.2 million Black students and 1 million Hispanic students attended schools where their standardized assessment scores were at least 10 percentage points below their schools' overall performance levels (Sargrad, Marchitello, \& Hanna, 2015). According to Turner, Ross, Glaster, and Yinger (2002) and the Housing Discrimination Study, Blacks and Latinos experienced discrimination in nearly half of their endeavors to rent or buy homes. Additionally, in 2015 Black citizens were three times more likely to be killed by police officers than were White citizens. Black males, who constituted $6 \%$ of the U.S. population, represented $40 \%$ of the unarmed citizens killed by police in that same year (Kindy, Fischer, Tate, \& Jenkins, 2015). According to Stovall (2013), the current post-racial rhetoric contradicts the material realities of communities of color in the United States and across the world.

\section{The New Racism: Color-blindness}

Over the last forty years, there has been a significant decline in overt expressions of racial prejudice, as social norms have shifted racial etiquette, redefining appropriate racial discourse (Bonilla-Silva \& Forman, 2000; Schuman, 1997). Yet, despite changes in legal statutes and social norms, the manifestations of racism in the current post-civil-rights era seems to have simply become more subtle and difficult to 
detect (Banks \& Banks, 2013; Bobo, Kruegel, \& Smith, 1997; Bonilla-Silva, 2001; Bonilla-Silva \& Forman, 2000; Crenshaw, 1997; Forman, 2004; Jones, 1999; Lewis, 2004; Lewis \& Diamond, 2015). Many Americans claim they do not see race or that they are beyond race, largely because racism has traditionally been narrowly defined in the United States, particularly by Whites (Bonilla-Silva, 2014; Bonilla-Silva, et al. 2003; Frankenberg, 1993; Lewis 2001; Ullucci \& Battey, 2011). According to BonillaSilva (2014), while most people of color would characterize racism as a systemic or institutional problem, Whites commonly perceive racism as isolated, overt acts of prejudice perpetrated by racist individuals, largely in the past.

The "new racism," in the supposed post-racialized society, is more covert and dominated by the notion of color-blindness (Banks \& Banks, 2013; Bonilla-Silva, 2014; Crenshaw, 1997; Forman, 2004; Lewis, 2004; Lewis \& Diamond, 2015). Individuals who subscribe to the color-blind ideology generally perceive themselves as completely free of prejudice. As a result, their lack of awareness can covertly manifest as "implicit bias," wherein these individuals are unaware of their assumptions and behaviors toward other racial groups (Dovidio, Gaertner, Kawakami, \& Hudson, 2002; Tatum, 2003). In reality, most people hold implicit racialized biases, which generally operate outside the level of conscious awareness (Sleeter, 2008; Sue, 2005, 2015). Ultimately, the color-blind ideology is problematic because it ignores the impact of systemic racism and denies that race has consequences in the lives of people of color, while continuously covering up implicit racial biases that are often subtle and nuanced (Derman-Sparks \& Ramsey, 2011; Rosenberg, 2004). 


\section{Color-blindness in Education}

A particularly troubling way in which color-blindness manifests itself in the United States is through silence about race and racism in PK-12 curriculum, instruction, and student educational experiences. Lewis and Diamond (2015) described "structural inequities, institutional practices, and racial ideologies that mutually reinforce each other and collectively generate different educational trajectories, but today often appear to be non-racial" (p. 167). Milner (2010) contended that educators often adopt a color-blind lens because they believe that race is inconsequential in education. This is problematic because educators' implicit racialized biases and assumptions then remain unchecked, and their unconscious discrimination can manifest itself as complacency in maintaining existing systems of privilege and oppression without questioning the racist assumptions

deeply embedded in the curricula (Cochran-Smith, 2000). Students' identities, which are critical to their academic achievement, are compromised when teachers are unable to identify and then move beyond their own racialized biases and assumptions (Delpit, 2006; Ladson-Billing, 2004; Tyson, 2003).

Further, Nieto and Bode (2012) acknowledged that well-intended teachers can unintentionally discriminate when they remain silent about race and racism, fearing that talking about race will only intensify the problem of racism. In reality, Milner (2010) suggested that, by maintaining a color-blind mindset, educators can actually exacerbate educational inequities for students of color. For instance, subtle discriminatory practices in schools can appear in disciplinary measures. Students of color, particularly Black students, Native American students, and multiracial students, 
are more frequently targeted for disciplinary actions in schools and are more likely to receive severe punishments than are their White peers (Johnston, 2000; Monroe, 2005; Noguera, 2008; Skiba et al., 2011; Townsend, 2000). In March 2014, the U.S. Department of Education Office of Civil Rights (OCR) released a report that noted disproportionately high rates of suspension and expulsion for students of color, especially Black students. Specifically, Black students are three times more likely to be suspended and 1.9 times more likely to be expelled than are White students (OCR, 2014). According to the Schott Foundation for Public Education (2006), if Black male students were suspended or expelled at the same rate as White male students, there would be approximately 500,000 fewer out-of-school suspensions and 10,000 fewer expulsions per year in the United States (Holzman, 2006).

Researchers have found that, although the behavioral offenses may be similar between Black and White students, Black students are more likely to be classified as insubordinate while White students are labeled as disruptive, and the categorization of these offenses can lead to different consequences (Skiba, Michael, Nardo, \& Peterson, 2002). In a national study of 364 elementary and middle schools, Skiba, Horner, Chung, Rausch, May, and Tobin (2011) found that African American and Latinx students were overrepresented in suspensions and expulsions relative to White students. Thus, research suggested that educators' implicit racialized biases and assumptions significantly contribute to racial disparities in school discipline.

Although the existence of the color-blind ideology in the United States is a wellresearched phenomenon, there is limited scholarship focused on the prevalence of color- 
blindness in the PK-12 education system. Only in the last few decades have researchers begun to document how racial color-blindness can manifest itself in the public school system, largely through ethnographic research. As an example, Lewis and Diamond (2015) conducted a five-year ethnographic study of Riverview High School, located in the Midwest of the United States. They observed patterns of racial inequality and colorblind discourse, which were reinforced by institutional practices and racial ideologies that often appeared nonracial and contributed to racialized outcomes at the school. For example, the researchers noticed that most Whites in that community subscribed to the cultural narrative that educational inequities were the result of deficiencies in Black families rather than in the institutional practices of the school. Ultimately, Lewis and Diamond found that, despite the best intentions, many of the Whites in Riverview drew upon the dominant racial ideology of color-blindness.

\section{Eurocentric Curriculum}

Educational scholars have noted that much of the mainstream curriculum used in the United States has been dominated by Western-centric and male-centric perspectives (Asante, 1991; Au, 2009; Banks, 1991; Banks \& Banks, 2013; Delpit, 1988; LadsonBillings, 2001; Nieto \& Bode, 2012; Zimmerman, 2004). This Eurocentric curriculum supports the White supremacist purposes of protecting White privilege and advantage in education, economics, politics, and so forth (Asante, 1991; Yosso, 2002). For example, Sleeter and Stillman (2013) conducted a study analyzing the historical-social frameworks and standards used in California public schools and found that the dominant content revolved around Europeans and European Americans. Over 10 grade levels, the history of 
the United States was told with 96 Americans identified as key players, 79 male (82\%) and 17 female (18\%). Of these, 74 were White (82\%), 17 were African American (18\%), 2 were Native American (2\%), 1 was Latinx (1\%), and none were Asian American (0\%). Comparatively, the U.S. Census Bureau indicated that in 2010 the population of California was $49.7 \%$ male and 50.3\% female, $72 \%$ White, $6.5 \%$ African American, 1.6\% Native American, 39\% Latinx, and 15\% Asian.

Eurocentricity leaves a portion of students in public education underrepresented and sometimes invisible in the mainstream curricula. According to Delpit and Dowdy (2002), students of color often feel alienated from schools in part because they experience cultural conflict that results from the cultural differences between the school and their home communities. Howard (2010) referred to these cultural incompatibilities as "cultural mismatches" and argues that this conflict is a primary factor in the underachievement of students of color. Gay (2006) and Townsend (2000) further suggested that teachers' cultural norms and ways of communicating in the classroom are often at odds with those of students of color. Ultimately, Eurocentric curriculum facilitates an incomplete education for all students by limiting perspectives, histories, and cultural knowledge.

\section{Talking about Race and Anti-racist Education}

Pollock (2008) argued that educators need to talk directly with students about race and racial disparities — specifically causes and solutions - in order to eliminate those disparities altogether. Without direct conversations about race, color-blindness will continue to dominate the field of education, and schools, educators, and students will 
remain ill-equipped to combat racism. Through direct teaching about race, however, educators have an opportunity to examine their own racial biases and assumptions. But unpacking the color-blind mindset requires that educators not only examine their own assumptions and biases but also understand that racial inequality and racism in education are systemic, are historical in nature, and will remain unchanged without examination. Ultimately, teaching about race empowers all students to critically analyze the world around them (Banks \& Banks, 2013).

One approach that educational researchers and educators have developed to address the problem of color-blindness and silence about race in schools is anti-racist curriculum, which directly teaches students about race, racism, and racial inequalities and intentionally interrupts the color-blind ideology. But anti-racist curriculum cannot itself exist as a stand-alone solution to racial color-blindness and inequities in schools. Rather, anti-racism calls upon educators themselves to be consciously anti-racist. Nieto and Bode (2012) suggested, "being anti-racist and anti-discriminatory means being mindful of how some students are favored over others in school policies and practices such as curriculum, choice of materials, sorting policies, and teachers' interactions and relationships with students and their families" (p. 43).

More specifically, anti-racist educators not only incorporate anti-racist curriculum but also employ anti-racist instructional practices. Such practices are often referred to as “culturally responsive teaching" (Gay, 2010). Culturally responsive teaching connects and infuses the cultural backgrounds and lived experiences of students of color into the curriculum and instruction, as a means for empowering and acknowledging all students 
(Gay; 2010; Vavrus, 2008). More precisely, in the words of one of the foundational scholars of culturally responsive teaching:

Culturally responsive teaching can be defined as using the cultural knowledge, prior experiences, frames of reference, and performance styles of ethnically diverse students to make learning encounters more relevant to and effective for them. It teaches to and through the strengths of these students (Gay, 2010, p. 31).

It is apparent that anti-racist curriculum requires a commitment from schools and educators to work deliberately to combat racism, not only with curriculum but also through instructional practices.

As an example of anti-racist curriculum, I conducted a research study with firstgrade students in which I developed anti-racist curriculum and directly taught students about race, racial categories, and racial identities. Over several days, the children participated in collaborative anti-racist lessons, including defining the term "race," discussions of racial categories, listening to children's literature about race, racial categories, and racial identities, and painting self-portraits. Using several children's books as anchor text for discussion (The Colors of Us by Karen Katz, Shades of People by Shelly Rotner, All the Colors We Are: The Story of How We Get Our Skin Color by Katie Kissinger, and Skin Again by bell hooks), I facilitated dialogue with the children about the social construction of race. In addition, the children explored their own racial identity by mixing and matching paint for their skin color for their self-portraits, naming their skin color, and writing identity statements (I identify as , and my skin color is

\section{Significance of the Problem}


Currently, large numbers of students in the United States-particularly students of color - are systematically marginalized in schools. The consequences of this marginalization are real, significant, and far-reaching, as evidenced by the disparities in academic achievement, educational opportunities, and overall school experiences when comparing students of color to their White peers (Banks, 2004; Darling-Hammond, 2007; Howard, 2010; Kozol, 1991; Ladson-Billings, 1995). Students of color are often marginalized in the day-to-day practices of the educational system, from silence around the topic of race to lack of representation of people like them in the curriculum and instructional practices. Ultimately, race continues to be a predictor of educational success and attainment for students in the PK-12 public education system (Bonilla-Silva, 2014; Hilliard, 2014; Howard, 2010; Kozol, 1991; Ladson-Billings, 1994; Noguera, 2008; Tatum, 1997).

The rapidly increasing number of students of color, emergent bi/multilingual students, and students from non-mainstream cultural backgrounds in U.S. schools creates a sense of urgency around this problem. The National Center for Education Statistics (NCES) predicts that, by the year 2025, White students will compose only $46 \%$ of the total population of public school students in the United States. Howard (2010) pointed out that, if current academic disparities across racial categories persist, an increasing proportion of the nation's citizens will be severely undereducated. The undereducation of large numbers of students would have serious consequences for the future of the United States. Geneva Gay explains:

In the long run segments of society suffer when human capital and intellectual potential of groups of color are neglected or squandered. Certainly, settling the 
educational debt owed to underachieving and marginalized students of color in the form of radical improvements in the quality of their educational experiences and outcomes is a moral imperative. It is the right and just thing to do. But it is more than that. It is a matter of survival, especially when survival is viewed as encompassing more than biological existence, but maximizing all aspects of human be-ing and be-coming (Howard, 2010, p. xxi).

Unless teachers adopt a critical framework for educational equity-exposing racism in education-inequities for students of color will remain inevitable. Maintaining the status quo means endorsing the false notion of "equal opportunity" for all students. The emphasis on a monocultural society will ultimately reify the hegemonic Eurocentric ideology and curricula that has dominated education since the inception of the common school. Ignoring the impact of race in education and subscribing to the ideology of colorblindness will only perpetuate educational inequities, leaving an increasing number of students of color behind and further perpetuating the myth of racial superiority in White students.

\section{Deficiencies in What We Know}

For some time now, scholars have been concerned with curriculum that narrowly defines knowledge and history, specifically the exclusion of the histories of people of color (DuBois, 1935; Ladson-Billings, 2001; Zimmerman, 2004). Many educational scholars have recognized the need for multicultural education and curricula to challenge the dominant Eurocentric ideologies and honor students' diverse experiences and backgrounds (Banks, 2001; Banks \& Banks, 2013; Nieto \& Bode, 2012; Sleeter, 2001). For years, educational scholars Banks (1993) and Nieto (2012) have advocated for multicultural education to address the nation's history of discrimination based on race. Banks (1993) suggests, “A major goal of multicultural education, as stated by specialists 
in the field, is to reform the school and other educational institutions so that students from diverse racial, ethnic, and social-class groups will experience educational equity" (p. 3). Unfortunately, many school districts have implemented multicultural education in the most generic sense, reducing such curricula to mere representation of diverse groups, thereby avoiding the difficult issues of racism and inequality that multicultural education is intended to address (Banks \& Banks, 2013; Kailin, 2002).

More recently, anti-racist education has been developed to go beyond multiculturalism. Anti-racist pedagogy aims to directly confront racism by engaging educators in critical self-examination in regard to their own beliefs and practices, while empowering educators and students to critically analyze knowledge paradigms and systems of oppression, including curriculum (Kailin, 2002). Yet, although anti-racist curriculum has been clearly defined and written about in theoretical literature, there remains limited empirical research on the topic. In my search for relevant research, I found only a handful of studies that address the use, writing and implementation, and effectiveness of anti-racist curriculum.

\section{Research Purpose and Rationale}

The context of this research study involved collaborative planning sessions in which the teacher participants developed resources and lesson plans to directly teach about race, racism, and racial inequities in their classrooms. Through this research, I hoped to gain a deeper understanding of the practice of developing anti-racist curriculum. The research could inform the educational field about challenges and barriers to implementation, as well as successful strategies and practices associated with 
implementing anti-racist curriculum in public education. Furthermore, this study addressed the gap in educational research around the topic of anti-racist curriculum, potentially yielding information to guide educational practices and further scholarship.

I intentionally designed this research study to be mutually beneficial for the teacher participants, the students, and myself. It provided the participants with collaborative planning time with other educators, resources for racial identity development and teaching about race, and opportunities to reflect on their own racial identities and teaching practices. In addition, teacher participants potentially had a direct impact on their students because part of the research study involved implementing antiracist curricula in their own classrooms.

Further, this research study offered benefits to the greater educational community as well. Currently, many school districts across the country are engaging staff in professional development involving the topic of race. Unfortunately, these experiences seem to have had minimal impact on classroom practices, curriculum, and the lives of students (Gay \& Kirkland, 2003). Therefore, the findings of this study can offer a roadmap for school districts to directly challenge the status quo Eurocentric curriculum and instructional practices through the employment of anti-racist curriculum. More specifically, findings from this research can help guide districts toward ways to support the multi-layered process by which teachers plan and implement curriculum rooted in the lives of students that works to dismantle racism and racial inequity in education.

\section{Research Questions}

This study sought to address the following three research questions: 
1. How do PK-12 teachers participating in a collaborative professional development experience describe the processes of planning and implementing anti-racist curriculum?

2. How do the teachers describe obstacles or challenges with planning and implementing anti-racist curriculum?

3. According to the teachers, how does participating in the collaborative sessions impact their teaching practices in anti-racist lessons?

\section{Methodology}

For this research study, I used a case study methodology. Case studies are generally described as methodological approaches for conducting empirical inquiry of a social phenomenon (the "case") within its natural context, using multiple sources of evidence (Dyson \& Genishi, 2005; Yin, 2003, 2014). I selected a case study methodology because I believed it was conducive to capturing individual participants' thinking about racial inequities and their racial identity development, as well as documenting potential social change with the implementation of new, non-Eurocentric curriculum.

This study incorporated collaborative planning sessions that were attended by the teacher participants. These sessions operated like a professional development series or college course, with opportunities for whole-group learning, collaborative work time, and feedback. Topics for the sessions included general curriculum planning as well as racial identity development, talking about race and racism, and anti-racist curriculum. Each teacher participant maintained a reflective journal for the duration of the study and was expected to write journal entries after every professional development session. In addition, the teacher participants were each separately interviewed after the completion of the study. 
My data collection consisted of interviews with each teacher participant, participant observation notes from the collaborative professional development sessions, as well as reflection journals and written lesson plans from each participant. The data were used to answer the corresponding research questions. In Table 1 below, the research questions are matched with the corresponding data sources, and additional details relevant to the particulars of the research questions are written out as well.

\begin{tabular}{|c|c|c|}
\hline Research Questions & Data Sources & More Specific Information \\
\hline $\begin{array}{l}\text { How do PK- } 12 \text { teachers } \\
\text { participating in a } \\
\text { collaborative professional } \\
\text { development experience } \\
\text { describe the processes of } \\
\text { planning and } \\
\text { implementing anti-racist } \\
\text { curriculum? }\end{array}$ & $\begin{array}{l}\text { Participatory } \\
\text { observation notes } \\
\text { from } \\
\text { collaborative } \\
\text { professional } \\
\text { development } \\
\text { sessions } \\
\text { - Reflection } \\
\text { journals for each } \\
\text { participant } \\
\text { - Individual semi- } \\
\text { structured } \\
\text { interviews with } \\
\text { each participant }\end{array}$ & $\begin{array}{l}\text { How do teachers describe the overall } \\
\text { experience? } \\
\text { - How do teachers go about planning } \\
\text { lessons? } \\
\text { - What resources do teachers have } \\
\text { available to them to write anti-racist } \\
\text { lessons? } \\
\text { - What materials or resources are } \\
\text { needed/do they have to gather for } \\
\text { writing lessons? } \\
\text { - What kind of emotions do teachers } \\
\text { experience throughout this process? } \\
\text { Do teachers collaboratively plan? } \\
\text { Individually plan? Or a } \\
\text { combination? } \\
\text { What is the experience like teaching } \\
\text { the lessons with their students? } \\
\text { - What did they change or need to } \\
\text { change in the lessons? } \\
\text { What would they do the } \\
\text { same/differently the next time they } \\
\text { taught the lesson? } \\
\text { - Would they teach the lesson again? } \\
\text { How do the students react to the } \\
\text { lessons? }\end{array}$ \\
\hline $\begin{array}{l}\text { How do the teachers } \\
\text { describe obstacles or } \\
\text { challenges with planning }\end{array}$ & $\begin{array}{l}\text { - Participatory } \\
\text { observation notes } \\
\text { from }\end{array}$ & $\begin{array}{l}\text { - Do teachers have support in their } \\
\text { education community to teach anti- }\end{array}$ \\
\hline
\end{tabular}




\begin{tabular}{|c|c|c|}
\hline $\begin{array}{l}\text { and implementing anti- } \\
\text { racist curriculum? }\end{array}$ & 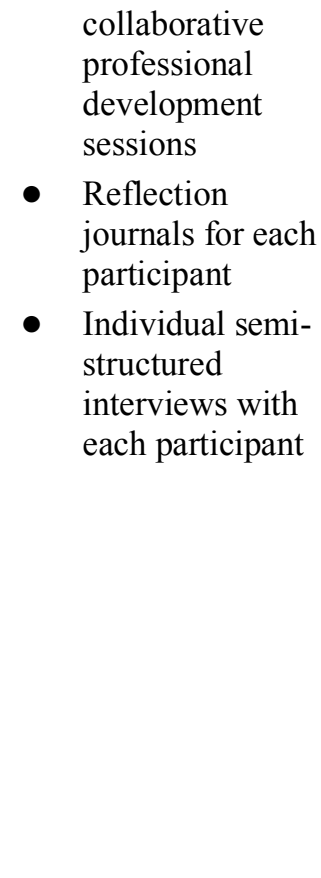 & 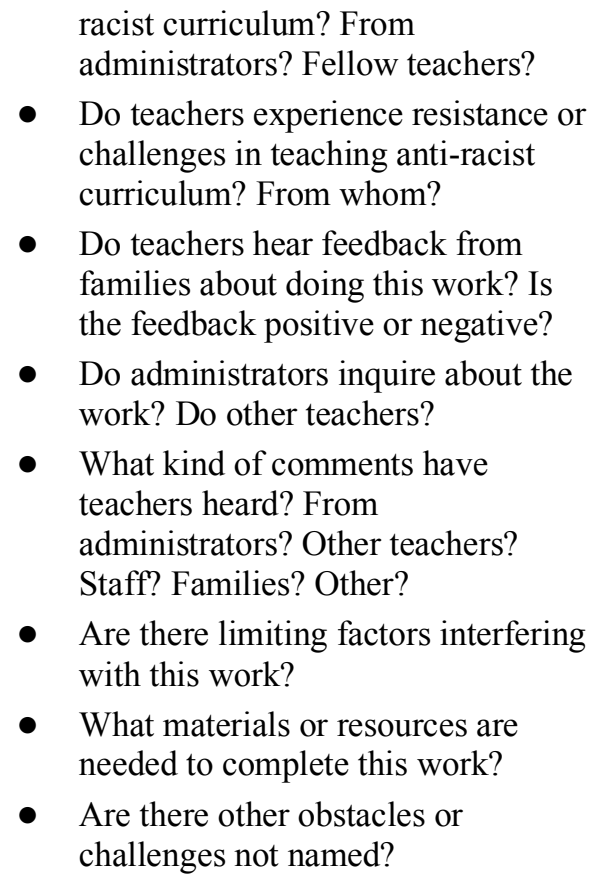 \\
\hline $\begin{array}{l}\text { According to the teachers, } \\
\text { how does participating in } \\
\text { the collaborative sessions } \\
\text { impact their teaching } \\
\text { practices in anti-racist } \\
\text { lessons? }\end{array}$ & $\begin{array}{ll}\text { - } & \text { Reflection } \\
\text { journals for each } \\
\text { participant }\end{array}$ & $\begin{array}{l}\text { What was the experience like } \\
\text { planning with other teachers? } \\
\text { - What was helpful about this } \\
\text { process? } \\
\text { - What was not helpful about this } \\
\text { process? } \\
\text { - Would teachers be willing to do } \\
\text { collaborative professional } \\
\text { development sessions again? } \\
\text { - How did this process impact or } \\
\text { influence the ability to write anti- } \\
\text { racist lesson plans? } \\
\text { - How did this experience impact their } \\
\text { teaching practice? } \\
\text { - What are their takeaways from this } \\
\text { experience? }\end{array}$ \\
\hline
\end{tabular}

\section{Conclusion}

The highly racialized history of the United States has contributed to persistent educational inequities in public education. Within schools, racial etiquette has shifted toward racial color-blindness, which on the surface seems positive but in reality fosters 
negative consequences for students when their racial, ethnic, cultural, and linguistic differences are ignored. Further, simply not talking about race and racism does not make racialized educational inequities go away, as curriculum in American public schools remains largely Eurocentric, devoid of representations of people and practices outside the White norm. This disconnect between the curriculum and the students remains problematic.

Anti-racist curriculum has been developed to intentionally interrupt color-blind ideology and to address the problem of silence about race in schools. Anti-racist curriculum directly teaches students about race, racism, and racial inequalities through empowering students to become critical thinkers, interrogate power inequities, and combat bias and oppression. Limited research has been conducted in the areas of racial color-blindness in education, alternatives to the Eurocentric curricula, and implementing anti-racist curriculum. As a result, the purpose of my research was to investigate the practice of directly challenging the color-blind mindset in education through the implementation of anti-racist curriculum.

In Chapter 2, I presented research related to my problem of practice, specifically focusing on educational inequities, the existence of the color-blind ideology in education, and the dominance of Eurocentric curriculum. Further, I explicitly defined the theoretical framework for this research and synthesize other research regarding anti-racist curriculum, which is used in curricular exercises. In Chapter 3, I further described the methodology of case study research as related to this research study and explain why case study is the appropriate research methodology. In addition, I explained the selection 
process for recruiting research participants, outline specific protocols and sources for data collection, and describe the process for data analysis. In Chapter 4, I shared my research findings and offer interpretations of the data by providing evidentiary material to support the themes and subthemes I identified in relation to each of my research questions.

Finally, in Chapter 5, I reviewed the overall purpose of the study, research questions, and findings. Then I provide discussion around the main findings of the study and offer recommendations and implications connected to the results of this research. 


\section{Chapter II \\ Review of the Literature}

The claim that race is irrelevant to education is patently false. Nowhere is race more visible with respect to education than in observation of racial inequality in achievement and attainment (Lucas, 2008, p. 62).

In Chapter 1, I explained how the historic, systemic, and institutional racism that pervades public schools in the United States has contributed to inequalities in educational opportunities and academic achievement for students of color. The goal of this chapter was twofold. First, I discussed what has been in the system of education, including the persistence of educational inequities, the existence of the color-blind ideology, and the dominance of Eurocentric curriculum. Next, I explored what could be in the system of education, outlining the theoretical framework for this research, presenting the possibilities of anti-racist curriculum, and introducing the potential of using a case study research methodology to study the process of planning and implementing anti-racist curriculum.

In this chapter, I first expanded upon the research I introduced in Chapter 1, providing a more extensive review of the literature surrounding racism in education. Next, I defined the term "curriculum" and review research on Eurocentric curriculum. Then I investigated relevant research regarding anti-racist curriculum, including examples of implementation and potential benefits, used to directly inform my study. For the final portion of this chapter, I outlined my argument for utilizing a case study research methodology. Specifically, I discussed the methodological approaches that have been used in similar research, define case studies, explore research studies that have used the 
case study methodology, and describe the rationale for my methodology to answer and distinguish my research questions.

\section{The Persistence of Educational Inequity}

The highly racialized history of the United States is a well-documented phenomenon (Bonilla-Silva, 2014; Howard, 2010; Lewis, 2004; Marable, 2002). The persistence of racism in the United States has left students of color behind Whites in virtually every area (Bell, 1992; Bonilla-Silva, 2014; Hilliard, 2014; Noguera, 2008). Currently, race continues to be a predictor of educational success and attainment for students in the PK-12 public education system, as is evident in the so-called academic “achievement gap" and disparate high school graduation rates (Bonilla-Silva, 2014; Hilliard, 2014; Howard, 2010; Kozol, 1991; Ladson-Billings, 1994; Noguera, 2008; Tatum, 1997).

The term achievement gap first appeared in the Chicago Board of Education's Hauser Report in 1964 and later in the U.S. Department of Education's Coleman Report in 1966 (Horsford \& Grosland, 2013). Currently, the achievement gap can be defined as "a gap in academic achievement [that] persists between minority and disadvantaged students and their White counterparts" (National Governors' Association, 2005). Over the last few decades, the achievement gap has been widely researched in the field of education (Delpit, 2012; Gay, 2010; Horsford \& Grosland, 2013; Howard, 2010; Noguera, 2008; Tatum, 2003a). For example, the National Assessment of Educational Progress (NAEP) documented disparities in academic achievement between White students and students of color in a 2009 sample of fourth-grade students across 48 states. 
Approximately $41 \%$ of the participating White students scored at or above the proficient level in reading; in contrast, only $15 \%$ of Black students, $16 \%$ of Hispanic/Latinx students, and $22 \%$ of American Indian/Alaska Native students scored at or above the proficient level in reading (NCES, 2013). The NAEP's 2009 eighth-grade student samples revealed similar patterns in reading achievement, with $39 \%$ of White students scoring at or over proficiency levels while Black, Hispanic/Latinx, and American Indian/Alaska Native students' scores lagged behind (13\%, 16\%, and 21\% respectively scoring at or above proficiency) (NCES, 2013).

In addition, graduation rates among students of color attending public schools in the United States have been significantly lower in comparison with those of White students (Holzman, 2006; Howard, 2010; Orfield, Losen, Wald, \& Swanson, 2004). During the 2003-04 academic year, Orfield and his colleagues (2004) found that only $52 \%$ of Black students and $56 \%$ of Latinx students graduated from high school, as compared to White students' graduation rate of $76 \%$. The statistics are even more dire when examining just Black male students, who had a graduation rate of $45 \%$ during the 2003-04 school year (Holzman, 2006). More recently, the NCES (2012) noted that Black students completed a four-year high school degree at a rate of $68 \%$, while the average completion rate was $81 \%$ in the total student population.

Many educational scholars have acknowledged the complexities of academic achievement for students of color in public schools in the United States. For example, Darling-Hammond (2007) has maintained that, "educational outcomes for students of color are much more a function of their unequal access to key educational resources, 
including skilled teachers and quality curriculum, than they are a function of race” ( $p$. 320). The historical denial to students of color of access to education, the inequitable resources they receive, and the prevalence of institutional and societal racism has created a highly racially segregated educational system (Howard, 2010). Therefore, terminology like "opportunity gaps" (Milner, 2010) more accurately describes the phenomenon of unequal academic achievement across racial groups than does the term achievement gap. Milner suggested that, "focusing on an achievement gap inherently forces us to compare culturally diverse students with White students without understanding reasons that undergird disparities and differences that exist” (p. 8). Further, Milner argued that the label of an achievement gap places much of the blame on the students themselves, while the term opportunity gap focuses on the systems and institutions that maintain the status quo, causing racial disparities in education.

\section{Color-blindness: The Silence around Race in Education}

Color-blindness persists as the dominant ideological approach to dealing with issues of race in the United States (Banks \& Banks, 2013; Bonilla-Silva, 2014; Crenshaw, 1997; Forman, 2004; Husband, 2016; Lewis, 2004; Lewis \& Diamond, 2015), while, in reality, race continues to be relevant to people's opportunities and outcomes and ignoring the impact of race has only led to the exacerbation of inequality. To find relevant empirical research studies, I searched Google Scholar using the phrases "racial colorblindness," "silence about race," and “color-blind ideology.” I was specifically concerned with findings that focus on racial color-blindness relative to educators and students in the PK-12 public education system in the United States, although I expanded this boundary 
when exploring the concept of children's understanding of race, as relevant research includes preschool-aged students. My searches yielded minimal results for specific empirical research about racial color-blindness; however, they did provide over 45 related theoretical articles and books. Ultimately, my reading of the scholarly literature indicated that there was a limited amount of research focused on the color-blind ideology in schools. In the research I found, scholarship seemed to focus on three key aspects of color-blindness in education: teacher silence about race, the consequences of not talking about race, and children's understandings of race. Therefore, in the next section of this chapter, I described the empirical research as related to these three aspects of colorblindness in education, including noting limitations of the research.

\section{Teachers Do Not Talk about Race}

Race is not merely a demographic descriptor of students; it is a social force that influences everything that happens in the institution of schooling, and yet most educators do not know how to discuss the topics of race and racism (Lewis, 2001; Pollock, 2004). Research suggests that teachers - particularly White teachers - have difficulty talking to children and other educators about race (Copenhaver, 2000; Glazer, 2003; Willis, 2003).

One of the seminal scholars in the field of anti-racist education is Mica Pollock. Her three-year ethnographic study (2001) at a racially mixed, low-income high school explored when and how members of the school community used race labels within both private and public discourse and yielded the term colormute, referring to the practice of deliberately not talking about race. Through thousands of hours of speech examples, collected through participant observation, Pollock notes patterned cultural practices of 
what she calls race talks amongst both students and staff. While the highly racially diverse students talked about race with relative ease, the teachers and administrators largely avoided talking about race except when addressing diversity as an abstract concept. For example, adults in the school community talked about the need for more literature featuring the Black experience but never addressed the racial demographics of the teachers and their students taking Honors English courses (Pollack, 2004). Thus, the predominantly White faculty adopted a colormute stance and generally refused to address the topic of race with students (Pollack, 2001). This meant that students' concerns and needs around race remained largely unmet, as racial tensions between students and teachers at the school were not openly addressed. Pollock concluded that teachers do notice race but choose to be colormute for fear of uncomfortable repercussions and, thus, avoid any responsibility for the racialized patterns in the school community.

It is important to note that, although Pollock's findings are grounded in extensive speech samples, the concept of suppressing conversations about race is subjective. Pollock does not clearly describe how she defines race talks nor colormuteness, and her methods for data analysis are not clearly spelled out. In addition, Pollock was a classroom teacher at the high school throughout the first year of the study. While her familiarity with the school environment gave her access to and trust within the school community, it might also have evoked her preconceived notions about the school's racial climate. Her biases may not have been adequately examined, and the participants may have acted differently because of her role in their educational community. 
In another ethnographic study, Lewis (2001) focused on the salience of race at a predominantly White suburban elementary school over the course of one year. Through interviews and observations, Lewis examined both the explicit curriculum-what is directly being taught—and the hidden curriculum — the cultural norms that reinforce the dominant narrative - in the school as they relate to race, racial difference, and racial equity. Lewis' findings indicated a consistent minimization of the impact of race, or what she calls the denial of race, by the adults in both the educational community and the community at large. Furthermore, she concluded that the dominant color-blind mentality held by the educators and community masks underlying racialized practices within the school and has a direct impact on the few students of color.

In this research, Lewis focused on a predominantly White suburban school, with data collection revolving around the adults in the community. While the findings are convincing, they would be more credible with more information and examples about how she defined and coded the denial of race and the impact on students of color. In addition, such ethnographic research relies on observations in the natural school environment, which presents challenges for research reliability and validity. Would the study have yielded similar findings had it been conducted in a more racially diverse student and teacher population? Within an urban setting? In addition, how might data collection focused on student voices and perspectives have changed the findings?

Modica (2015) conducted an ethnographic study related to talking about race at a publicly funded suburban charter school serving a multiracial student population. Over the course of five months, Modica collected data through participant observations - in 
classrooms and other school settings - and conducted informal interviews with staff and students. Modica found that, despite the "we all get along here" attitude prevalent at the school, the school environment is riddled with anxiety and tension around the topic of race. Modica noted that many White students and staff members are fearful of being called the "R word" (racist); therefore, White students and especially White staff members actively avoided "racially charged" conversations. Modica concluded, "If teachers are not comfortable engaging in honest conversations about race in the classroom, students cannot benefit from sharing ideas about race with those whose backgrounds and experiences differ from their own" (p. 415).

Although Modica referred to the school as "multiracial," in fact the student population is predominantly $(60 \%)$ White, with the majority of the educators being White as well. This research could have been strengthened by clearly identifying the dominant Eurocentric ideology and including research participants who reflected more than just the White perspective in the school community. My study also included mostly white educators, but I do not claim this study is "multiracial" and do attempt to point out dominant Eurocentric ideology.

Schofield (2006) conducted a four-year intensive study at a racially mixed middle school, examining peer relationships between African American and White students. Data collection included over 500 hours of observational field notes and recordings, randomly selected open-ended interviews with students, teacher and administrative interviews, questionnaires, and a collection of school artifacts including bathroom graffiti, bulletin boards, and public announcements. Schofield noted that many people in 
the school community feel that even the acknowledgement of race is a possible sign of prejudice. In addition, teachers openly denied noticing race, even amongst themselves, and asserted that the students rarely notice race either. More specifically, the data revealed that, over the course of one school year-with nearly 500 hours of observations from classrooms, hallways, and teachers' meetings — students and staff members made only 25 direct references to race (Schofield, 1989).

In contrast to the other research studies, Schofield's (2006) data-gathering techniques and analysis were systematic and transparent. She made great efforts to triangulate her data collection in an attempt to corroborate her findings across multiple data sources. The 500 hours of observations and interviews were recorded, transcribed, and coded using a systematic technique and trained coders (Schofield, 2006). Schofield's study stands out because her research explicitly described the analytic processes that led to her findings, which is a limitation of many ethnographic studies.

Overall, these four studies made a strong case that race is not being openly discussed in schools and that colormuteness is indeed a practice of many educators. All four of the studies used ethnographic research methodologies, creating rich data generated in the context of everyday educational life. Although many ethnographic researchers engaged in the practice of self-reflection - called reflexivity in qualitative research (Krathwohl, 2009) — asserting the validity of ethnographic findings can be challenging because data collection and analysis are based on the observations and perceptions of the researcher and not the participants. Without self-reflection and an awareness of factors that might affect the researcher's point of view, ethnographic 
research is problematic when dealing with an emotionally charged topic such as race. This area of research could benefit from a wider range of methodologies, including other qualitative methods, mixed methods, and quantitative methods to reify findings in these ethnographic studies.

\section{Consequences of Not Talking about Race}

Although many teachers have chosen to adopt the color-blind mentality, there are serious consequences that result from the widespread practice of not talking about race, racial inequities, and racism in schools. Pollack (2004) noted, "although talking about race in racial terms can make race matter, not talking in racial terms can make race matter too" (p. 16). Avoiding the topic of race produced several negative consequences for teachers and students. First, racial color-blindness hinders a school's ability to combat racism by directly addressing racial inequalities and issues that arise in the school community. Lewis (2003) found that teachers' reluctance to talk about race and racism in any substantive way created barriers for combatting and resolving racial issues taking

place at school. Second, not talking about race limits students' abilities to develop tools for combating racism and critical thinking skills for engaging in a multicultural and highly racialized society. Modica's (2015) research suggested that silence around race actually denied students the skills needed to speak effectively about race and critically examine the role of racism in their relationships with others. Third, the lack of conversation about race only reified the racial status quo and ignored opportunities for students to explore their racial identities (Bonilla-Silva \& Embrick, 2008; Hawley \& Nieto, 2010; Sleeter, 1996). Fourth, educational systems have traditionally maintained 
racial hierarchy and have done little to challenge oppressive systems (Bonilla-Silva \& Embrick, 2008) and further, schools that subscribe to the colorblind approach often reproduce racialized educational inequities (Modica, 2015).

Despite the fact that research on the impact of racial color-blindness has been conducted, the limited number of studies available in this area of research remains a major problem in affirming this phenomenon in education. Here, I once again relied upon the same few studies to substantiate not only the existence of racial color-blindness in schools but also the consequences of not directly discussing race with students. Unquestionably, more research is needed in this area to identify and clarify the consequences of this phenomenon for students.

\section{Children Understand Race}

Although many teachers and adults feel uncomfortable discussing it, children do understand the concept of race. Research dating back to the 1950s has indicated that children begin to construct concepts of race and racism at a very early age (Clark, 1988; Derman-Sparks \& Ramsey, 2011; Goodman, 1952). In a classic study, Goodman (1952) investigated the racial attitudes of 103 Black and White preschool-aged children in a Northeastern urban community in the United States. Over the course of one year, Goodman collected an extensive amount of data while observing both the children and their families. Through her observations, Goodman concluded that not only do children have racial awareness by age three or four but that nearly $25 \%$ of children express strongly developed beliefs about race at that age. Goodman maintained that some of the children in the study hold what she describes as "entrenched race-related values" (as cited 
in Katz, 2013, p. 126), wherein White children never express a desire to be Black, but some Black children exhibit distress about being Black. Further, Goodman noted discrepancies between children's actual racial awareness and their parents' perceptions of their awareness, with many parents reporting that their children are unaware of race.

As with other research studies regarding race, Goodman's conclusions were based on her interpretations of how children created meaning around the topic of race. She did not specifically describe examples of how the children expressed those "entrenched racerelated values." Regardless, this seminal study has since been replicated many times, in different contexts, yielding similar results.

More recently, Feagin and Van Ausdale (2001), in their ethnographic study of 58 racially mixed preschoolers, observed and recorded speech samples of young children hiding conversations about race and discriminatory behaviors from their teachers. At the conclusion of the yearlong study, the researchers showed parents and teachers the observational transcripts — which documented the children's understanding of race—and many of the adults claimed that the children were "confused." Feagin and Van Ausdale concluded that, as a consequence of the adults' denial, the young children, particularly children of color, were forced to remain silent about race, bear the burden of racism, and develop coping skills without adult support. Feagin and Van Ausdale also suggested that the children's views reflect society's racial hierarchy: "Not surprisingly, all children in this society learn at an early age that, generally speaking, Whiteness is privileged and darkness is not—and thus their choices in this regard are usually not surprising" (p. 57). As yet another ethnography investigating race, this study's findings were based on the 
researchers' interpretations of the children's understandings of race. In addition, the authors claimed that the students' views were reflective of the larger society's racial hierarchy, which could have been further explained and verified through relevant research.

Apfelbaum, Pauker, Sommers, and Ambady (2010) researched children's ability to recognize racialized bias after exposure to a narrative that endorsed either a color-blind or a value-diversity ideology. Upon being introduced to one of these narratives, the participants -60 children between the ages of 8 and 11 -were read stories about racial bias. The researchers found that children exposed to the color-blind narrative were less likely to detect incidents of racial discrimination. In addition, the researchers noticed that, when the children exposed to the color-blind narrative recounted these incidents, they were more likely to minimize the racial incidents, decreasing the likelihood that adults would intervene to correct the discrimination.

Although this research is quite compelling, the study involved participants in an artificial problem-solving activity, which may or may not mirror the results of an authentic, real-life activity. The research did illuminate the children's thinking processes, but the researchers inferred that exposure to a particular type of narrative was causally related to the practice of color-blindness. This research would be more compelling if there were observational follow-ups with the students to see if their ability or lack of ability to recognize racial bias continued in real-life situations.

Similarly, Apfelbaum, Pauker, Ambady, Sommers, and Norton (2008) conducted a research study investigating children's tendency to either acknowledge or avoid the 
topic of race in a series of tasks involving social categorization. For this study, 101 children, ages 8 to 11 , were recruited from three middle-upper/middle-class suburban schools and were sorted into two groups: 8- and 9-year-olds and 10- and 11-year-olds. As part of the research, the participants were asked to play a version of the children's game “Guess Who," where each player selected an image of a famous person and answered his or her opponent's yes-or-no questions about the image while trying to first guess which image his or her opponent had selected by asking yes-or-no questions about that image.

At first the older sample group outperformed the younger sample group when presented with images where only one racial group was represented; however, the opposite results were achieved when discussing race became a factor in completing the task. The researchers noted that the older sample group avoided talking about race, even though asking a race-related question would have significantly increased the probability of winning the game. The researchers suggested that the older children's tendencies to avoid acknowledging race are the result of their greater awareness of racialized norms, inferring that the older children had been socialized to not talk about race while the younger children had yet to internalize such social norms. Although one could argue that the children's ability to play a game does not directly mean they are taking a color-blind stance. Ultimately, avoiding asking questions about race hindered the older children's ability to participate in the categorization, and thus, the internalized social norms began to influence their behavior, even when such regulation came at a cost.

\section{Conclusions}


More research is needed in this area to further understand the prevalence of racial color-blindness and to more specifically identify how color-blindness manifests itself in schools. The existing research, however, suggested the need for dismantling the racial status quo and establishing more race-conscious attitudes and practices because the colorblind approach has been shown to be ineffective in changing students' racial attitudes and biases (APA Presidential Task Force, 2012; Apfelbaum, Pauker, Ambady, Sommers, \& Norton, 2008; Neville, Lilly, Duran, Lee, \& Browne, 2000; Plaut, Thomas, \& Goren, 2009; Richeson \& Nussbaum, 2004; Verkuyten, 2005). Thus, adults should have direct conversations with students about race through methods such as implementing anti-racist curriculum.

\section{Curriculum}

Definitions of curriculum vary amongst scholars and practitioners. According to Bobbitt (2013), the word curriculum, when applied to education, means a "series of things which children and youth must do and experience by way of developing abilities to do things well that make up the affairs of adult life; and to be in all respects what adults should be" (p. 13). Along these same lines, Au (2013) suggested that, in its simplest form, curriculum represents a body of predetermined content knowledge that schools are generally organized around and students are expected to master. Apple (2004) described curriculum in terms of the "legitimate knowledge" or knowledge forms situated within the institutions of schools. From this perspective, the school uses curriculum as a mechanism for preserving and distributing the ideology of the dominant culture. 
Elliot Eisner (1985) asserted that three types of curricula are present in schools: the explicit, the implicit, and the null. The term explicit curriculum referred to the content being taught, such as mathematics, science, social studies, or English language arts. In contrast, the implicit curriculum included values and expectations not explicitly spelled out in the formal curriculum but nevertheless learned by students as part of their school experience. For instance, classroom rules and routines - which often reflect EuroAmerican social norms_-are reinforced as part of schools' implicit curriculum. Last, Eisner defined that which schools do not teach as the null curriculum. The topics of race and racism fall into both the categories of implicit and null curriculum.

For the purposes of my study, I wanted to expand Bobbit's, Au's, and Eisner's definitions of curriculum to more accurately reflect the transactional nature of curriculum. Therefore, I posit that curriculum represents both the what (noun) and the how (verb). For this work, I referred to "curriculum" as both the contextual knowledge and the interactive construction of such information amongst educators and students. I also focused on shifting the the topics of race and racism (implicit and null curriculum) to explicit curriculum, which represented the predetermined, "legitimate" knowledge and transaction of such that schools were expected to teach and students were required to learn.

\section{Eurocentric Curriculum}

Educational scholars have observed that much of the PK-12 curriculum in the United States is dominated by Eurocentric beliefs, assumptions, and points of view (Asante, 1991; Au, 2009; Banks, 1991; Banks \& Banks, 2013; Delpit, 1988; Ladson- 
Billings, 2001; Nieto \& Bode, 2012; Zimmerman, 2004). Banks and Banks (2013) defined Eurocentric curriculum as "a curriculum in which concepts, events, and situations are viewed primarily from the perspectives of European nations and cultures and in which Western civilization is emphasized" (p. 354). Whites continue to overshadow the storylines and narratives of other racial groups in mainstream curricula, which largely reflect European-American experiences and worldviews, particularly in the language arts and social studies content areas (Clawson, 2002; Foster, 1999; Gay, 2000; Loewen, 1995; Sleeter \& Grant, 1991). For instance, according to the Cooperative Children's Book Center (CCBC), the publication of books by and about people of color have remained relatively flat over the last 20 years. In 2015, CCBC reviewed 3,400 of the approximately 5,000 children's books that were published in the United States during that year. Of the reviewed books, only 270 featured African/African American main characters (8\%), only 42 had American Indians/First Nations main characters (1\%), only 113 had Asian/Asian Pacific Islander main characters (3\%), and only 83 had Latinx main characters (2\%). Similar patterns followed in the curriculum used in public schools in the United States.

Two studies explored the claim that the narratives of White European Americans are disproportionately represented in the explicit curriculum (Eisner, 1985). Buescher, Lightner, and Kelly (2016) analyzed four core first-grade reading programs used in the United States, specifically examining the representation of authors and illustrators of different races and genders. Through coded analysis of 120 stories across the fourreading series, the researchers found a drastic overrepresentation of White authors and illustrators in the textbooks for young children. These researchers also drew upon the data 
from the $\mathrm{CCBC}$, and noted that 3,039 of the 3,400 books reviewed were written by White authors. In conclusion, the researchers observed that narratives in the reading curricula, which contributed to the sociocultural norms promoted in schools, were disproportionately written by White authors.

The findings of this research are compelling in that they quantify the Eurocentricity of literacy curricula, though the research was limited by its exclusive examination of the authors and illustrators rather than the stories' main characters. By only collecting data about the races and genders of authors and illustrators, the researchers made presumptions about how author/illustrator race/gender shapes story content and characters as opposed to considering whether the racial representations of the main characters were authentic and non-stereotypical. In addition, the researchers concluded that White authors were still controlling the conversation in literacy curriculum.

In a study I discussed in Chapter 1, Sleeter and Stillman (2013) analyzed the social studies standards used in California's public education system and find that, over 10 grade levels, the history of the United States is largely told through White key players. Therefore, the scholarly literature suggested that curriculum in the United States continued to be monopolized by Western-Eurocentric ideology as represented by White narratives and characters, though of course this research was limited to content standards in California.

Ultimately, Eurocentric curriculum is not only devoid of the representation of many racial and ethnic groups but also often reinforces racial and ethnic stereotypes 
embedded within the curriculum-Eisner's (1985) implicit curriculum (Clarke, 1993; Franklin \& Higginbotham, 2010; Milner, Pearman, \& McGee, 2013; Stanton, 2015). For example, historical narratives have often depicted examples of White "settlers" attempting to civilize "savage," "less developed," and "primitive" cultures (Solórzano, 1997; Stanton, 2015; Willis, 1994). Stanton (2015) conducted research examining the teacher's editions of five eleventh-grade U.S. history textbooks, specifically focusing on the historical period called westward expansion (roughly 1869 to 1900). Through critical discourse analysis, Stanton evaluated the textbooks' representations of Native American experiences during this period. He described several themes from the content, including continued marginalization of the Indigenous experience, acceptance of the dominant culture's narrative regarding assimilation, and little attention given to Native oral traditions and storytelling. Further, Native Americans were frequently characterized as the savage other, with violent tendencies and cult-like beliefs. This research was limited to only five textbooks, and although the findings of this research were solid, further analysis of other history textbooks would be useful to support its claims.

Research also indicated that students as young as 10 years can develop stereotypical interpretations of historical events. Epstein (2000) conducted a study documenting students' beliefs about and interpretations of U.S. history in two fifth-grade classrooms. For this study, Epstein interviewed a total of 10 Black and 10 White students from the two classrooms, at the beginning and the end of the school year. Epstein found that Black and White students have differing, highly racialized descriptions of history. For instance, White students described slavery as a time when "Black people were 
slaves." In contrast, Black students explained slavery as a time when "White people beat Black people and treated them mean." Consequently, Epstein concluded that students interact with curricula based on their lived experiences and funds of knowledge, which included their race, ethnicity, and culture. Even with a limited number of participants, this research clearly demonstrated how racial stereotyping was present amongst young children. It may be advantageous to duplicate this study with more student participants at various grade levels to strengthen the research findings.

This research reified the dominant narrative where racism is often presented as having occurred in the past, and perpetrators of racism are framed as a few bad individuals rather than components of a system of oppression. Challenges to racism are typically presented as heroic individual acts rather than organized struggles (Alridge, 2006; Brown \& Brown, 2010).

Freire (2000) and other critical theorists have suggested that Eurocentric explicit curriculum also serves to reinforce the "hidden curriculum" (comparable to Eisner's implicit curriculum). McLaren (2015) described the hidden curriculum as the assumed cultural norms and means for constructing knowledge, which lead to the unintended outcomes of education. The hidden curricula in schools are never neutral. Rather, hidden curricula serves to validate the dominant culture's forms of knowledge and often leads to discrimination on the basis of race, class, and gender (Giroux, 1997; McLaren, 2015; Sleeter, 1995; Solórzano, 2013). Thornton (2013) noted that, "all teachers are curricularinstructional gatekeepers - they largely decide the day-to-day curriculum and activities students experience" (p. 334), although the degree to which teachers hold autonomy over 
their curricula and instructional practices varies depending on the instructional and curricular demands of particular school districts.

Banks (2004) suggested that the extreme bias presented in Eurocentric curriculum means that content taught to children is at best incomplete and at worst inaccurate and distorted. Further, a teacher's cultural norms and ways of communicating can often be at odds with students who operate outside that set of cultural norms (Gay, 2000; Townsend, 2000). This mismatch can lead to the formation of what Nieto and Bode (2012) have called deficit theories. According to these scholars, deficit theories are often used in education to explain differences in academic achievement between groups of students. Deficit theories assume that some students - because of genetic, cultural, and home experiential differences - are inherently inferior to other students. Paris (2012) noted that, "the goal of deficit approaches [is] to eradicate the linguistic, literate, and cultural practices many students of color bring from their homes and communities and to replace them with what were viewed as superior practices" (p. 93). Other consequences of cultural marginalization include low teacher expectations (Ford \& Grantham, 2003; Gould, 1996; Solórzano, 1997; Valencia, 1997), academic tracking (Broaded, 1997; Delpit, 2012; Ladson-Billings, 2009; Nieto \& Bode, 2012; Noguera, 2008), and disproportionate rates of disciplinary action (Johnston, 2000; Monroe, 2005; Noguera, 2008; Skiba, Horner, Chung, Rausch, May, \& Tobin, 2011; Skiba, Michael, Nardo \& Peterson, 2002; Townsend, 2000).

Noticeably absent from educational research regarding Eurocentric curriculum was the frequency with which the topic of race is taught (or not taught) in schools. In my 
search, I have yet to encounter a research study that even attempts to quantify the number of lessons being taught about race, racism, and racial oppression, let alone how often students encounter discussions of race in their educational experiences. The field could benefit from such scholarship in order to understand students' experiences and to quantify the silence around race in education.

\section{Anti-racist Curriculum}

Thus far in Chapter 2, I have focused on relevant research related to what has been in the system of education. Proceeding forward in this chapter, I described what could be in the system of education, by first defining the underlying assumptions and essential components of anti-racist curriculum and then presenting relevant empirical research about anti-racist curriculum to directly inform my own research.

\section{Defining Anti-racist Curriculum}

It is important to understand that anti-racist curriculum is not just a version of multicultural education with mere representation of racial and ethnic groups injected into the curriculum. Based on a review of research, Sleeter (2011) noted that:

Simply infusing representation of racially and ethnically diverse people into curriculum only marginally affects students' attitudes because racial attitudes are acquired actively rather than passively. Curricula that teach directly about racism have a stronger positive impact than curricula that portray diverse groups but ignore racism (p. viii).

Michael (2015) suggested that multicultural curriculum is not enough to create an anti-racist classroom because it does not include regular examination of one's own biases and stereotypes. For these reasons, anti-racist curriculum should not simply be the 
representation of diverse groups but instead must include direct teaching about race and racism and regular reflection on personal biases and stereotypes.

The purpose of anti-racist curriculum has been to move content about race and racism from the null curriculum to the explicit curriculum, which in turn would impact the implicit curriculum. Edin Lee (2014) described anti-racist education as, "a point of view that cuts across all subject areas, and addresses the histories and experiences of people who have been left out of the curriculum" (as cited in Milner, 2014, p. 10). Ultimately, anti-racist education is about empowering students, families, and educators to combat racism and discrimination and, thus, to help move the dominant European perspectives over to the side, making room for other cultural perspectives.

Building upon these notions of anti-racism, Cheng and Soudack (1994) constructed a framework for anti-racist curriculum that incorporates several underlying assumptions:

- Race and racism are deeply embedded social constructs that are structural and institutional, not merely individual acts of bigotry (Bell, 1992; Bonilla-Silva, 2014; Cheng \& Soudack, 1994; Delgado, 1995, 2000; Delgado \& Stefancic, 2012; Derman-Sparks \& Ramsey, 2011; Ladson-Billings, 2013; Morrison, 1992).

- Racism is the result of historical, political, social, and economic factors that have created unequal opportunities, rights, and privileges in society $(\mathrm{Au}$, 2009; Banks, 1991; Bonilla-Silva, 2014; Donner, 2013; Gillborn, 2009; Horsford \& Grosland, 2013; Ladson-Billings, 2001, 2013; Ladson-Billings \& Tate, 1995; McLaren, 2015; Nieto \& Bode, 2012; Solórzano, 2013; Stovall, 2013).

- Racism is defined by the impact or effects, rather than the intention (Crenshaw, 1997; Gillborn, 2009; Michael, 2015).

- Racial color-blindness exists in the system of education, as it does in the greater society (Banks \& Banks, 2013; Bonilla-Silva, 2014; Bonilla-Silva \& Forman, 2000; Crenshaw, 1997; Donner, 2013; Forman, 2004; Lewis, 2004; Ullucci \& Battey, 2011). 
- Racism impacts all students in the system of education, but particularly students of color (Cochran-Smith, 2000; Darling-Hammond, 2007; Hawley \& Nieto, 2010; Sleeter, 1996; Tatum, 1992, 2004b).

- Schools are responsible for addressing educational inequities and opportunity gaps that serve to perpetuate the cycle of oppression (Giroux, 1997; Horsford \& Grosland, 2013; Nieto \& Bode, 2012, Solórzano, 1997; Tatum, 1992).

In conjunction with these underlying assumptions, anti-racist curriculum emphasizes several key tenets. First, anti-racist curriculum explicitly acknowledges and interrogates inequities related to race, in turn directly challenging the color-blind mindset. Anti-racism means working to dismantle and combat racism beyond merely talking about race (Derman-Sparks, 2011; Horsford \& Grosland, 2013; Nieto, 1996; Pollack, 2004). It is essential to expose racial inequities, including historical, political, social, and economic factors that have created unequal opportunities, rights, and privileges in society ( $\mathrm{Au}$, 2009; Banks, 1991; Bonilla-Silva, 2014; Gillborn, 2009; Horsford \& Grosland, 2013; Kalin, 2002; Ladson-Billings, 2001; McLaren, 2015; Nieto \& Bode, 2012; Solórzano, 2013). Educational inequities will never be overcome in the U.S. public education system without the acknowledgement of disparities past and present (Horsford \& Grosland, 2013).

Second, anti-racist curriculum emphasizes critical-thinking skills and helps students identify societal inequities and racial stereotypes (Barlett, 2005; Cheng \& Soudack, 1994; Darder, 2014; Freire, 2000). Teaching about race empowers all students to critically analyze the world around them, including the explicit and implicit curricula. As an example, Cochran-Smith (2000) calls for the interrogation of what she regards as the "racial text" of curriculum. From an anti-racist perspective, classroom materials, including children's literature and textbooks, should be examined for the overt 
perpetuation of racial stereotypes and the covert exclusion of people of color (Kailin, 2002).

Third, anti-racist curriculum highlights the historical and cultural experiences and perspectives of racial groups that have been historically marginalized (Cheng \& Soudack, 1994; Derman-Sparks, 2011; Kailin, 2002; Ladson-Billings, 2013; Solórzano \& Yosso, 2001). Because the storylines and narratives of Whites continue to overshadow those of other racial groups in mainstream curricula, anti-racist curricula integrates experiences outside the cultural norm as a regular part of the curriculum (Clawson, 2002; Foster, 1999; Gay, 2000; Loewen, 1995; Sleeter \& Grant, 1991). Anti-racist curriculum benefits all students, including White students, because students receive only a partial education when limited perspectives are presented in the curriculum.

Fourth, anti-racist curriculum affirms all students' racial and ethnic identities. Silence around the topic of race can deprive students of the chance to build positive racial identities, which have been linked to other aspects of academic success (Bonilla-Silva \& Embrick, 2008; University of Pittsburgh School of Education, 2016). Steele and CohnVargas (2013) conducted a yearlong research study in 84 racially and ethnically diverse elementary classrooms, where they investigated characteristics of classrooms that had positive effects on student learning, called identity-safe classrooms. Their research suggests that identity-safe classrooms are not color-blind; instead, racial diversity is seen as a resource for learning in those spaces. Furthermore, the research indicates that, when students saw themselves reflected in the daily life of the class, they had a stronger sense of belonging and thereby increased their social and academic competence. Steele and 
Cohn-Vargas also find that using a critical-multicultural (what I refer to as anti-racist) approach helps students from both the non-dominant and dominant groups develop positive racial identities for themselves and have acceptance and appreciation of others.

Finally, anti-racist curriculum emphasizes social activism, expecting students to examine their own racial biases and beliefs through ongoing reflection and direct action to interrupt educational inequities. Moreover, anti-racist curriculum should empower students with the tools needed to resist bias and oppression in their everyday lives (Cheng \& Soudack, 1994; Cochran-Smith, 1995; Kailin, 2002; Leonardo \& Boas, 2013; Schultz, Neyhart, \& Reck, 1996). An anti-racist individual must be aware of his or her own racial identity but also understand that a commitment to anti-racist actions is a lifelong journey that includes forming new understandings (Barndt, 2007). Without a critical awakening of consciousness, the racial inequities embedded in the institution of education will persist.

\section{Research on Anti-racist Curriculum}

To date, very few research studies have investigated the development and implementation of anti-racist curriculum (Cheng \& Soudack, 1994; Derman-Sparks, 2011; Kailin, 2002; Michael, 2015). In my search, I used targeted key phrases: "teaching about race," "anti-racist curriculum," and "teaching children about race." I was interested in finding research studies about implementing anti-racist curriculum with students in the PK-12 public education system in the United States. When I had limited success, I broadened my search to encompass teaching any lessons about race and included 
countries outside of the United States. My research ultimately yielded around 20 articles and books, out of which I found three relevant empirical studies.

Kailin (2002) conducted a qualitative research study in which she documented the process of teaching an anti-racist staff development course in a "liberal" school district located in the Midwest of the United States. This course consisted of a series of professional development workshops held within the teachers' school district, and each teacher received district support for his or her participation in the form of continuing education credits. Approximately 345 teachers participated in the course, of which 89\% identified as White and 11\% identified as people of color. The purposes of these workshops were to provide opportunities for teachers to reflect on their own racial identities; to evaluate the impact of race in their own lives, school settings, curricula, and teacher-student interactions; and to develop a framework for teaching against racism. The aim of this study was to document the teachers' experiences as they embarked on the process of learning about anti-racist practices and curriculum.

The theoretical assumptions of Kailin's research revolved around a structuralist analysis of racism. From a structuralist perspective, the struggle against racism is not simply a matter of combatting individual stereotypes and attitudes but rather of combatting the ways in which race and racism can be a social construct embedded within societal institutions such as politics, the legal system, education, and culture (Kailin, 2002). One critique of this perspective is that it focused solely on the social context and the interplay of overlapping contexts in society. 
Kailin's data sources included field notes, recorded group sessions, reflective journal entries, racial autobiographies, unstructured interviews, open-ended questionnaires, and additional information about teachers' backgrounds and school demographics. Kailin's analysis focused on the experiences of teachers throughout the anti-racist staff development course. Kailin derived several themes from her data analysis, including resistance, self-reflection, and action. First, many of the teacher participants initially demonstrated a resistance to talking about race and racism in schools, as very few of them had ever challenged the dominant discourse in education. Second, for many of the White teacher participants, this was the first time that they had examined White privilege and Whiteness. Many found Peggy McIntosh’s 1988 article "White Privilege: Unpacking the Invisible Knapsack" extremely helpful in developing their understanding of how race operates in society. Finally, many teacher participants reported that this course had a direct impact on their lives and teaching practices. For example, many teachers found that they were taking the course topics home with them and discussing the issues with friends and family. Others revealed that they had become more vocal about challenging racism in schools, especially with other staff members.

One of the major limitations of this research study was the lack of transparency about the analysis leading to the research findings. Although Kailin extensively described her data collection, she did not reveal her research questions nor did she explain her data analysis. As a result of this lack of transparency, the credibility and validity of her research findings could be questioned. 
In the second of the three research studies, Casas (2013) conducted a longitudinal study with 52 Mexican and Chicano students enrolled at an alternative middle school in Texas. Casas' primary goal was to motivate and reengage these students (40 male, 12 female) who had been sent to this alternative school due to misconduct at their prior schools. Another goal of this research was to describe how anti-racist curriculum could be incorporated into middle-school curriculum. Casas used Latinx critical pedagogy (LatCrit) as the theoretical foundation for her research study, which is a derivative theory of CRT that centers Latinx experiences and perspectives. Casas saw Latinx critical pedagogy as a teaching approach that encouraged these Mexican and Chicano students to question and challenge current beliefs and practices in today's society.

For this study, Casas designed and implemented anti-racist curriculum during twice-weekly four-hour learning sessions, integrating language arts and social studies, over the course of 14 months. In addition, the researcher incorporated Texas Essential Knowledge and Skills (TEKS), which were cross-curricular goals and objectives required by the Texas Department of Education. She used both qualitative and quantitative methodologies in her data collection. She collected data via videotaped and nonvideotaped class discussions, pre- and post-study questionnaires, student interviews, student journals, student work, and drawings.

Casas' research findings focused on the experiences of implementing anti-racist curriculum within middle-school curricular content. She drew three primary conclusions: First, from the researcher's perspective, incorporating both language arts and social studies was beneficial for expanding discussions around race and ethnicity. Second, using 
the experiential knowledge of the students, especially regarding experiences with race and racism, allowed for deeper understanding of the issue. Third, when social justice was the central focus of education, students were empowered to engage in their own learning process as a form of liberation and freedom.

One of the obvious critiques of this research involved the apparent disconnect between the data collection and the research findings/discussion. Although the aim of this research was twofold, the findings/discussion only illuminated how anti-racist curriculum could be successfully implemented within the traditional middle-school curriculum. Casas seemed to gloss over how and why students were re-engaged and exclusively focuses on how-to's for other educators. The students' voices appeared to have been largely left out of the findings/discussion. This too could be a critique of my research study, since the context of my work does not incorporate students' experiences.

In a third study, Wood (2016) documented the process of two co-teachers planning and implementing culturally restorative and anti-racist education in their kindergarten classrooms in Ontario, Canada. This study used an action research methodology, wherein the two participating educators led students through a process of inquiry while also examining their own pedagogical practices. The focal point of this research was the incorporation of practices and curriculum that reflected the cultural backgrounds of Aboriginal students whose communities experienced years of cultural genocide.

The research study began with a full-day workshop for the two teacher participants and other early learning educators, which provided an overview of the PK-12 
inquiry process and documentation of learning. The planning was a co-constructed process where the teachers took an active role in designing learning experiences for their students, incorporating both students' interests and formal curricular expectations. Other formal planning meetings were held during the project for collaborative reflection and refinement of the process. In addition, throughout the study, teachers met in small research groups to review documentation and to reflect on student and teacher learning.

According to Wood (2016), following the workshop, the two teachers were successful in incorporating the home cultures of the Aboriginal children into the classroom and in developing a positive, inclusive, and affirming classroom community. Further, this process provided an opportunity for non-Aboriginal children to learn about and from the Aboriginal children and moved the teachers toward an anti-racist classroom community. The analysis that determined these outcomes were the summation of the process of pedagogical documentation in which multimodal forms of evidence were collected and evaluated, including writing samples, photographs, anecdotal records, and video and audio recordings focused on the children's learning.

The example of teaching in Wood's research embodied the full range of ideas and practices of implementing anti-racist curriculum, although he did not refer to the curriculum as such. Furthermore, Wood used an inquiry-based research approach that relied heavily on the teacher participants as co-constructors of the study. Wood utilized basic category generalization and initial meaning reconstruction to analyze these data sources (Wood, 2016). The design of this study closely related to the collaborative professional development sessions and implementation of curriculum that I employed for 
my research study, although my research centered around the experiences of teachers and not their students.

One critique of Wood's research could be that his theoretical framework revolved around culturally restorative practices, which referred to the instructional methods used. By solely focusing on the practices, the students' experiences and the impact of such practices could be overlooked. As another critique, Wood concluded that the study created a positive, inclusive, and affirming classroom community, but the findings would have been more convincing if students' perspectives had been incorporated. In addition, this research was conducted in Canada, which could pose potential limitations for generalizing the findings to the United States due to differing cultural communities, racial groups, and educational systems and policies.

Despite the fact that all three studies were informative in regards to discussing and using anti-racist curriculum, empirical research about anti-racist curriculum has been extremely limited. Within the research available, scholarship appeared to be limited to just the experiences of teachers attending professional development workshops, with some creation and implementation of anti-racist curriculum. Currently, research related to the challenges and obstacles in creating and implementing anti-racist curriculum in PK12 settings in the United States does not seem to exist. Thus, my research has the opportunity to fill a void in academic scholarship and the potential to directly inform the field of education.

\section{Shortcomings of Anti-racist Curriculum}


None of the tenets or underlying assumptions of anti-racist curriculum addressed the need for educators to unpack their potentially color-blind beliefs. Rather, much of the tenets focused on student outcomes to being exposed to anti-racist curriculum, and not the beliefs and knowledge necessary for educators to effectively teach anti-racist curriculum. Therefore, an educator could employ anti-racist curriculum facilitated from a color-blind lens, which would almost certainly limit the benefits of such curriculum and could cause direct harm to students. Instead, anti-racist educators need to employ antiracist instructional practices or "culturally responsive teaching" (Gay, 2010). Culturally responsive pedagogy makes direct connections to students, infusing the cultural backgrounds and lived experiences of students of color into the curriculum and instruction as a means for empowering and acknowledging students (Gay, 2010; Vavrus, 2008).

\section{Theoretical Framework: Transformative Curriculum}

In furthering the conversation about what could be in the system of education, I developed a new theoretical framework called transformative curriculum (TC). The rationale for developing such a framework is twofold: first, to build upon the shortcomings of anti-racist curriculum by incorporating educators' personal reflections, knowledge construction, and instructional practices as part of the curriculum; and second, to create an analytical tool to deconstruct curricular practices and curriculum development, to address the research questions for this study.

The three theoretical frames used in Kailin, Casas, and Wood's research studies helped describe educational inequities in schools through an understanding of 
the historical, political, and cultural constructs of society. Yet none of these theoretical perspectives described or considered the perspective of the individual; rather, the focus remained largely at the macro-levels of curriculum development. Therefore, I believed that the framework of TC could more precisely examine the phenomenon in this research study, which considered both the individual and the collective experiences of participants.

\section{Defining Transformative Curriculum}

TC takes a critical view of education, derived from the work of Paulo Freire and critical pedagogy. Specifically, TC is grounded in Freire's (1970) notion of conscientization, or the need for reflection, understanding, and action. In addition, TC incorporates several components of anti-racist curriculum (Cheng \& Soudack, 1994) and builds upon the previously mentioned shortcomings of anti-racist curriculum by allowing for the examination of educators' beliefs, biases, and identities through culturally responsive pedagogy (Brown-Jeffy \& Cooper, 2011). Figure 1, below, outlines the interconnected aspects of TC. 


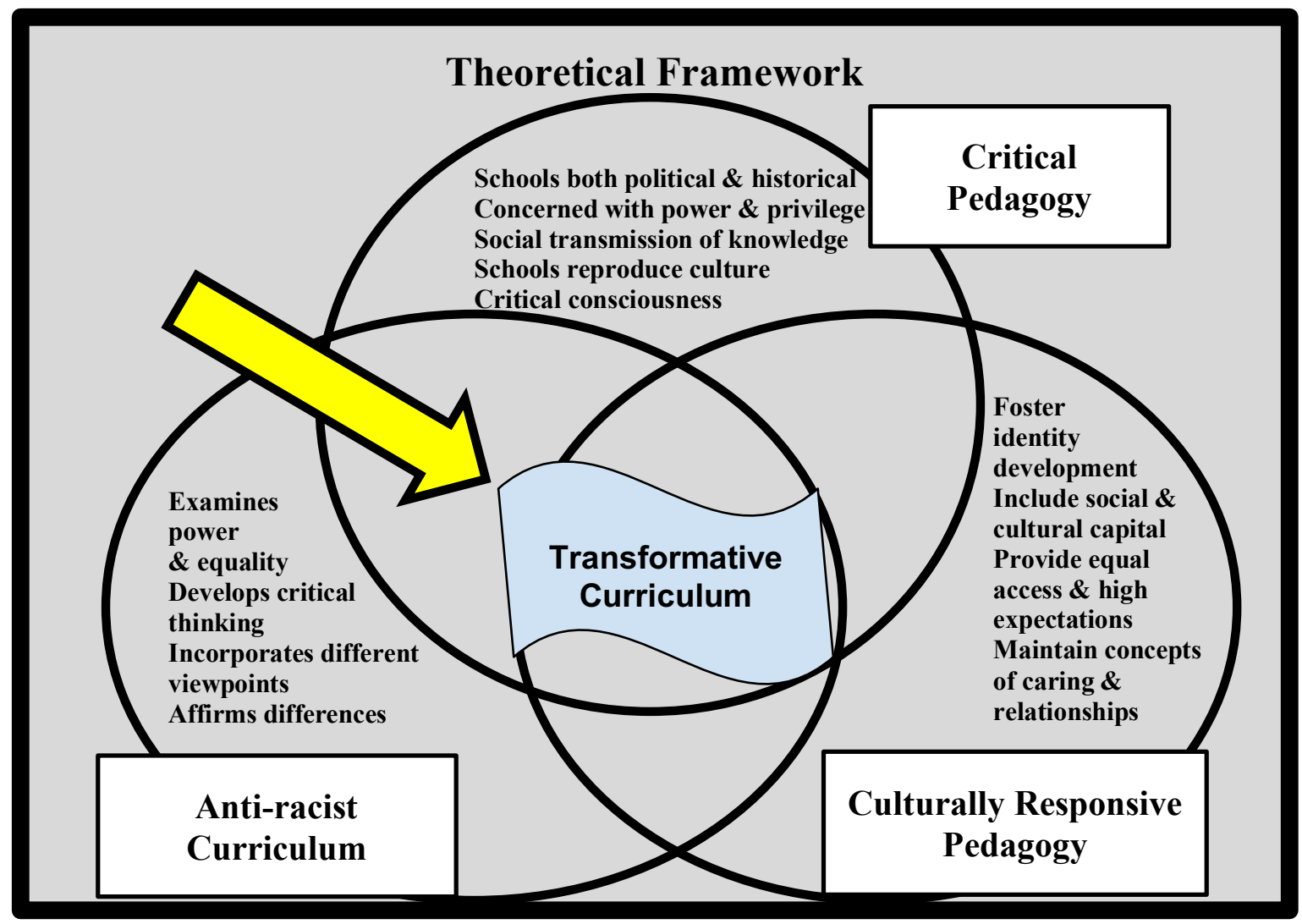

Figure 1. Transformative curriculum: Incorporating critical pedagogy, anti-racist curriculum, and culturally responsive pedagogy.

Critical pedagogy. Critical pedagogy foregrounds the underlying assumptions of TC through its examination of schools in their political and historical contexts and its fundamental concern with power and privilege in education and the social transmission of knowledge (Giroux, 1989, 1995; McLaren, 2015). More specifically, critical pedagogy in education focuses on how culture is reproduced through institutional practices such as how one teaches, what is being taught, and how one learns (Giroux, 1997; Sleeter, 1995). Further, critical pedagogy views schooling as a form of cultural politics and takes the stance that schools can never be neutral institutions removed from the concepts of power, politics, and history (McLaren, 
2015; Solórzano, 2013). Ultimately, critical pedagogy intends to liberate and empower the powerless while taking action to combat social inequalities and injustices (McLaren, 2015). Critical pedagogy calls upon teachers - as public intellectuals - to understand their roles in the perpetuation of power and knowledge (Giroux, 1997). Current understandings of critical pedagogy are largely based on the work of Freire (McLaren, 2000). Freire (2000) sharply critiques supposed democratic, meritocracy-based schooling and insists that teachers reject the traditional "banking" system of education. Specifically, Freire decries a system wherein teachers are transmitters of the dominant ideology and values while students remain dependent on their teachers for the acquisition of knowledge, arguing instead that education should be the practice of freedom (Freire, 2000; Solórzano, 2013). He views education and knowledge as forms of liberation through which students and teachers are engaged in partnership and collaboration, where the educational process is humanized and promotes a "problem-posing" method that regards dialogue as indispensable to the process of cognition, in turn creating critical-thinking skills in students (Barlett, 2005; Darder, 2014; Freire, 2000).

Freire further elaborates on the educational process with his conception of conscientization as an explicit and systematic form of critical analysis (Freire, 1970). Within this process of conscientization, individual reflection is only possible through the understanding and acknowledgment of the social and historical contexts within society. Thus, action for freedom derives from the dialectical exchange between educators and students, which considers the individual within the larger context. At the 
core of the concept of conscientization, consciousness and actions are considered inseparable (Freire, 1970).

Anti-racist curriculum. Next, TC draws upon the curricular assumptions and focal concepts associated with anti-racist curriculum at the micro level of examination, summarized below in Table 2 .

Table 2

Tenets of Anti-racist Curriculum (Cheng \& Soudack, 1994)

Anti-racist curriculum:

1. Examines issues of power and equality and deep-seated problems related to unequal power distribution.

2. Develops critical thinking through recognizing stereotypes, prejudice, and discrimination.

3. Incorporates different viewpoints with the history, experiences, and cultural values of all.

4. Develops positive attitudes and respect for differences.

5. Affirms racial and cultural differences throughout the school year.

6. Includes contributions of both males and females from all racial and ethnic backgrounds.

7. Bolsters self-esteem in ethnic minority students.

Culturally responsive pedagogy. Finally, TC builds upon critical pedagogy's notions of reflection and reaches beyond the tenets of anti-racist curriculum to address teachers' beliefs, biases, and identities, which can impact implementation of curriculum. TC utilizes components of Brown-Jeffy and Cooper's (2011) framework for culturally responsive pedagogy, in which they outline educators' dispositions, beliefs, background knowledge, and inclusive practices as essential for effectively facilitating learning in the classroom. Further, through their review of the work of Gay (2010), Ladson-Billings (1994), and Nieto (1999), Brown-Jeffy and Cooper described five thematic components of culturally responsive pedagogy (see Table 3 below). 
Additionally, culturally responsive pedagogy encourages critical reflection amongst educators, which is vital in education because, as Gay (2010) notes, "racial and cultural attitudes and beliefs are always present, often problematic, and profoundly significant in shaping teaching conceptions and actions" (p. 143). Through the concepts of culturally responsive pedagogy, educators are encouraged to engage in deep reflections about their beliefs and identities as a means for understanding how their biases about race, culture, and class can affect their instructional practices. Ultimately, TC draws upon Brown-Jeffy and Cooper's (2011) framework of culturally responsive pedagogy as guidelines for educators' reflective processes regarding their beliefs, biases, identity, and instructional practices.

\section{Table 3}

Overview Conceptual Framework of Culturally Responsive Pedagogy (Brown-Jeffy \& Cooper, 2011)

(1) Identity and Achievement: Identity development, cultural heritage, multiple perspectives, affirmation of diversity, and public validation of home-community cultures, which includes social and cultural capital.

(2) Equity and Excellence: Dispositions, incorporation of multicultural curriculum content, equal access, and high expectations.

(3) Developmental Appropriateness: Learning styles, teaching styles, and cultural variation in psychological needs (motivation, morale, engagement, and collaboration).

(4) Teaching the Whole Child: Cultural context, home-school-community collaboration, learning outcomes, supportive learning community, and empowerment.

(5) Student-teacher Relationships: Concepts of caring, relationships, interaction, and classroom atmosphere.

\section{Tenets of Transformative Curriculum}

Informed by the concepts of critical pedagogy (Freire, 1970), anti-racist

curriculum (Cheng \& Soudack, 1994), and culturally responsive pedagogy (Brown- 
Jeffy \& Cooper, 2011), the tenets of TC are organized into three interconnected stages: reflection, understanding, and action (see Figure 2 below).

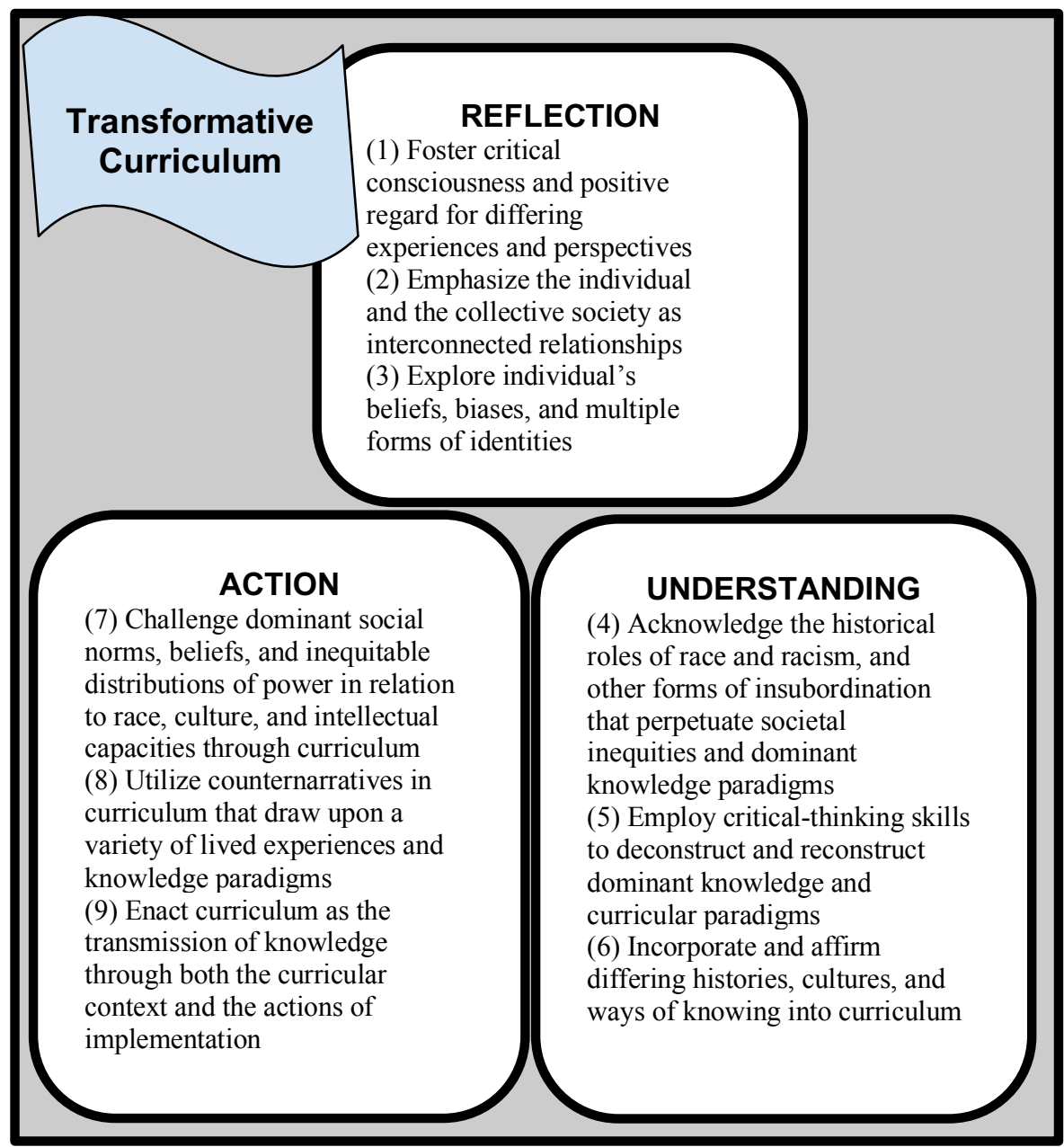

Figure 2. Tenets of transformative curriculum.

Reflection. For this stage, the tenets of TC focus on reflective practices, with consideration of the individual as well as the collective. Freire (1970) asserts that humans exist relationally in and with the world. As such, the practice of reflection inextricably links the individual with his or her worldly context. Freire further suggests, "only beings who can reflect upon the fact that they are determined are 
capable of freeing themselves" (p. 453). Thus, the TC tenets encompassed in this stage of reflection:

1. Foster critical consciousness and positive regard for differing experiences and perspectives (anti-racist curriculum and critical pedagogy).

2. Emphasize the individual and the collective society as interconnected relationships (anti-racist curriculum and critical pedagogy).

3. Explore the individual's beliefs, biases, and multiple forms of identities (culturally responsive pedagogy).

Understanding. Because the individual and the society are intermeshed, it is essential that teachers understand the social, political, and economic conditions that impact education and their roles in the perpetuation of the status quo (Darder, 2010; Freire, 2000). Accordingly, the tenets of TC that focus on contextual understandings associated with curricular practices and curriculum development:

4. Acknowledge the historical roles of race and racism, and other forms of insubordination that perpetuate societal inequities and dominant knowledge paradigms (anti-racist curriculum and critical pedagogy).

5. Employ critical-thinking skills to deconstruct and reconstruct dominant knowledge and curricular paradigms (anti-racist curriculum and critical pedagogy).

6. Incorporate and affirm differing histories, cultures, and ways of knowing into curriculum (anti-racist curriculum and culturally responsive pedagogy).

Action. Freire (1970) believes that, in order to transform social conditions, educators must direct their curricular and contextual understandings into actual actions as a regular part of their practice. For this reason, the process of applying critical knowledge to social practice becomes a critical component in the educational system, specifically as it relates to social change in education (Freire, 2000; McLaren, 2015). 
Drawing on these concepts, the tenets of TC that inform actions associated with curricular practices and curriculum development:

7. Challenge dominant social norms, beliefs, and inequitable distributions of power in relation to race, culture, and intellectual capacities through curriculum (anti-racist curriculum).

8. Utilize counternarratives in curriculum that draw upon a variety of lived experiences and knowledge paradigms (anti-racist curriculum).

9. Enact curriculum as the transmission of knowledge through both the curricular context and the actions of implementation (culturally responsive pedagogy and critical pedagogy).

\section{Summary of Transformative Curriculum}

The overarching components of TC focus on curricular practices and development through the stages of reflection, understanding, and action (see Figure 3 below). Like critical pedagogy, anti-racist curriculum, and culturally responsive pedagogy, the tenets of TC challenge the historical systems that have served to reify racism and educational inequities. TC's tenets also seek to confront the dominant Eurocentric ideology and color-blind mindset widely used in mainstream curricula, insisting that race and racism should remain central in educational. Further, the tenets of TC also demand that educators reflect upon their beliefs, biases, and multiple identities as a means for effectively implementing curriculum. Ultimately, the lens of TC serves as a mechanism for directly analyzing the participants' process of reflection, understanding, and action through their development of anti-racist curriculum for this research study. 


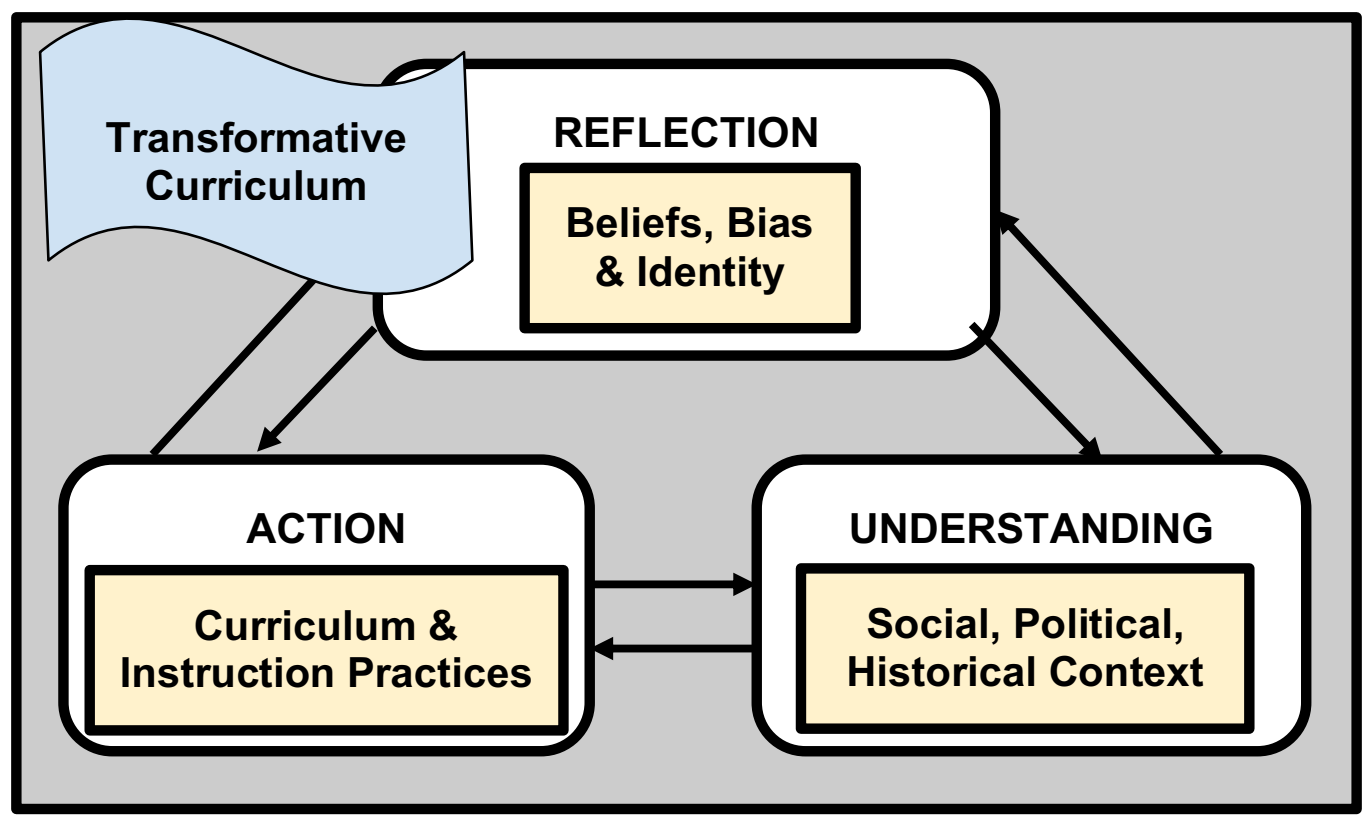

Figure 3. Overarching components of transformative curriculum.

\section{Case Study Research}

There are several methodological approaches that scholars have used to study color-blindness in education and anti-racist curriculum. The most common approach in these areas has been ethnography. While ethnographies can provide substantial data, challenges arise with research reliability and validity when researchers do not provide clear descriptions of their methods for data analysis. One of the major disadvantages of ethnographic research has been the time commitment, as researchers often need to immerse themselves in the culture or group they are studying.

Other methodological approaches I have cited include general qualitative studies, mixed methods studies, and action research. Kailin (2002), Copenhaver (2001), Hughes et al. (2007), and Rickford (2001) utilized general qualitative methods, which largely focus on participatory observations and interviews. Not unlike ethnographies, this 
methodology can provide rich data collected in natural settings. However, general qualitative methods do not always have clearly defined boundaries around what is being researched. For the purposes of my research, it was imperative to understand the teachers' perspectives within the context of planning and implementing anti-racist curriculum, which in itself is a phenomenon. Therefore, general qualitative methods fall short for generating the optimal data for my study.

Both Casas (2013) and Lipka et al. (2005) used mixed methods approaches, integrating both qualitative and quantitative methods. The advantages of mixed methods include the incorporation of both open-ended and closed-ended information, the opportunity to triangulate data, and the possible illumination of a more complex and comprehensive understanding of the research problem. Conversely, mixed methods can present challenges in coordinating the implementation of methods and interpreting any discrepancies that arise from the differing methods. While there are great advantages to this type of research methodology, these methods may not best achieve the goal of representing teachers' perspectives within the planning and implementing of anti-racist curriculum.

Last, Wood (2016) adapted an action research methodology for his study, focused on the co-collaboration of the teacher participants and the implementation of curriculum. In general, action research lends itself to both qualitative methods and extensive collaboration with the participants themselves. As part of this study, Wood collected research artifacts as the primary data sources of data, which included photographs, anecdotal records, videos, and audio recordings. Although this research provided rich 
descriptions from the teacher participants, this work was context specific and not necessarily generalizable.

\section{Defining Case Study Research}

For my research, I branched out beyond the research methodologies that have been used for this topic by utilizing case study research. I believed that the case study approach was optimal for addressing my research questions because such research can incorporate multiple data sources to understand the phenomenon of developing and teaching anti-racist curriculum. Case study research can be defined as a qualitative method of empirical inquiry that investigates a social phenomenon (the "case") within its natural context, using multiple sources of evidence (Dyson \& Genishi, 2005; Yin, 2003, 2014). Hancock and Algozzine (2015) suggested, "Doing case study research means identifying a topic that lends itself to in-depth analysis in a natural context using multiple sources of information" (p. 16). Case study methodology has been widely used across a range of social science disciplines, including anthropology, psychology, sociology, and education (Yin, 2014). Such studies incorporated participant observation, interviews, and collection of artifacts and were grounded in the social context of a phenomenon. Researchers investigated the happenings, communication, and organizational flow of a particular setting. Case study research is grounded in varied sources of information and is richly descriptive, often employing quotes from participants as key sources of data.

The case study approach largely derived from the constructivist paradigm, relying on the premise of the social construction of reality (Baxter \& Jack, 2008). This type of research was often conducted with close collaboration between the researcher and 
participants, enabling participants to more naturally share themselves and their perspectives (Crabtree \& Miller, 1999). In turn, this collaborative relationship can provide the researcher more in-depth understanding of the participants' experiences and points of view within a given phenomenon (Lather, 1992).

\section{Why Case Study Research?}

Case study was the optimal methodological approach for answering my research questions because it was a useful structure for documenting complex phenomena, such as the design and implementation of anti-racist curriculum by teachers engaged in collaborative learning about race, racism, and racial oppression. For my study, case study research was a collaborative process that afforded opportunities for in-depth dialogue and reflection, aiding me in gathering and interpreting data about the process and the teachers' point of view. A case study was useful for structuring and documenting such a complex phenomena of collaborative learning and curriculum development. Further, case study also served as an appropriate approach for investigating the topics of educational inequities - such as race and racial oppression, Eurocentric curriculum, racial colorblindness, and implementation of anti-racist curriculum — because this methodology allowed for deep investigation, which were be both intimate and richly descriptive.

In sum, I believed that case study research was the appropriate methodology for gathering and interpreting data about the process of designing anti-racist curriculum from the teachers' points of view, including understanding how teacher participants describe the obstacles and challenges of designing and implementing anti-racist curriculum and 
how the collaborative sessions of this study influenced their teaching practices with antiracist lessons.

\section{Research Studies Using Case Study Methodology}

Although case study research remains a popular methodology in the field of education, few case studies have investigated anti-racist curriculum. In an extensive search, I only located one relevant study in which the researchers used the case study approach to describe and evaluate an anti-racist project. Short and Carrington (1987) describe research that was conducted with fourth-grade students attending an all-White school in a working-class community in England and centered around the examination of economic, social, and cultural change in post-WWII England. The aim of this research was to challenge the notion that children are incapable of learning about the concept of racism by directly teaching about race and immigration. For example, students were asked to take the perspective of a recent immigrant to England from the West Indies and imagine writing a letter to a close relative or friend who was interested in joining them in England. In the letters, students made various references to racial violence, name-calling, and job restrictions based upon race. Ultimately, the researchers concluded that the children repeatedly demonstrated the ability to conceptualize race, as noted through class discussions and the various tasks. Further, the authors stated that, despite living in an allWhite community, the students were able to discuss race and racial inequities and, therefore, could not be described as color-blind.

Of the research conducted in this area to date, Short and Carrington's study most closely aligned with my research. The theoretical framework of this anti-racist project 
were commensurate with the threads of my theoretical framework, noting that knowledge is socially constructed and that race/racism is of a historical nature and must be directly taught. Further, their project utilized anti-racist curriculum and culturally responsive teaching practices, as aspects of the project focus on the students' lived experiences. Finally, their case study employed several qualitative data collection methods and their findings revolve around participant quotes, observations, and written artifacts.

As a result of the limited number of case studies I was able to locate while researching anti-racist curriculum, I decided to widen my search to find case studies encompassing the broader themes of my research, including collaborative curriculum development, critical literacy, and social justice education. To begin with, Nunan (1989) described an example of a collaborative curriculum case study in which Australian public-school teachers play the central role in a curriculum development project in a collaboration with curriculum developers. Through the Australian Adult (Im)migrant Education Program (AMEP) — which is a large, federally funded English language education program for immigrants and refugees - a voluntary program called the National Curriculum Project (NCP) was established to support teacher development of curriculum in the late 1980s. During this time, the NCP funded 100 curriculum proposals from the nearly 1,500 teachers who supported the approximately 130,000 immigrant and refugee students. The teachers were charged with developing curriculum for the students in their given schools, either independently or in small teams of teachers, and in collaboration with curriculum developers provided by the NCP. 
Ultimately, this project yielded mixed results. Although the teacher participants overwhelmingly reported a high degree of satisfaction with the project, it was extremely difficult to consistently collect data from the 100 projects, as many never reported any information about their curriculum development. Therefore, it was challenging to analyze and evaluate the "effectiveness" of such a program. However, out of the data provided arose a pattern of consistent practices for planning and implementing anti-racist curriculum and several rich narratives provided by the teachers of a few projects.

In another study focused on collaboration and curriculum, Graham (2007) conducted a mixed method case study investigating the relationship between the professional learning community (PLC) and teaching effectiveness in a middle school located in a large, southeastern school district, serving a population of predominantly White, middle-class students. At this middle school, 24 of the 44 teachers were considered core academic teachers (language arts, math, science, or social studies). These teachers were the focal participants of this case study. Although all of the core teachers participated in multiple PLCs, the majority of PLC time was spent in same-grade, samesubject teams (e.g., all seventh-grade language arts teachers). The same-grade, samesubject PLCs represented a shift from the more traditional focus on the interdisciplinary collaborative teams generally found in middle schools. Data collected for this case study include a professional development survey, teacher interviews, and a review of school records. The analysis of the data indicated that the PLC with same-subject, same-grade teacher teams had the most potential of all the PLC configurations to improve teaching effectiveness. However, this effectiveness was dependent on a number of factors, 
including the development of community amongst the PLC teams, the nature of the conversations and activities during PLC meetings, and the school's leadership and organizational practices.

Many case studies have also focused on critical literacy and social justice education. For example, Gloria Ladson-Billings (1992) utilized case study methodology in one of her seminal research studies, "Liberatory Consequences of Literacy: A Case of Culturally Relevant Instruction for African American Students." Her investigation centered around one teacher who was considered a successful teacher of African American students by the educational community in which she worked. The teacher identified as an Italian American woman who had taught sixth grade for 14 years at a low-income, predominantly African American school. The data sources for this case study included interviews (with community members and the teacher herself), as well as observations and video recording (in the school setting and classroom). Through her analysis, Ladson-Billings arrived at several overarching findings from this teacher, who incorporated both critical literacy and culturally relevant teaching in her educational practice. When critical literacy and culturally relevant teaching are practiced in a classroom:

- Students who have been historically marginalized are often the intellectual leaders of the classroom;

- Students are always treated as if they already know something, rather than taught isolated and unrelated skills;

- Students' life experiences are valued as part of the official curriculum in the classroom;

- Teachers and students engage in literature that incorporates varied genres and perspectives; 
- Teachers and students collectively struggle against the educational status quo; and

- Teachers emphasize critical literacy and culturally relevant teaching and engage in ongoing self-reflection, demonstrating awareness of themselves as political beings.

Lopez (2011) also researched critical literacy and social justice education using case study methodology. Her research was conducted at a large multilingual and multiracial suburban secondary school in Ontario, Canada. Her case study focused on one African-Canadian, twelfth-grade English teacher with over 10 years of teaching experience. As part of the research, this teacher was observed during a performance poetry unit emphasizing critical literacy and cultural awareness. The researcher used a collaborative research approach with both the teacher and the students, in conjunction with observations, informal and formal dialogues, and inquiry-group meetings with the students and teacher as the primary sources of data. As a result of her analysis, Lopez concluded, "Using performance poetry as a form of critical literacy to engage in culturally relevant teaching in [a] diverse classroom is valuable in building cross-cultural understanding, raising critical consciousness and helping students to understand how oppression works in multiple ways" (p. 88). Further, the research underscored the importance of creating space in the curriculum to develop agency for social justice teaching and other equitable practices that involve a variety of genres and knowledge. Ultimately, Lopez suggested that culturally relevant teaching was good teaching for all students, serving to increase engagement, promote academic achievement, and raise students' critical consciousness.

\section{Conclusion}


In response to historical inequities, racialized student outcomes, and the colorblind mentality, anti-racist curriculum directly challenges the status quo of education in the United States. Anti-racist curriculum is defined by a set of guiding principles that include interrogating power inequities, identifying stereotypes, incorporating multiple racial perspectives, and empowering students to resist bias and oppression in their everyday lives (Cheng \& Soudack, 1994).

My research investigated the practice of directly challenging the color-blind mindset in education through the collaborative design and implementation of anti-racist curriculum. Through this study, I sought to understand how teacher participants described the process of designing and implementing anti-racist curriculum, along with obstacles or challenges experienced during this process, and how the collaborative sessions of this study impacted their teaching practices with anti-racist lessons. I utilized transformative curriculum as a theoretical framework and analytical tool to evaluate the participants' experiences, with consideration of their own beliefs and identity. My use of a case study research methodology provided an optimal lens for examining this educational phenomenon through data-rich descriptions. 


\section{Chapter III \\ Research Design}

It is not enough for people to come together in dialogue in order to gain knowledge of their social reality. They must act together upon their environment in order critically to reflect upon their reality and so transform it through further action and critical reflection (Freire Institute, 2016).

Thus far, I have described the racialized educational inequities that persist in public education in the United States. Also, I have illustrated how educators' reluctance to talk about race and racism in schools perpetuates the color-blind ideology, which deprives students of opportunities to build positive racial identities and limits opportunities for both the school community and individual students to develop skills necessary for understanding and resolving racial conflicts and inequities. The objective of my research study is to examine the practice of directly challenging the color-blind ideology in education through the collaborative design and implementation of anti-racist curriculum. Through this study, I seek to understand how the teacher participants describe the process, obstacles, and challenges of designing and implementing anti-racist curriculum and how the collaborative sessions of this study influence their teaching practices for anti-racist lessons.

In this chapter, I explicitly explore my rationale for my qualitative research methodology. Next, I illustrate the step-by-step process by which I conducted this study. Lastly, I outline the specific procedures and sources for my data collection and describe the process for data analysis.

\section{Case Study Research}


According to VanWynsberghe and Khan (2007), case study research tends to incorporate several key features. First, the case study approach calls for an intensive and in-depth focus on a specific phenomenon, which generally requires a much smaller sample size than survey research. Second, the aim of case studies is to give the reader a sense of "being there" by providing a highly detailed, contextualized analysis of the situation or phenomenon. Third, because case study focuses on systematically studying situations where there is often little control over behavior, organization, or events, it is uniquely suitable for research in complex settings. Fourth, case studies are bound by time and space, using detailed description of specific temporal and spatial boundaries. Fifth, although case study researchers can generate working hypotheses, natural conclusions often surface during data collection and analysis. Sixth, case studies routinely use multiple sources of data, which facilitates triangulation and offers findings that are likely to be convincing and accurate.

Ultimately, the case study approach allows for in-depth, multifaceted exploration of complex issues in their real-life settings. Yin (2012) refers to this type of case study research as descriptive case study; it aims to portray a rich depiction of what happened in a particular phenomenon. Accordingly, case study research affords me the best opportunity to answer my research questions while investigating and describing the phenomenon of teachers collaboratively planning and implementing anti-racist curriculum.

\section{Research Procedures}


In this portion of the chapter, I will clearly describe the procedures used to conduct my study. I will review the overarching process for this research (as documented in Table 4), describe participant recruitment and selected participants, and lay out a stepby-step agenda for conducting the collaborative professional development sessions.

\section{Table 4}

Overview of Research Procedures \& Resources

\begin{tabular}{|c|c|}
\hline Actions Steps & Resources \\
\hline $\begin{array}{l}\text { Collaborate with the College of Education and the } \\
\text { Curriculum \& Instruction department chair for } \\
\text { reaching in-service teachers and preservice teachers } \\
\text { with advertising course through email listserv. }\end{array}$ & \\
\hline $\begin{array}{l}\text { Connect with interested participants and provide } \\
\text { course and study information. }\end{array}$ & \\
\hline $\begin{array}{l}\text { Inform teachers about research project and obtain } \\
\text { informed consent from interested teacher participants. }\end{array}$ & Written informed consent (Appendix A) \\
\hline $\begin{array}{l}\text { Give teacher participants short survey about } \\
\text { educational experiences, attitudes about race, racial } \\
\text { identity development, and beliefs about talking with } \\
\text { students about race. }\end{array}$ & Survey (Appendix B) \\
\hline $\begin{array}{l}\text { Facilitate collaborative professional development } \\
\text { sessions for racial identity development and anti- } \\
\text { racist curriculum design. }\end{array}$ & $\begin{array}{l}\text { Ongoing throughout/Later transcribed: } \\
\text { Participant observation notes (Appendix D), } \\
\text { researcher memos, and artifacts: reflection } \\
\text { journals (Appendix E) and written lesson plans }\end{array}$ \\
\hline $\begin{array}{l}\text { Collect artifacts at the conclusion of collaborative } \\
\text { professional development sessions. }\end{array}$ & Reflection journals and written lesson plans \\
\hline $\begin{array}{l}\text { Conduct semi-structured interviews with each } \\
\text { participant (after the conclusion of the collaborative } \\
\text { professional development sessions). }\end{array}$ & $\begin{array}{l}\text { Audio recorded/Later transcribed: Interview } \\
\text { protocol (Appendix C) }\end{array}$ \\
\hline $\begin{array}{l}\text { Follow up with participants about data for member } \\
\text { checking. }\end{array}$ & $\begin{array}{l}\text { Transcriptions: Participant observation notes, } \\
\text { researcher memos, and artifacts: reflection } \\
\text { journals and written lesson plans }\end{array}$ \\
\hline
\end{tabular}

\section{Participants}


For this research study, I partnered with currently employed in-service teachers as well as pre-service teachers enrolled in a graduate teacher education program in a large metropolitan area in the western United States. In conjunction with a local public university, I developed and taught a graduate-level course called Multicultural Curriculum and Design, the class meetings of which served as the collaborative professional development sessions for this research study. I intentionally decided to call the course "multicultural curriculum," since I was concerned that the term "anti-racist curriculum" would deter White teachers from participating given the dominant cultural norms around talking about race. This course was offered during two different school terms, which meant there were two groups of teacher participants. Through the College of Education at this university, the course was available to alumni students from the Masters of Education programs and graduate teacher education programs and to current students in the Masters of Education programs and part-time graduate teacher programs, which was preapproved by the chair of the Curriculum and Instruction department. In turn, the announcements advertising the course were distributed by the department through the various email listservs. Interested students were directed to contact me regarding course specifics. Participants had the option to either register for graduate-level credits or take the course for free for no credit as part of this research study.

Maxwell (2013) refers to this type of sampling as purposive sampling, wherein the participants are deliberately selected to provide information that is particularly relevant to the research questions and goals. Weiss (1994) describes this purposeful process as the selection of "people who are uniquely able to be informative because they 
are experts in an area or were privileged witnesses to an event" (p. 17). In order to effectively answer my research questions, I needed the expertise of in-service and/or preservice teachers who have firsthand knowledge of the field of education and the process by which to plan and implement curriculum. Furthermore, these participants had access to graduate courses in the College of Education, were able to attend several face-to-face sessions, and were willing to engage in the process of developing anti-racist curriculum. Once teachers chose to be a part of this research, I provided them with an overview of the research project and obtained their written consent to participate (see Appendix A), which was the mechanism for ensuring that the participants understood what it meant to participate in this research study. At the same time, I provided detailed information about their participation, including the purpose of the study, expectations of the participants (including the amount of time required), and expected risks and benefits (both psychological and social). I explained how confidentiality would be maintained and provided the name and contact information of the person to whom they could direct questions about one's rights as a participant. I created pseudonyms for the participants, schools, and school districts involved in this research to maintain confidentiality. In addition, I asked participants to assure confidentiality for the other participants as part of the collaborative nature of this work. Further, I emphasized that participation was voluntary and that anyone could withdraw at any time with no negative repercussions. Below, Table 5 outlines descriptions of each of the participants, including their selfidentified racial categories and current and previous educational experiences.

Table 5 


\begin{tabular}{|c|c|c|c|c|}
\hline \multicolumn{5}{|c|}{ Overview of Participants } \\
\hline Pseudonym & $\begin{array}{l}\text { Course } \\
\text { Date }\end{array}$ & $\begin{array}{l}\text { Self-Identified } \\
\text { Race }\end{array}$ & $\begin{array}{l}\text { Current Educational } \\
\text { Context }\end{array}$ & $\begin{array}{l}\text { Other Educational } \\
\text { Experience }\end{array}$ \\
\hline Nick & Fall 2017 & White & $\begin{array}{l}\text { In-service } 5^{\text {th }} \text { grade teacher, } \\
\text { public school, } 4^{\text {th }} \text { year } \\
\text { teaching }\end{array}$ & $\begin{array}{l}\text { Parent, teacher in Japan } \\
\text { (6 years), nanny }\end{array}$ \\
\hline Kimberly & Fall 2017 & White & $\begin{array}{l}\text { In-service } 2^{\text {nd }} \text { grade } \\
\text { teacher, dual-language } \\
\text { public charter, } 10^{\text {th }} \text { year } \\
\text { teaching }\end{array}$ & Student teacher \\
\hline Derrick & Fall 2017 & White & $\begin{array}{l}\text { In-service high-grade } \\
\text { chemistry teacher, public } \\
\text { school, } 6^{\text {th }} \text { year teaching }\end{array}$ & Parent, student teacher \\
\hline Hazel & $\begin{array}{l}\text { Summer } \\
2018\end{array}$ & White & $\begin{array}{l}\text { Pre-service elementary } \\
\text { teacher candidate, public } \\
\text { school special education } \\
\text { paraprofessional }\end{array}$ & $\begin{array}{l}\text { Previous English } \\
\text { language development } \\
\text { paraprofessional, } \\
\text { English teacher in } \\
\text { South Korea }\end{array}$ \\
\hline Cecilia & $\begin{array}{l}\text { Summer } \\
2018\end{array}$ & White & $\begin{array}{l}\text { Pre-service elementary } \\
\text { teacher candidate, private } \\
\text { school preschool assistant }\end{array}$ & $\begin{array}{l}\text { Childcare provider, } \\
\text { student preschool } \\
\text { intern, camp counselor }\end{array}$ \\
\hline Gwen & $\begin{array}{l}\text { Summer } \\
2018\end{array}$ & White & $\begin{array}{l}\text { In-service } 7 \text { th } / 8 \text { th grade } \\
\text { teacher, environmental } \\
\text { science public charter, } 6^{\text {th }} \\
\text { year teaching }\end{array}$ & $\begin{array}{l}\text { Outdoor camp } \\
\text { counselor, taught ESL } \\
\text { for adults, mountain } \\
\text { bike coach, K-8 } \\
\text { enrichment teacher }\end{array}$ \\
\hline Josie & $\begin{array}{l}\text { Summer } \\
2018\end{array}$ & $\begin{array}{l}\text { Latina/Native } \\
\text { American }\end{array}$ & $\begin{array}{l}\text { Pre-service elementary } \\
\text { teacher candidate, } \\
\text { practicum student }\left(1^{\text {st }} \text { and }\right. \\
\left.4^{\text {th }} \text { grade }\right)\end{array}$ & $\begin{array}{l}\text { Parent, school volunteer } \\
\text { (11 years), after-school } \\
\text { enrichment teacher }\end{array}$ \\
\hline
\end{tabular}

\section{Collaborative Professional Development Sessions}

In general, professional development experiences in education are "one-anddone" sessions, wherein learning opportunities for teachers are offered as one-shot workshops that provide minimal follow-up or support (Guskey \& Yoon, 2009). Spark 
(2002), however, outlines several fundamental characteristics to high-quality professional development for educators that indicate how a more sustained approach would be more beneficial. First, high-quality professional development should focus on deepening teachers' content knowledge and pedagogy. Second, professional development must include opportunities for practice, research, and reflection. Third, professional development is most effective when embedded in the educators' workplace and occurring during the workday. Fourth, professional development should foster ongoing learning sustained over time. And finally, professional development should be founded in a sense of collegiality and collaboration with other educators focused on solving important problems related to teaching and learning.

In planning for the professional development sessions for this study, I incorporated most of Spark's (2002) key characteristics of high-quality professional development, with the exception that I conducted the sessions in a location other than the participants' workplaces. In addition, the series of collaborative sessions had three main focal topics: (1) understanding anti-racist curriculum, (2) fostering racial identity development, and (3) curriculum development. Table 6 provides an overview of the collaborative sessions.

Table 6

Outline of Collaborative Professional Development Sessions

\begin{tabular}{|l|l|l|}
\hline $\begin{array}{l}\text { Face-to-Face } \\
\text { Session } \\
\text { Number }\end{array}$ & Topics & Materials and Resources \\
\hline 1 & $\begin{array}{l}\text { Introductions } \\
\text { What Is Anti-racist Curriculum? }\end{array}$ & $\begin{array}{l}\text { Survey (Appendix B) } \\
\text { Wiggins \& McTighe }\end{array}$ \\
\hline
\end{tabular}




\begin{tabular}{|l|l|l|}
\multicolumn{1}{|c|}{} & $\begin{array}{l}\text { Examining Teacher Beliefs } \\
\text { Curriculum: Big Ideas/Central Topic Selection }\end{array}$ & $\begin{array}{l}(2011) \\
\text { Sleeter \& Carmona (2016) }\end{array}$ \\
\hline 2 & $\begin{array}{l}\text { Social Context of Anti-racist Curriculum } \\
\text { Racial Identity Development } \\
\text { Curriculum: Big Ideas/Central Topics \& } \\
\text { Backward Planning } \\
\text { Transformative Intellectual Knowledge }\end{array}$ & $\begin{array}{l}\text { "I Am" poems (Tatum, } \\
\text { 2017) } \\
\text { Wiggins \& McTighe } \\
(2011) \\
\text { Sleeter \& Carmona (2016) }\end{array}$ \\
\hline 3 & $\begin{array}{l}\text { Racial Identity Development } \\
\text { Curriculum: Big Ideas/Central Topics \& } \\
\text { Planning/Guide/Assessment } \\
\text { Feedback from Group }\end{array}$ & $\begin{array}{l}\text { Wiggins \& McTighe } \\
(2011) \\
\text { Sleeter \& Carmona (2016) }\end{array}$ \\
\hline 4 & $\begin{array}{l}\text { Curriculum: Planning/Guiding/Assessment } \\
\text { Presentation of Unit \& Feedback from Group } \\
\text { Implementation Plans }\end{array}$ & $\begin{array}{l}\text { Wiggins \& McTighe } \\
(2011) \\
\text { Sleeter \& Carmona (2016) }\end{array}$ \\
\hline
\end{tabular}

Additionally, I tried to create an atmosphere of collegiality and collaboration through intentional actions on my part. First, I rearranged the classroom furniture for each class session to form a large table area where all the participants and myself could sit and face each other. Rather than standing in front of the room and lecturing, it was important for me to position myself as a member of the community by sitting at the table with the participants. Second, in each class session participants had time to share where they were at with their curriculum development (we called this "the come as you are party"). Each participant took turns informally presenting their work and then received feedback from myself and their peers -asking clarifying questions and making suggestions to push their thinking. Throughout the study, peer feedback progressively became the central source for constructive comments, as I assumed more of the role of co-collaborator and facilitator. I believe these are a few of the actions that helped to foster 
a collaborative community, which will further be discussed in the research findings forthcoming.

Anti-racist curriculum. Educational researchers have suggested that lasting change in education will not occur until educators critically examine current educational practices and reflect on their own beliefs and practices (Darling-Hammond \& McLaughlin, 1995; Freire, 2000; Mezirow, 1997; Tatum, 2003). In turn, I felt it was important to unpack terminology like "anti-racist curriculum" as a precursor for unpacking participants' privileges and beliefs. I accomplished this goal of understanding what is meant by anti-racist curriculum through engaging participants in activities including reading relevant scholarship, watching related video clips, and participating in group discussions. During these collaborative sessions, I specifically focused on why it is important to use anti-racist curriculum and talk with students about race, as outlined in Chapters 1 and 2.

In the second collaborative session, I shared the anti-racist curriculum that I had created and implemented with first graders (this project was further outlined in Chapter 1) which focused on directly teaching students about race, racial categories, and racial identities. Specifically, I shared my process for developing lessons, including generating a central idea with an anti-racist focus, gathering materials, defining learning objectives and establishing desired student outcomes. Further, I allowed the participants to look at my written lessons plans, the curricular materials (children's literature), and view photographs of the entire project. 
Racial identity development. Throughout the sessions, I also focused on individuals' racial identity development because teachers with minimal awareness about their own racial identity may require more education, coaching, and self-reflection before being able to design or even discuss anti-racist curriculum. Research indicates that reflective practices aimed at social justice and educational equity need to be oriented toward racial identity development (Freire, 2000; Mezirow, 1997). Foundational racial identity development scholar Beverly Daniel Tatum (2017) identifies stages of racial identity development, particularly amongst her White students. This research is of particular importance to the field of education, as White teachers compose over $80 \%$ of the teacher workforce (Feistritzer, 2011).

Since I was interested in having the participants explore their own racial identities, plus their understanding of and experiences with anti-racist curriculum, I requested that each participant complete a multiple-question survey to investigate their experiences and beliefs (see Appendix B). More specifically, the purpose of the survey was to gain a sense of each teacher's background and educational experiences, their attitudes about race and racism in education, their awareness of their own racial identity development, and their beliefs about talking with students about race. In addition, I asked participants to maintain an electronic reflective journal throughout the professional development and encouraged them to continue writing about their racial identity development even after it had ended.

Throughout this study, I found it crucial to share my own experiences with my racial identity development. As a White person, I speculated that for most of the 
participants (with whom were White), talking about race and racism was likely an uncomfortable task. I used my personal stories to stimulate dialog and contribute to our collaborative discussions. For example, I talked about how during my childhood that my White family never talked about race and racism.

Curriculum development. For the purposes of designing anti-racist curriculum, I utilized curricular concepts from both Sleeter and Carmona (2016) and Wiggins and McTighe (2011). Sleeter and Carmona (2016) outline a methodological approach to designing multicultural curriculum in their book Un-standardizing Curriculum:

Multicultural Teaching in the Standards-based Classroom. I incorporated their curricular planning process into the professional development, including starting with studying one's own ideological/epistemological beliefs, building curriculum from big ideas/central concepts, developing transformative intellectual knowledge about the big ideas/central concepts before writing lessons, and backward planning from the intended outcomes of the lessons. As described in their book, both authors used such multicultural curriculum design in the graduate level course they taught at their respective universities. Through email, I was able to correspond with both authors and was given access to their course syllabi, which I incorporated in my course design.

I also integrated aspects of Wiggins and McTighe's (2011) book The Understanding by Design Guide to Creating High-quality Units. Specifically, I adopted their 10-step curriculum-planning guide, including step-by-step guided questions that required the teacher participants to write extensive reflection throughout the process of developing their lesson plans. In the collaborative sessions, I guided my participants 
through the curriculum development process with the support of an electronic planning template, which outlined the ideas that I have described from both of these books. In the end, the participants completed this step-by-step planning template prior to composing formal lesson plans.

For example, during one class session I facilitated several steps of the curriculumplanning guide to help the participants flush out their central ideas for their individual anti-racist unit. For this writing exercise, participants were first asked to brainstorm concepts they could teach. Next, using this generated list of concepts, participants then labeled their ideas according to the following criteria; worth being familiar with ("W"), important to know and/or do ("I"), or essential to enduring understanding ("E"). Then, participants sorted through the labeled concepts to decide on a central idea. Once selected, participants were asked to write their central idea in the form of a question and list concepts students are expected to understand by the end of the unit. As an example, Gwen's central idea was "How does change happen in democracy?" and included student understandings as: (1) racism and injustice are part of the American narrative, (2) understand that change is possible but not equal, (3) I have rights and responsibilities as a citizen, and (4) my story is not everyone's story.

\section{Data Sources and Protocols}

The data collection was composed of participant observation notes and materials, including surveys, research artifacts (reflection journal entries and written lesson plans), and semi-structured interviews. The bulk of the data was gathered during the collaborative professional development sessions and individual interviews. Many of the 
materials were collected electronically; all electronic materials were stored on a password-protected computer and on an external hard drive to which only I had access, to maintain confidentiality.

\section{Participant Observation}

I served as the participant observer and collected observation notes throughout the research. Krathwohl (2009) describes participant observations as "circumstances wherein individuals are aware that they are being observed, but the observer, by participating in the situation as normally as he or she can, is unobtrusive as possible" (p. 699). In other words, participant observation refers to a type of observation in which the researcher is not merely a passive observer (Yin, 2014). Instead, the researcher participates in the ongoing activities of the phenomenon while recording observations. Participant observation affords the researcher an opportunity to gain access to events or groups from the viewpoint of someone "inside" the case, often creating a more accurate portrayal of a case phenomenon (Yin, 2014). According to Glesne (2016), the main goal of participant observation should be to clearly understand the phenomenon, especially the research setting, its participants, and their behavior. Therefore, the researcher should observe as a means of learning about the participants - their perspectives and behaviors — and as a way of developing a thick description and deep understanding of the phenomenon (Glesne, 2016).

During each of the collaborative professional development sessions for this study, I openly took electronic notes about participants' interactions, group discussions, individual commentary, and other relevant observations. More specifically, I used jotted 
notes, which are a few words or phrases to help remember thoughts or descriptions that will be completed later on (Glesne, 2016). My goal was to capture (1) quotes, words, descriptions, and explanations that had a tone of urgency or emotion; (2) how the teachers described the processes of planning; (3) any challenges in implementation and teaching identified by the teachers; (4) benefits or positive statements related to teaching; and (5) narratives and counter-narratives that disrupted the status quo/bias (Glesne, 2016). The observation protocol can be found in Appendix D.

Additionally, I engaged in reflective research memo writing (Glesne, 2016). I spent time after each session reflecting on and writing more expansively about my recorded notes, including describing the processes of planning and implementing antiracist curriculum, obstacles and challenges to implementation, and impacts on teaching practices. Further, I used the post-session reflection time to record my own potential biases, unconscious tendencies, and preferences that could affect my observations, interpretations, and findings (Krathwohl, 2009).

\section{Survey}

Participants in this research were given a short survey as part of the initial steps for study (see Appendix B). In the field of research methods, the term "survey" evokes a variety of definitions. For the purpose of this study, "survey" refers to a written instrument with a set of open-ended questions, used to facilitate two-way communication between myself and each participant and to elicit specific information related to the research study (Krathwohl, 2009). 
The survey for this study consisted of 12 open-ended questions, including several general questions about the participant's background and experiences as well as more specific questions about social justice, anti-racist curriculum, and racial identity

development. I distributed the survey to participants through email as a shared electronic document, and the participants typed their responses.

\section{Research Artifacts}

As part of this study, I collected research artifacts, specifically reflective journal entries and the lesson plans written by each participant. Physical artifacts can be an important component in creating an in-depth picture of the overall case (Hancock \& Algozzine, 2011; Yin, 2014). Glesne (2016) describes such written-word artifacts as current or primary documents that hold a particular meaning in a given phenomenon.

Participant reflective journals. I requested that participants write journal entries reflecting their experiences during this study. As mentioned previously, Hargreaves and Dawe (1990) and Spark (2002) suggest that reflective practices should be used as a central component for high-quality professional development, to facilitate practical problem-solving, collegiality, and self-reflection. In addition, Given (2008) notes that journals are one of the most effective research tools for investigating the rich personal experiences and emotions of participants' inner lives.

The journal reflections for this research allowed the teacher participants opportunities to participate in ongoing reflection as a means for deepening their understanding of anti-racist curriculum, their racial identity development, and the process of designing and implementing anti-racist curriculum. Talking about the taboo topic of 
race — particularly in a society dominated by the color-blind ideology—can evoke discomfort and an array of emotions. Nieto and Bode (2012) suggest that teachers need emotional support and resources in order to effectively engage in social-justice-oriented education. Thus, it was essential that the participating teachers have an outlet and safe place for documenting their process, experiences, and emotions, and thus the journal writing served as an opportunity to meet this need.

I provided the teacher participants with electronically shared journal entry templates to prompt their reflections and documentation of their experiences after each professional development session (see Appendix E). While participants were given the option of either electronically recording or hand-writing their journal entries, all of them chose to utilize the electronic form. The teacher participants' journal entries were held in strict confidence. In the journal entries, I prompted for the following as part of the data collection: (1) descriptions of the planning process, (2) challenges in implementation and teaching, (3) benefits or positive statements related to teaching, (4) narratives and counternarratives, (5) insights/awakenings, and (6) racial identity development.

Lesson plans. One of the expected outcomes of the collaborative professional development series was that each teacher participant would write lesson plans to implement. The teacher participants shared their planning artifacts, curricular resources, and electronic lesson plans as artifacts for this research study. These detailed documents provided insight as to how the lessons were planned and details of the process of implementation in the classrooms. Further, these lesson plans addressed my specific research questions and corroborated my findings for this study. As a point of clarity, 
throughout this paper I refer to the lessons that the participants created as "anti-racist curriculum." This should not be conflated with the theoretical framework of transformative curriculum, which I utilized as an analytical tool for understanding the phenomenon of designing and implementing anti-racist curriculum.

\section{Semi-Structured Interviews}

For this research, I also conducted one-on-one semi-structured interviews with each participant to gain an understanding of how they experienced the process of designing and implementing anti-racist curriculum. In their simplest form, interviews are often described as straightforward, face-to-face question-and-answer sessions between an interviewer and interviewee (Krathwohl, 2009). Seidman (2013) states, "At the root of indepth interviewing is an interest in understanding the lived experience of other people

and the meaning they make of that experience" (p. 9). Interviews can take on a variety of forms, including structured, semi-structured, and unstructured.

Semi-structured interviews are an approach wherein researchers ask predetermined but flexibly worded questions, which invites the interviewee to express themselves freely and openly while defining the questions from their own perspective (Hancock \& Algozzine, 2011). This technique also allows the researcher to probe further in response to the participant answers. As a result, semi-structured interviews tend to be more personal than scripted formal interviews because of the use of open and direct questioning to elicit detailed narratives and stories (DiCicco-Bloom \& Crabtree, 2006).

At the end of the research study, I interviewed each participant independently, with more general, open-ended questions followed by questions directly related to the 
research questions of this study. The interviews lasted approximately 70 minutes and were mostly conducted in person. All interviews were recorded electronically and later transcribed for analysis. The interviews featured follow-up or clarifying questions from participants' completed surveys and open-ended questions regarding their overall experiences (see Appendix C). In addition, the interviews asked the participants to (1) describe the processes of planning and implementing anti-racist curriculum, (2) describe obstacles or challenges in planning and implementing anti-racist curriculum, and (3) outline how participating in the collaborative professional development sessions impacted their teaching practices in anti-racist lessons (see Appendix C).

Like participant observation notes, interviews can provide richly descriptive insights to directly inform research questions. In addition, case studies often employ quotes from participants as key sources of data in order to describe a phenomenon. For this study, the interviews were an essential component of understanding participants' perspectives regarding the process of writing and teaching anti-racist curriculum. The interviews offered firsthand accounts of the experiences of the teacher participants, who were able to directly answer the research questions in their own words.

\section{Data Triangulation}

As displayed in Figure 4 below, I used the multiple data-collection instruments to triangulate the data as a means for establishing factual accuracy (Krathwohl, 2009). With this variety of instruments, I hoped to capture the teachers' experiences of designing and implementing anti-racist curriculum, as well as obstacles and challenges they faced and the overall impact of such experiences on their practice. 


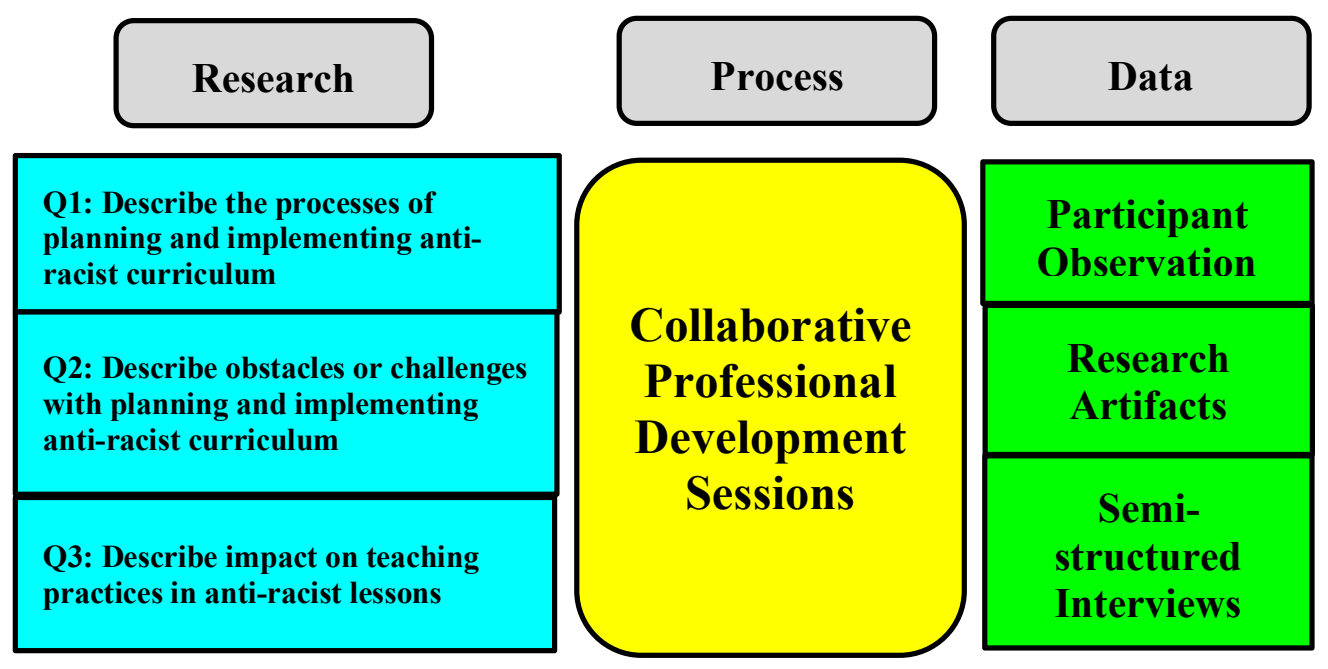

Figure 4. Data sources \& research questions.

\section{Role of the Researcher}

In case study methodology, the researcher can't help but play an integral role in the process of collaboration and the co-construction of the research. The researcher is not only responsible for the overall research study but may also serve as an intimate member of the phenomenon as well. Through this study, I-as the researcher and facilitatordirectly interacted with the teacher participants as I observed the process of planning antiracist curriculum and facilitated the collaborative professional development sessions. I had an ongoing relationship with the participants, as the facilitator and resource for their work.

Throughout this process, it was imperative that I was mindful of my own biases because the subject matter in anti-racist curriculum can often elicit strong emotional responses based on political, historical, and personal experiences. Ladson-Billings (1995) describes the importance of situating oneself as a researcher, especially with regard to one's membership in one's respective racial/cultural group, as this point of view may 
cause bias and influence the research study and the findings. Krathwohl (2009) also speaks of the importance of qualitative researchers conveying trustworthiness to participants to gain entry. Therefore, as the researcher, I needed to be transparent with the participants about my role in the research, my racial identity, and my personal biases in order to effectively facilitate the research study and evaluate research findings.

Maxwell (2013) points out that, since it is impossible to eliminate the subjectivity of the researcher - often called bias - it is imperative that the researcher have integrity and disclose potential biases. In response to such threats to research validity, some scholars have suggested that qualitative researchers keep a journal to record selfreflective memos. Krathwohl (2009) suggests that researchers should continuously practice self-reflection as a means for actively looking for potential bias. Creswell and Miller (2000) describe this specific method of qualitative researcher self-reflection as "researcher reflexivity." This procedure allows researchers to self-disclose the personal beliefs, values, and biases that may shape their inquiry. To do so, I kept a journal of research memos documenting my biases, beliefs, and preferences that could affect my observations, interpretations, and findings. I allotted time for this reflection after each collaborative professional development session.

In full disclosure, I identify as a White woman who lives in a large urban area on the West Coast. I was raised in a single-family house in the suburbs and brought up with the values of color-blindness and meritocracy. I attended public school for my entire educational career, which includes college and five subsequent graduate school programs. I am the mother of two White children, one with exceptional needs. I consider myself an 
aspiring anti-racist educator, as I am still recovering from my meritocratic and colorblind upbringing.

This positionality, of being a White woman in a profession dominated by White women, afforded me a sort of credibility amongst the White participants. Gwen mentioned, "You are a White teacher that has taken on this issue, [which] was really helpful for me because basically [there] was, like, no excuse, you know, you can teach this stuff even if you don't feel qualified to." It was important for me to create a community of trust, and thus I chose to be vulnerable with the participants and share personal stories about exploring my racial identity, unpacking my biases and beliefs, and my own experiences writing and teaching anti-racist curriculum. I believe this openness allowed me to be seen as relatable by the participants which initiated honest conversations amongst the group. However, my direct involvement and relationships with the participants may have also created conditions in which I blinded by my own whiteness.

\section{Data Collection and Analysis}

In the remaining portion of this chapter, I describe the data sources, data collection procedures, and data analysis plans for this research study, and their connections to the research questions. It is important to note that this embedded case of professional development supporting racial identity development and the creation of antiracist curriculum incorporates the two sub-cases (fall 2017 and summer 2018) and all seven participants. 
According to Hancock and Algozzine (2011), collecting and analyzing data from case study research involves ongoing examination and interpretation of the data as a means for determining research findings. Additionally, these authors suggest that case study researchers adhere to several guidelines as they examine and interpret information gathered from the research. To begin with, research questions may need refinement, especially in the early stages of the research, but the focus of the study should remain on the research questions being investigated. Further, only data that is potentially meaningful to the research should be collected and analyzed in a systematic and organized manner. Finally, available resources - including computer software programs - should be used to assist in the collection and interpretation of the information. In alignment with these suggestions, I designed the data collection and analysis for this research to be an ongoing endeavor, focused on the research questions and systematically organized.

\section{Data Collection}

As stated, the data collection for this research incorporated a variety of instruments, as case studies routinely use multiple sources of data to facilitate triangulation and offer findings that are more convincing and accurate (Krathwohl, 2009; VanWynsberghe \& Khan, 2007). Below, Table 7 matches the data sources with their corresponding research question for this study.

\section{Table 7}

Research Questions \& Data Collection Sources

\begin{tabular}{|l|l|l}
\hline Research Questions & Data Sources & More Specific Information
\end{tabular}




\begin{tabular}{|c|c|c|}
\hline $\begin{array}{l}\text { How do PK-12 teachers } \\
\text { participating in a } \\
\text { collaborative professional } \\
\text { development experience } \\
\text { describe the processes of } \\
\text { planning and } \\
\text { implementing anti-racist } \\
\text { curriculum? }\end{array}$ & $\begin{array}{l}\text { Participatory } \\
\text { observation notes } \\
\text { from } \\
\text { collaborative } \\
\text { professional } \\
\text { development } \\
\text { sessions } \\
\text { - Reflection } \\
\text { journals for each } \\
\text { participant } \\
\text { - Individual semi- } \\
\text { structured } \\
\text { interviews with } \\
\text { each participant }\end{array}$ & $\begin{array}{l}\text { How do teachers describe the overall } \\
\text { experience? } \\
\text { - How do teachers go about planning } \\
\text { lessons? } \\
\text { What resources do teachers have } \\
\text { available to them to write anti-racist } \\
\text { lessons? } \\
\text { - What materials or resources are } \\
\text { needed/do they have to gather for } \\
\text { writing lessons? } \\
\text { - What kind of emotions do teachers } \\
\text { experience throughout this process? } \\
\text { Do teachers collaboratively plan? } \\
\text { Individually plan? Or a } \\
\text { combination? } \\
\text { - What is the experience like teaching } \\
\text { the lessons with their students? } \\
\text { - What did they change or need to } \\
\text { change in the lessons? } \\
\text { What would they do the } \\
\text { same/differently the next time they } \\
\text { taught the lesson? } \\
\text { - Would they teach the lesson again? } \\
\text { - How do the students react to the } \\
\text { lessons? }\end{array}$ \\
\hline $\begin{array}{l}\text { How do the teachers } \\
\text { describe obstacles or } \\
\text { challenges with planning } \\
\text { and implementing anti- } \\
\text { racist curriculum? }\end{array}$ & $\begin{array}{l}\text { Participatory } \\
\text { observation notes } \\
\text { from } \\
\text { collaborative } \\
\text { professional } \\
\text { development } \\
\text { sessions } \\
\text { - Reflection } \\
\text { journals for each } \\
\text { participant } \\
\text { - Individual semi- } \\
\text { structured } \\
\text { interviews with } \\
\text { each participant }\end{array}$ & $\begin{array}{l}\text { Do teachers have support in their } \\
\text { education community to teach anti- } \\
\text { racist curriculum? From } \\
\text { administrators? Fellow teachers? } \\
\text { Do teachers experience resistance or } \\
\text { challenges in teaching anti-racist } \\
\text { curriculum? From whom? } \\
\text { Do teachers hear feedback from } \\
\text { families about doing this work? Is } \\
\text { the feedback positive or negative? } \\
\text { Do administrators inquire about the } \\
\text { work? Do other teachers? } \\
\text { What kind of comments have } \\
\text { teachers heard? From } \\
\text { administrators? Other teachers? } \\
\text { Staff? Families? Other? } \\
\text { Are there limiting factors interfering } \\
\text { with this work? } \\
\text { What materials or resources are } \\
\text { needed to complete this work? }\end{array}$ \\
\hline
\end{tabular}




\begin{tabular}{|c|c|c|}
\hline & & $\begin{array}{l}\text { Are there other obstacles or } \\
\text { challenges not named? }\end{array}$ \\
\hline $\begin{array}{l}\text { According to the teachers, } \\
\text { how does participating in } \\
\text { the collaborative sessions } \\
\text { impact their teaching } \\
\text { practices in anti-racist } \\
\text { lessons? }\end{array}$ & $\begin{array}{l}\text { Reflection } \\
\text { journals for each } \\
\text { participant } \\
\text { - Individual semi- } \\
\text { structured } \\
\text { interviews with } \\
\text { each participant }\end{array}$ & $\begin{array}{l}\text { What was the experience like } \\
\text { planning with other teachers? } \\
\text { What was helpful about this } \\
\text { process? } \\
\text { - What was not helpful about this } \\
\text { process? } \\
\text { Would teachers be willing to do } \\
\text { collaborative professional } \\
\text { development sessions again? } \\
\text { - How did this process impact or } \\
\text { influence the ability to write anti- } \\
\text { racist lesson plans? } \\
\text { - How did this experience impact their } \\
\text { teaching practice? } \\
\text { What are their takeaways from this } \\
\text { experience? }\end{array}$ \\
\hline
\end{tabular}

\section{Data Analysis}

For the qualitative data analysis in this study, I followed Saldaña's (2013) suggested multi-cycle process and incorporated coding, categorization, and thematic sorting. The first cycle of analysis began with initial or open coding (Saldaña, 2013), in which I created tentative codes as I collected the data throughout the study. When the data collection was complete, I analyzed the data line by line utilizing descriptive coding (Saldaña, 2013), in which I wrote words or short phrases to index or link thoughts and actions across bits of data (Glesne, 2016). After multiple read-throughs of the materials, I began by first coding the surveys, journal entries, participant observation notes, research memos, and lesson plans, which resulted in approximately 447 codes.

Next, I listened to all of the audio-recorded semi-structured interviews and then coded the written interview transcripts, which generated an additional 561 codes. In total 
for this initial round of analysis, I assigned over 1,000 descriptive codes to the data collected, which encompassed over 500 pages of written materials. Examples of descriptive codes include, "struggle finding materials," "benefits of planning," "emotions with process," and "role of race."

In the second cycle of analysis, I employed axial coding, which consisted of identifying thematic relationships amongst the initial codes (Saldaña, 2013). To accomplish this, I reread all of the materials, followed by organizing and grouping the 1,000 descriptive codes with shared characteristics into 14 thematic categories. Examples of these thematic codes include "racial identity," "emotions," "collective experience," and "challenges."

Then, in the third cycle of analysis, I applied theoretical coding as a means for specifying the possible relationships between categories and moving the analysis in a theoretical direction (Saldaña, 2013). Thus, I returned to the research questions and evaluated the 14 categories through the lens of those three questions. In turn, I reorganized the categories and corresponding codes to match the research questions, as appropriate. For example, under research question two (focused on challenges and obstacles), I incorporated the categories "challenges," "collective experiences," "challenges in the field," and "emotions." In the end, four of the categories were not utilized as they did not relate to any of the research questions which included; “importance of social justice," “defining vocabulary," "held values," and "seeking truth". From here, I comparatively examined the categories underling each question through the framework of TC, specifically noting if the categories reinforced any of the 
tenets of TC. Figure 5 below illustrates an overview of the qualitative data analysis for this research study.

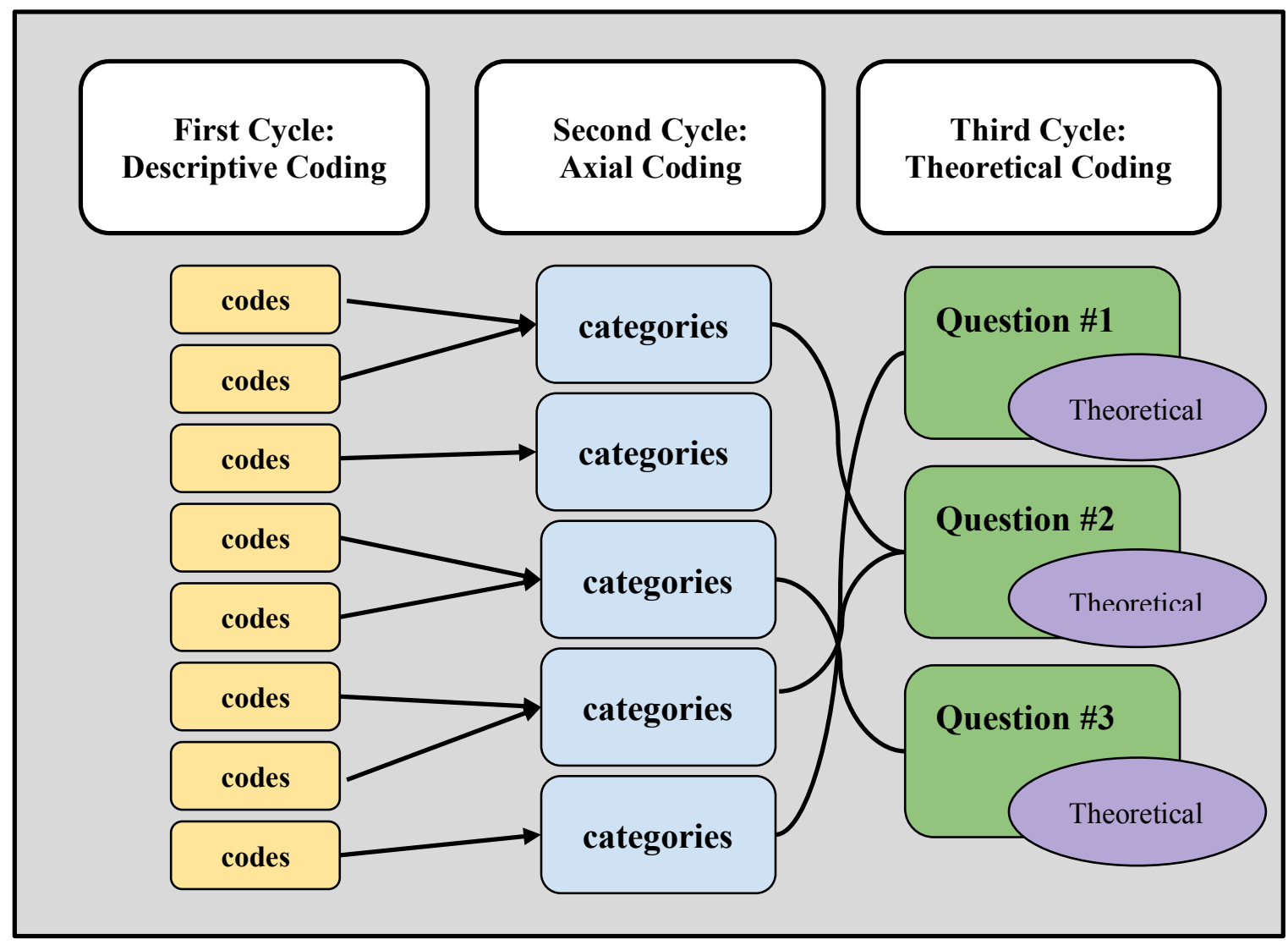

Figure 5. Overview of data analysis.

Finally, I considered the collective themes and subsequent subthemes that I grouped under each of the research questions. Ultimately, these themes were substantiated with evidentiary material from the surveys, journal entries, lesson plans, transcribed interviews, participant observation notes, and research memos to result in the findings. Figure 6 documents the main themes and subthemes that resulted from the analysis. 


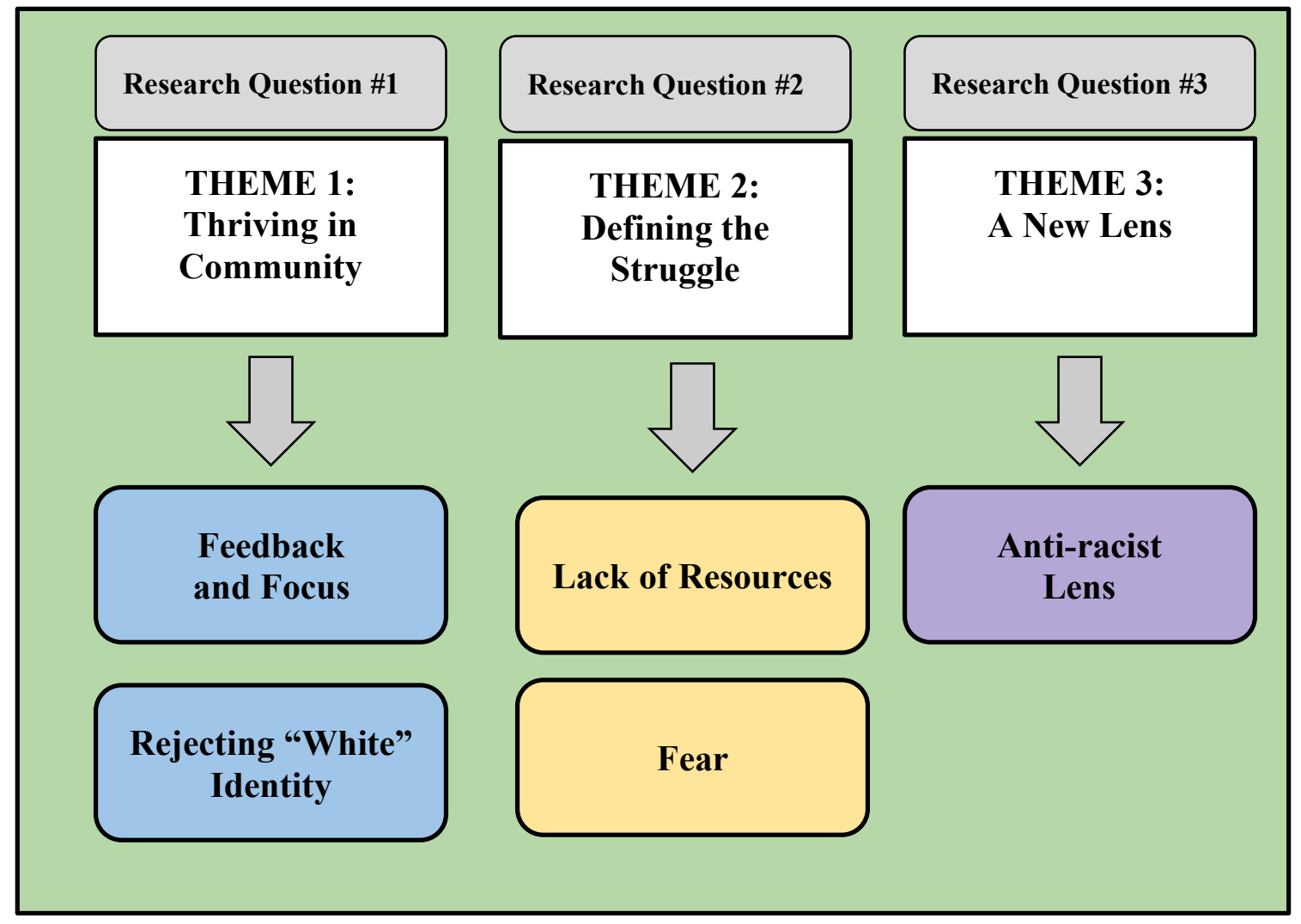

Figure 6. Generated themes and subthemes from data analysis.

Research Validity. When considering the research design, collection of data, and processes of analysis, it was important to take actions to bolster the claim that the findings generated by this research were valid. Maxwell (2013) describes the validity of qualitative research in terms of the credibility of the descriptions, conclusions, explanations, and interpretations. Further, Maxwell rejects the quantitative notion of validity as the "objective truth" (p. 122). Creswell and Miller (2000) identify several procedures for establishing credible qualitative research. From their perspective, researchers need to consider the lens and paradigm assumptions of their research in order to establish appropriate validity procedures. 
In this study, the research took a critical perspective, which sought to challenge and critique the current system, disrupt hidden assumptions, and see narrative accounts reflective of political, cultural, ethnic, and social antecedents (Creswell \& Miller, 2000). Therefore, Creswell and Miller suggest the following procedures to ensure reliability: researcher reflexivity, collaboration, and peer debriefing. First, I tried to ensure researcher reflexivity by engaging in ongoing self-reflective memo writing and responsively adjusting my practices and thinking as a researcher and facilitator of the collaborative sessions. Second, I collaborated with the participants throughout the study and allowed participants to check my tentative insights and findings as a demonstration of respect and validation. Specifically, I shared the transcribed interviews with each participant as a means for collaboration and member-checking. Third, my peer debriefing involved reviewing the data and research process with someone-my academic advisorfamiliar with the problem of practice. In this role, my reviewer provided support and challenged my assumptions, methods, and interpretations.

\section{Conclusion}

The purpose of my research was to investigate the practice of directly challenging the color-blind mindset in education through the implementation of anti-racist curriculum. More specifically, I sought to understand how teacher participants describe the process of implementing anti-racist curriculum, along with obstacles or challenges experienced during this process, and how the collaborative sessions of this study impacted their teaching practices in anti-racist lessons. 
As part of the process of developing and implementing anti-racist curriculum, the teacher participants attended several collaborative professional development sessions, which incorporated exploring one's own racial identity, learning about anti-racist tenets, and creating lesson plans while collaborating with fellow participants. The dataincluding participant observation notes, surveys, reflective journals, lesson plans, and semi-structured interviews - were analyzed through a multi cycle process of coding. The coding, categorization, and thematic analysis of the transcribed data and corresponding data were ultimately used to address the research questions. In Chapter 4, I will explicitly unpack each of the themes and subthemes generated from the data analysis. 


\section{Chapter IV \\ Research Findings}

Knowledge emerges only through invention and re-invention, through the restless, impatient, continuing, hopeful inquiry human beings pursue in the world, with the world, and with each other (Freire, 2000, p. 72).

Throughout this paper, I have argued that racialized educational inequities and racial color-blindness are ever-present aspects of public education in the United States. Further, I have described the negative consequences associated with the color-blind ideology, which deprives students of opportunities to build positive racial identities and inhibits the development of skills necessary for addressing racial conflicts and disparities. I have suggested that anti-racist curriculum affords a possible antidote to the persistent silence about race, racism, and racial inequities in education. The purpose of this study was to examine the practice of directly challenging the color-blind ideology in education through a collaborative process of developing anti-racist curriculum.

In this chapter, I will further expand upon the research findings I introduced in Chapter 3. Specifically, I first provide more details about each of the research participants to contextualize their identities and participation within the study. Next, I present the findings and offer interpretations of the data by providing evidentiary material from the data collected to support the themes and subthemes I identified relative to each of my research questions. Finally, I identify several limitations of the study, which sets up the discussion to follow in Chapter 5.

\section{Participant Details}

For this research study, I partnered with four in-service teachers working in local schools and three pre-service teachers enrolled in a graduate teacher education program. 
Each participant self-selected to take part in this research study by enrolling in my graduate-level course. All of the participants offered unique perspectives that were informed by their beliefs, values, educational backgrounds, experiences with children, and own identities. Below, I have provided summaries describing each participant at the time of the study.

At the time of the study, Nick was in his fourth year of teaching fifth grade at a predominantly White public elementary school and was parenting two young children. He identifies as a White male, although he admitted that it is hard for him to see himself as a particular race. Prior to his entry into the field of education in the United States, he taught on and off in Japan for nearly six years, where he worked as both a teacher and a nanny. During the course, Nick expressed a teaching philosophy that was guided by the notion that kids are human beings who deserve respect, and he strove to motivate them through kindness and connection. He believed that children can handle the truth; thus, to him social justice means giving them a more mature, nuanced look at the world in which they live. Nick enrolled in my course during the fall of 2017 and planned an extensive anti-racist unit around the historical experiences of African Americans.

When she took the course, Kimberly had been a teacher for over 10 years and taught English to second-grade students at a dual-language public charter school, predominantly serving Asian and White students. She identifies as a White female, although she described feeling disconnected from her own heritage. Kimberly believed that teaching for social justice means teaching about core values, respecting others, exploring multiple points of view, and getting students the support they need. In the fall 
of 2017, Kimberly took my course and created a series of anti-racist lessons looking at children's multiple identities.

When Derrick attended my course in the fall of 2017, he was a chemistry teacher completing his sixth year at a predominantly White, upper-middle-class high school and was the parent of one child. Derrick identifies as a White, heterosexual man and acknowledged that he benefits from the biased systems. He considered teaching for social justice a practice that involves incorporating viewpoints that are often ignored or underrepresented in society. He wanted his students to understand that there are disparities in society that can be seen in multiple aspects of life and that we can utilize knowledge and understanding to support people who are often disregarded and disenfranchised. During the course, Derrick constructed an anti-racist chemistry unit that focused on the racialized impact of energy sources.

At the time of the study, Hazel was a pre-service teacher candidate working on attaining her teaching license in elementary education with an endorsement in English Speakers of Other Languages (ESOL). She worked as an educational assistant in a special education classroom that supported predominantly White students with high behavioral needs. Previously, Hazel had worked as an ESOL educational assistant and taught English in South Korea. Hazel identifies as White but had a hard time seeing herself as such because being White is often associated with White supremacy. To her, teaching for social justice meant being aware of and sensitive to the diverse experiences of all students and families, plus recognizing one's own privilege and the presence of systemic 
inequalities. While attending my course in the summer of 2018, Hazel created anti-racist lesson plans that addressed immigration in the United States.

When she took my course, Cecilia was a pre-service elementary education teacher candidate who worked as an assistant in a predominantly White private preschool while completing a teaching practicum experience in a second-grade classroom in a racially diverse public school. Cecilia identifies as White, as her family originated from the United Kingdom. Although she acknowledged her privilege as a White person, she struggled with what it means to have White skin and felt that the color of your skin should not determine who you are. She believed that teachers should meet students where they are at and that teaching for social justice involves teaching students to be good people who are fair and can fight for people without a voice. For my class in the summer of 2018, Cecilia designed third-grade lesson plans focused on racial identity.

When she took the course, Gwen had been a teacher for over six years and had worked as a seventh-/eighth-grade English Language Arts teacher at a predominantly White public charter school. Previously, Gwen had worked as an outdoor camp counselor and taught English as a second language to adults. She considers her racial identity to be White, informed by her "wholesome White hippie childhood." Gwen viewed teaching for social justice as providing access to experiences, stories, and holistic worldviews while exposing kids to problems in society and challenging them to come up with the solutions. During the summer of 2018, Gwen constructed a large anti-racist unit exploring the formation of the United States government, voting rights, immigration, and advocacy. 
In the summer of 2018, while taking my course, Josie was a pre-service teacher candidate seeking her teaching license in elementary education with an endorsement in literacy. She was completing her teaching practicum in both a first-grade and a fourthgrade classroom, composed mostly of students who identify as Black or Latinx. In addition, she was parenting three school-aged children and had volunteered in her children's classrooms for over 11 years. Josie identifies as Mexican and Native American, while acknowledging that she is also part White, but she gave little value to this facet of her identity because she is never perceived as White. She viewed teaching for social justice as a way of looking at the world and a way of teaching that considers whose voices and perspectives are being talked about and whose are not. When participating in the study, Josie planned anti-racist lessons exploring cultural and ethnic identities.

\section{Presentation of the Results}

The following findings describe the experiences of teachers working in collaboration to develop anti-racist curriculum. The research findings are organized around the following themes: (1) thriving in community, including receiving feedback and reflecting on identity; (2) defining the struggle by acknowledging the lack of resources and combatting fear; and (3) fostering a new lens with critical analysis (see Table 8 below). Forthcoming, I unpack each of the themes generated from the data analysis, defining the collective experiences of the participants - from both the fall of 2017 and the summer of 2018 - as the "case" for study. Then, I compare the themes with 
relevant tenets of transformative curriculum as another analytical tool for understanding the research questions.

\begin{tabular}{|l|l|}
\hline $\begin{array}{l}\text { Table } 8 \\
\text { Results of Study: Main Themes \& Subthemes }\end{array}$ & Themes and Subthemes \\
\hline Research Questions & $\begin{array}{r}\text { Theme 1: Thriving in Community } \\
\text { - Feedback and focus } \\
\bullet \quad \text { Rejecting "White" identity }\end{array}$ \\
\hline $\begin{array}{l}\text { How do PK-12 teachers participating in a collaborative } \\
\text { professional development experience describe the processes } \\
\text { of planning and implementing anti-racist curriculum? }\end{array}$ & $\begin{array}{l}\text { Theme 2: Defining the Struggle } \\
\text { support } \\
\text { How do the teachers describe obstacles or challenges with } \\
\text { planning and implementing anti-racist curriculum? }\end{array}$ \\
$\begin{array}{l}\text { According to the teachers, how does participating in the } \\
\text { collaborative sessions impact their teaching practices in } \\
\text { anti-racist lessons? }\end{array}$ & $\begin{array}{r}\text { Theme 3: Fostering a New Lens } \\
\text { Anti-racist lens }\end{array}$ \\
\hline
\end{tabular}

\section{Theme 1: Thriving in Community}

One of the main themes I identified through my data analysis was the idea of thriving in community. My first research question was concerned with how the research participants describe the processes of planning and implementing anti-racist curriculum. As indicated throughout this paper, I designed the professional development sessions with a focus on community and collaboration. When developing the context of each of the collaborative sessions, I envisioned the co-construction of knowledge between myself and the participants as collaborative knowledge-building (Freire, 2000). I also relied upon the notion that high-quality professional development for educators should be founded in a sense of collegiality and collaboration with other educators (Spark, 2002). 
As it happened, the experience of collaboration itself was salient for all of the participants, as highlighted by their feedback and commentary. In fact, the research participants made very positive remarks about the process of collaboration in curriculum development, as reflected by the nearly 180 descriptive codes affirming such. More specifically, the participants found useful the meaningful conversations, constructive feedback, structure for curriculum development, and safe, respectful, and judgement-free zone that was fostered throughout this process. All seven of the participants appeared to hold the collaborative community cultivated in this study in high regard. As an example, Josie noted:

I found this collaborative experience incredibly helpful and quite enlightening. Working with other educators has been an invaluable experience. They have really helped me illuminate ideas that have been stirring around in my mind and helped me focus in on topics that are important. I have gotten some wonderful feedback that has truly benefited my unit and my own personal transformative knowledge. I found everything helpful.

In a like manner, Kimberly commented, "Planning with other teachers allows teachers the luxury of professional input from other colleagues. It can be very helpful when approaching a sensitive or unfamiliar topic, like when generating plans to teach anti-racist lessons.” In addition, Derrick stated:

This workshop has been very positive and valuable for me. I was able to have meaningful conversations around relevant topics and was given time to work on [a] focused unit and was provided with helpful feedback about my ideas. I couldn't have asked for more from a workshop.

The participants described the aspects of the collaborative community process that were most meaningful in their personal and professional growth. Through my analysis, I organized these descriptions into the subthemes of feedback and focus and rejecting 
"White" identity. I found that these sub-themes aligned with the tenets of TC featured in Table 9 (below).

\begin{tabular}{|l|l|}
\hline $\begin{array}{l}\text { Table } 9 \\
\text { Research Theme } 1 \text { \& Connection to Theoretical Framework }\end{array}$ \\
\hline Themes and Subthemes & Tenets of Transformative Curriculum \\
\hline $\begin{array}{l}\text { Theme 1: Thriving in Community } \\
\text { - Feedback and focus } \\
\text { Rejecting "White" } \\
\text { identity }\end{array}$ & $\begin{array}{l}\text { Reflection: } \\
\text { 1. Foster critical consciousness and positive regard for differing } \\
\text { experiences and perspectives } \\
\text { 3. Explore individual's beliefs, biases, and multiple forms of } \\
\text { identities } \\
\text { Understanding: } \\
\text { 6. Incorporate and affirm differing histories, cultures, and ways } \\
\text { of knowing into curriculum }\end{array}$ \\
\hline
\end{tabular}

Feedback and focus. The first subtheme centers around participants' experiences with constructive feedback and a focused process of curriculum development. There were many other aspects of the collaborative sessions that the participants deemed meaningful; however, these were the two that most frequently appeared in the interview transcripts, participant observation notes, and journal entries.

Feedback. To start, the participants found the feedback they received from their peers and from me throughout the process of planning their anti-racist lessons to be useful. As described by Nick:

It has been great to be truly heard by my peers and by Kelly. I feel like I spend so much time thinking and planning on my own, and I wonder how my thinking and ideas might be received by others. I really want to be challenged to find that which is most important or central to my ideas, and it seems like, when collaboration has this focus, it can provide the results. I also really enjoyed hearing what other teachers were interested in doing and trying to support them without superimposing my belief system on their thinking. 
Further, Hazel "loved" the way the sessions were set up as a "come as you are party," where each of the participants brought their lessons as-is for feedback. She explained how the brainstorming sessions, in which they were able to share ideas, led to a helpful refinement of her ideas. Cecilia shared a similar sentiment:

I liked when we brainstormed. I think hearing from other people that I bit off more than I could chew was, like, helpful. Because I am an inexperienced teacher and so hearing from other people, like, you know what, I have advice for you. And being open to that advice was really good.

After the collaborative sessions ended, Nick expressed concern about not having feedback from a colleague with the same topic for creating anti-racist lesson plans: "We were working on such different projects, at times it was hard to gain any real insight into my own project through the collaboration." Although many of the topics had overlapping concepts, it may have been drawback of this process that no one in either group had the same topic or content area as any of their peers.

Focus. The participants also found the streamlined, focused implementation structures for lesson planning very helpful in their process to develop curriculum. As described in Chapter 3, I incorporated a curricular planning process focused on (1) studying one's own ideological/epistemological beliefs, (2) building curriculum from big ideas/central concepts, (3) developing transformative knowledge about the topic before writing lessons, and (4) backward planning from the intended outcomes. These became the guiding tasks for our collaborative sessions and the basis for most class discussions. Hazel remarked:

Backward planning, that was revolutionary for me because I do have a tendency to find the perfect activity, and then build my goal, objectives, and assessments from that...it makes so much sense and it's such a better way of approaching it, I 
think, to start with your objective, and that allows you to start with your assessment and then allows you to be more critical with the materials you select.

Further, Kimberly commented, "The process is both flexible and complex. Settling on the 'big ideas' or unit goals is so critical. Since those goals guide the design of the whole unit, it made it hard to decide what to select."

In addition to preparing a curricular planning structure, I also provided a sample anti-racist lesson that I developed (as mentioned in Chapter 1). Most of the participants utilized this example to focus their own lesson plans and found this model lesson helpful. Gwen noted, “It was really neat to see your [Kelly's] whole unit on the color palette for skin colors and see what it was like in a creative way to teach those books, that are accessible." Also, Nick mentioned, "Your unit and the way it was packaged for me to just teach pretty much the way it was, this was a real gift because it made me see it was possible."

When examining this subtheme through the theoretical lens of the TC framework, I found two distinct connections. To begin with, the participants indicated that the collaborative sessions — including feedback and the focused structure-were facilitated through a safe and caring environment in which participants felt comfortable sharing. These experiences emulated the first tenet of TC, which strives for critical consciousness through positive regard for differing experiences and perspectives. In addition, the constructive feedback given in the collaborative sessions often correlated with the sixth tenet of TC, which encourages the incorporation of differing histories, cultures, and ways of knowing into curriculum. These tenets were enacted to varying degrees amongst the participant. 
In sum, the participants fondly described their experiences with collaborative planning, which fostered positive regard for differing perspectives and ways of knowing. These findings were also commensurate with research that identifies constructive feedback and a clear focus as essential aspects of meaningful collaboration (Poulos, Culbertson, Piazza, \& D’Entremont, 2014). Further, these findings indicate a need for more collaborative experiences for educators, as a means for fostering community amongst educators creating curriculum.

Rejecting "White" identity. An additional way in which the community orientation for the course was important to the experiences of participants was as a context for critical exploration of identity. Engagement with one's own racial identity development was one of the focal topics for the collaborative sessions. As mentioned in Chapter 3, critical reflection on one's identity is essential for understanding one's interpretations, beliefs, and habits of mind or points of view (Mezirow, 1997), and such reflection should serve as a prerequisite for writing anti-racist curriculum.

Therefore, throughout these collaborative sessions I facilitated activities and discussions to foster personal reflection regarding individuals' racial identities. For all six of the White research participants, the experience of talking about race and racial identity in such an open manner was unfamiliar. Hazel suggested, "One of the hallmarks of being White is that you don't think about it." These same participants also noted that they seldom talked about race growing up, which is consistent with the color-blind ideology of viewing race as an invisible characteristic that should not be discussed (Derman-Sparks \& Ramsey, 2011; Lewis, 2001). Kimberly disclosed, "I personally feel disconnected 
[from] my own heritage, as my family rarely discussed our relatives and origins."

Conversely, Josie — the one participant who identifies as a person of color — felt very comfortable with her racial identity but mentioned, "I'm comfortable often talking about [race] with people of color, but this has really pushed me to have conversations with people, um, that are White."

Surprisingly, each of the White participants had a tenuous relationship with their own racial identity and struggled to various degrees with accepting the category of "White." Participants were able to identify their race as White but expressed deep ambivalence about whether they wanted to claim the identity of being White. For example, Nick reflected, “I'm trying to keep myself engaged...I am a White man. Just keeping that more in the forefront of my mind. Like, really thinking about myself in terms of race consciousness and just to see what sparks." Nick further stated:

It's hard for me to view myself as a race. I've been becoming more and more aware. I think that's the stage I'm at now. Just becoming more and more aware of the fact that I don't see myself as a race.

Likewise, Hazel explained:

I struggle with having a firm understanding of my racial identity...I find it difficult to identify as 'White,' as for me there is no culture associated and no defining traits other than skin color. I know that I am White, although that is not part of how I define myself. However, I recognize that the ability to say such a statement is due to my White privilege.

Derrick was very much aware that, as a White man, he is the beneficiary of White privilege and systems of bias. Still, he appeared to be ashamed when talking about how easily he can fall back into the habits of Whiteness: "I have even noticed this in my own 
habits of mind, and I am amazed how easy it is to fall into habits of tradition and White supremacy even unconsciously."

Gwen also pointed out her struggles with her racial identity, reflecting on moving from her "wholesome, White, hippie" childhood to teaching in a predominately Black school: "I was placed in that school where I was the only White person in the classroom and I was in the position of power. Since then, I've been asking myself questions, and I feel like I haven't gotten answers.” More bluntly, Cecilia confessed:

I wish I was Black most of the time. I don't know if that's okay to say, but, like, after going to [a predominantly Black high school], like, I just always was...I would never say that to anybody of color because they'd be like, what? What are you talking about? Like, you're White, like, you don't get looked at weirdly in stores, you have faces in children's literature, and all these books represent you. Why would you want to change that? I want to be around the group that I feel more comfortable around.

These examples of reflecting upon one's own racial identity brought to life the third tenet of TC, which encouraged the exploration of an individual's beliefs, biases, and multiple forms of identity as a precursor to curriculum design and implementation. Participants' level of understanding about their own racial identity and their ability to deeply engage in this process varied greatly, depending on their prior knowledge and experiences.

Although I was an active participant in this process, I was unable to see the collective dynamic of rejecting being White until I was deep into the first cycle of data analysis. Upon reflection, I could empathize with that dilemma, as some years ago I faced this crisis of identity myself as a White person. For me, this was a problem of conflating the racial category of White with the concept of Whiteness. Leonardo (2002) unpacks this 
issue by clarifying that, "WWhiteness' is a racial discourse, whereas the category 'white people' represents a socially constructed identity, usually based on skin color" (p. 31). I inferred that this same entanglement was happening with many of the White participants.

Ultimately, this finding surprised me because I had selected participants who wanted to create anti-racist curriculum and expressed concrete understandings of teaching for social justice throughout the class dialogues, journal entries, and interviews. These findings suggest that most of the White participants had a level of acceptance regarding the impact of race in society yet struggled to integrate an understanding of their own race.

In looking back, I recalled that we spent an entire collaborative session addressing racial identity development by examining Tatum's (2017) stages of White identity development. During this session, each of the White participants took it upon themselves to assess which stage of development they would identify themselves with and readily discussed their self-assessments with the group. For example, many of the White participants identified with the "pseudo-independence" stage, where a White person is beginning to understand institutional, cultural racism and their own identity but is not yet sure what to do about it (Tatum, 2017).

While Tatum's stages served as helpful scaffolds for participants' thinking, analysis of participant interview data, field notes, and reflections revealed that these stages do not fully account for the complex incongruence wherein the individual demonstrates a solid commitment to address racism in society, but not within themselves. Like other racial identity development frameworks, Tatum's stages present as linear, clear-cut categories, which presumes congruence between societal and individual 
understandings of race and racism. In reality, the participants' comments portrayed an enmeshment of thoughts, beliefs, and emotions that cannot be explained through linear stages of development. My findings open the door to a more elaborate and nuanced understanding of White identity development that is not currently represented in the literature.

Summary. Within the theme of thriving in community, the research participants described positive experiences with the process of planning in community, receiving feedback from peers, and operating with a clear and structured focus for developing antiracist curriculum. The collaborative feedback from myself and their peers provided opportunities for the participants to build positive regard for differing perspectives and incorporate multiple histories, cultures, and ways of knowing into their curriculum, as reflected by their incorporation of the feedback and their reflective statements about this process. Prior research findings align with these participants' positive valuation of collaboration experiences, by indicating that teachers who work in collaboration with their peers report significantly greater job-related skills, job satisfaction, professional commitment, internal motivation, and efficacy (Pounder, 1999). While participants in this study experienced facets of racial identity development described in existing literature, the phenomenon of disconnect between awareness of racism inherent in society and one's own personal experiences of race, as well as the phenomenon of rejecting White identity, add nuance to current understandings of racial identity development, particularly among teachers. This uncovering indicates areas of future growth for the participants and possibilities for further professional development. 


\section{Theme 2: Defining the Struggle}

As I analyzed the data relevant to how participants describe obstacles and challenges to developing anti-racist curriculum (my second research question), I found that defining the struggle was an important theme. Due to the openness and collaborative nature of this project, the collaborative sessions became spaces for the participants to freely express their challenges and frustrations, as both a means to invite problem-solving and a place to emotionally vent. In particular, participants expressed obstacles and challenges that aligned with two key subthemes: lack of time, materials, and support and combatting fear. Both of these phenomena were foregrounded by or arose from a call to challenge dominant social norms, beliefs, and inequitable distributions of power through curriculum development, as described in the seventh TC tenet (see Table 10 below).

\section{Table 10 \\ Research Theme 2 \& Connection to Theoretical Framework}

\begin{tabular}{|c|l|}
\hline Themes and Subthemes & Tenets of Transformative Curriculum \\
\hline $\begin{array}{c}\text { Theme 2: Defining the Struggle } \\
\text { Lack of time, materials, } \\
\text { and support }\end{array}$ & $\begin{array}{l}\text { Action: } \\
\text { - Challenge dominant social norms, beliefs, and inequitable } \\
\text { distributions of power in relation to race, culture, and } \\
\text { intellectual capacities through curriculum }\end{array}$ \\
\hline
\end{tabular}

Lack of time, materials, and support. Participants described concrete obstacles or challenges to developing anti-racist curriculum. A majority of public school teachers in the United States face the challenges of inadequate planning time, unavailability of teaching materials, and lack of support (American Federation of Teachers, 2017); 
however, according to the participants, these obstructions were exacerbated when planning for topics related to anti-racist curriculum.

Time. To begin with, as Nick said, "Time is the biggest enemy." It goes without saying that lack of time was a frequent concern amongst the participants during the planning process. All of them were working professionals attending graduate school and navigating other personal obligations. Derrick commented that just trying to balance his daily work life and home life made it quite difficult to work on this unit. He further pointed out:

Trying to plan a detailed lesson while teaching and functioning as a day-to-day educator is very challenging. There are plenty of demands that are placed on a working teacher that hinder their ability to perform this detailed planning and curriculum development.

Kimberly began to consider the time commitment necessary to continue to build such curriculum going forward: "Overall, the process could be very lengthy and take months, which raises questions about the feasibility of developing multiple units for a year's study." Ultimately, the shortage of planning time was not solved within this group, but it was a frequent topic of conversation.

As a former classroom teacher myself, the concern regarding the lack of time felt consistent with my experiences. In general, I found it was nearly impossible to teach and plan lessons within the given school day, and therefore I would often spend evenings and weekends planning my lessons. My passion for implementing curriculum beyond the Eurocentric norm drove my interest in developing my own curriculum and curricular materials. 
Materials. The lack of available teaching materials_-including lesson plans, textbooks, children's books, websites, videos, and activities — has been an ongoing problem in education. Still, participants found this obstacle one of the most challenging aspects of planning anti-racist lessons. Not only are there very few view existing antiracist lesson plans (most of which are written for middle school and high school students), but there are scarcely any lesson plans, books, or teaching materials that address race at all. As a result, the participants found themselves spending vast amounts of time searching for relevant materials. Kimberly repeatedly commented on how she spent hours looking for children's books to use with her lessons. Throughout this process, she had a hard time determining the quality and authenticity of the books, and the relevant books she did find she ended up purchasing with her own money.

Josie was forced to change topics for her lessons due to the lack of available materials: "Well, for my initial idea, it was hard because I really wanted to do something about something local, like indigenous culture, but there's no curriculum.” Nick struggled to find age-appropriate materials for his students:

[There were] very few lessons, say, like, on slavery and Jim Crow and civil rights for fifth grade, that had integrity and they could handle... [they] just seemed a little bit too simplified or so difficult that I had to rewrite everything.

Given the prevalence of Eurocentric curriculum in America, the lack of pertinent materials for anti-racist lessons was not surprising and remains one of the major challenges to the development and implementation of anti-racist curriculum.

Support. Again, the shortfall of resources and supports available for teachers in schools is hardly unique to anti-racist planning and instruction. Although the participants 
described a variety of types of supports within schools, their most pressing "lack of support" pertained to lagging interpersonal support from their peers. This scarcity of positive support amongst their peers appeared as color-blind racism in the form of negative and undermining comments, open defiance, and toxic gossip. The lack of support from other educators often served as an intimidating factor for both creating and teaching anti-racist curriculum. Gwen explained:

I was told by a coworker that we don't need multicultural education because we're not a multicultural school... [when] staff believe it's not your problem because you're privileged and everyone looks like you at your school, then we have a real serious issue.

In one of our class sessions, we talked about how the famous children's book author Dr. Seuss had allegedly created his infamous Cat in the Hat character from blackface. Cecilia relayed this information to one of her coworkers: "I brought up Dr. Seuss being racist, and she said she's not going to change her curriculum." Hazel described a scenario in which the district that she works for was providing professional development around anti-racist curriculum (which is a very unusual occurrence). She recalled:

The teachers are hesitant to go as far to say that they want to teach anti-racist work and to work against oppression...teachers were talking about how uncomfortable it made them feel that they were being called out... and the district is taking equity too far.

This discomfort and resistance on the part of the participants' school colleagues exemplifies the Eurocentric ideologies and color-blind mindsets that dominate schools throughout the United States, which serve as barriers for educational opportunities and justice. Through the implementation of anti-racist curriculum, the participants were able 
to take action to disrupt the dominant Eurocentric and color-blind ideologies. Such actions overlap with the seventh tenet of $\mathrm{TC}$, which calls for challenging dominant social norms, beliefs, and inequitable distributions of power in relation to race, culture, and intellectual capacities through curriculum. For future consideration, these actions of challenging the dominant narratives could move beyond the individual classrooms to the entire school community, where anti-racist curriculum could be implemented.

Acknowledging the challenges facing educators can serve as a healthy part of collaboration (Poulos, Culberston, Piazza, \& D’Entremont, 2014), although finding time to collaborate is one of the most consistent hurdles teachers face (Darling-Hammond \& Richardson, 2009). The insights these findings provide lays the groundwork for considering solutions for these real barriers surrounding anti-racist curriculum.

Combatting fear. Although the work of understanding anti-racist curriculum, the context of color-blind racism in education, and one's own racialized identity provoked a variety of emotional responses from the participants, fear was the most frequently expressed emotion. Fear took a variety of forms during this project, including (1) fear of causing harm to students with materials that are not "age-appropriate," (2) fear of looking foolish when representing others' cultures and perspectives, and (3) fear of the possibility of push-back from families and administrators.

To start, many of the participants struggled with selecting topics for their lessons because of an overarching fear around the "appropriateness" of any given topic. For most, topic selection caused confusion and self-doubt. For instance, Nick wondered: 
How much to explicitly tell them [students] and how to get them to find the information on their own. Because these subjects are so politically charged, the information can be so filled with emotions.

Likewise, Cecilia grappled with what was appropriate to talk about with kids and how to determine what topics or content were "out of bounds." She asserted, "I think some limiting factors are what we think is appropriate to talk about with students; we don't want to come off as offensive or biased." Kimberly also commented, "I often second-guess myself in planning anti-racist plans...[it's] difficult to adapt materials intended for older students; is it developmentally appropriate for younger students?" For several of the participants, underlying much of the fear were concerns about causing harm to students and being criticized for talking about such controversial topics with them.

Further, there was fear amongst the participants regarding how to best represent all groups of people and wondering whether it was their place to do so. Gwen mentioned her fear about misrepresenting other points of view and causing harm to students:

I'm a White teacher. Like, that's the most common type of teacher they're going to see. How do I, without speaking for other people, expose them to the truth of what's going on and has gone on in this country?

Gwen was fearful about how to address racial identity with her students when some of those students may not know their racial makeups or family backgrounds. In thinking about how to represent all students in class, Josie considered:

What happens when your students are in foster care or adopted, and how [do] you navigate that space and not make them feel bad or uncomfortable or like they don't have something to bring if they don't know about it? 
Josie's fear was rooted in not wanting to cause harm to her students as she worried about what kind of reaction this type of activity would garner from her students' families and from her school administrator.

Finally, at some point in the process all of the participants expressed raw, unadulterated fear. As Hazel designed her lessons, she worried about getting flak from parents: "When planning, that [fear] was in the forefront because nowadays you hear about so many teachers that try to have those conversations, and maybe they weren't approached in the best way, but there's a lot of political sensitivity." When reflecting upon implementing her lessons, Gwen shared:

I was scared shitless. I was really nervous that I would get a lot of blowback from families that I didn't want to handle. I was also really nervous that I would be, in presenting these multicultural perspectives, be an inauthentic voice...but, like, make them stand out as other. I didn't want to do that, but I didn't see a way around that completely because they have been othered.

Gwen's fears regarding confrontations with families and administrators stemmed from her fear of losing her job. She loved her job and wondered at times whether teaching this type of curriculum was worth the risk.

Despite these participants' willingness to engage in the work of building antiracist curriculum, at one point or another fear crept in for all of them. Levine-Rasky (2000) notes that fear is a common stumbling block for educators when having to face Whiteness. Beyond the general term fear, my study identified specific examples and contexts in which fear played out for my participants. In other words, it appeared as though each of these participants became aware - whether consciously or unconsciously - that they were going against the societal grain of White normative 
values, and these incongruencies caused some emotional upheaval. Regardless of the best intentions, the participants seem to have been caught up in the emotionality of Whiteness. As the researcher and facilitator of the collaborative sessions, I was not surprised that fear arose as part of this study. What I was surprised by was the intensity of fear that each participant faced. Whether it was expressed in class discussions, individual journal entries, or the interviews, at one point or another every participant faced fear that appeared to me to be overwhelming. Since within each class session there was designated time for discussion, those discussions became a natural time for participants to share their worries and fears. During these times, I was able to help the participants navigate such concerns by asking questions to clarify the context, details, and emotional underpinnings of their fears. Ultimately, the group discussions became a regular space for all group members to work out their fears and other entanglements related to developing such curriculum.

Summary. Beyond the typical limitations of schooling - time and resources - the participants found that anti-racist curriculum carried additional burdens of scarcity of relevant materials and lagging support from peers. Additionally, fear was a notable factor for all of the participants, which may have impacted the construction and implementation of their lesson plans. In turn, the lack of resources and the emotionality associated with this work are salient reminders of the current culture of schooling.

\section{Theme 3: Fostering a New Lens}

Over the course of the professional development experience, data from interviews, reflections, lesson plans, and observations indicated that the participants were 
beginning to take up and use an anti-racist lens with curricular materials, leading to my identification of the final theme of fostering a new lens. This theme corresponds with my third research question, which was concerned with how the teachers' experiences participating in the collaborative sessions impacted their teaching practices. According to the data analysis, the most substantiated takeaway for participants was the subtheme of an anti-racist lens, which corresponds with the following tenets of TC (see Table 11 below).

\begin{tabular}{|l|l|}
\hline \multicolumn{2}{|l|}{$\begin{array}{l}\text { Table } 11 \\
\text { Research Theme } 3 \text { \& Connection to Theoretical Framework }\end{array}$} \\
\hline Themes and Subthemes & Tenets of Transformative Curriculum \\
\hline $\begin{array}{c}\text { Theme 3: Fostering a New Lens } \\
\bullet \quad \text { Anti-racist lens }\end{array}$ & $\begin{array}{l}\text { Understanding: } \\
\text { 5. Employ critical-thinking skills to deconstruct and reconstruct } \\
\text { dominant knowledge and curricular paradigms } \\
\text { Action: } \\
\text { 8. Utilize counternarratives in curricula that draw upon a } \\
\text { variety of lived experiences and knowledge paradigms }\end{array}$ \\
\hline
\end{tabular}

Anti-racist lens. Under the overarching theme of fostering a new lens was a subtheme that I labeled anti-racist lens. For all of the participants, the course on antiracist curriculum construction was an eye-opening experience that generated new knowledge and skill sets. One of the most salient outcomes for the participants was the adoption of a new way of thinking, or what Josie called an "anti-racist lens." This idea of a new lens was originally discussed during a session in which we examined the racial representations of main characters in children's books. As part of this session, I shared the information collected by Cooperative Children's Book Center (2015), which indicates that over $70 \%$ of newly published children's books still feature White people as the main characters (see Chapter 2 for more details). This was an "ah-ha" moment for many of the 
participants, as they began to consider taking racial representation inventories of all the curricular materials they use with students.

From here, the participants began to describe this new lens as a filter through which to view the world. Each participant had a slightly different interpretation of this new lens. For instance, Hazel reflected:

Looking at the materials in my room with that lens, how can I make sure that all my students are represented, and even those that aren't in my classroom...I wouldn't have known to see that before or to look for that in the past. And I think that's such a simple thing that, even if teachers get their hackles raised about the thought of doing anti-racist work, that's such a simple thing that I can change that it's not that crazy new idea, for teachers to think about.

It is important to consider why Hazel had never noticed such a thing before. It appears that, having grown up in a mostly White context where White was likely considered “normal," Hazel had not developed a critical lens for the racialized context of schooling.

Prior to this course, Cecilia had never considered who was represented in or writing children's books. She commented:

I am wondering about making sure that the literature is written by students, people of color instead of just White people making literature like that...I don't think before this class that I really paid attention to that, but now it's definitely something that I try to pay attention to. It's like it's a fraud.

In this way, Cecilia seemed to be awakening to the idea that there has been and continues to be misrepresentations in children's books. She understood this to be fraudulent, because much of children's literature continues to be written by White authors who are often narrating stories about characters that do not represent their readers' race, ethnicity, and/or cultural experiences. 
The experiences in this course also pushed the participants to think about curriculum more broadly. As an example, Kimberly expressed a desire to interweave core subjects in school curriculum and then address anti-racist issues throughout the content in writing, reading, and social studies. Similarly, Josie remarked:

My whole perspective on curriculum will be forever changed as a result of thinking about curriculum from a multi-perspective anti-racist lens. I will forever question who the intended audience is and from what perspective is the curriculum I will be teaching from... Now I cannot help but think, like, who really is this for? Not just, like, what is it trying to say, but who are we talking to? Who are we not talking to?... Anything that I'm looking at now with that lens, who is this for?

This new lens also impacted some of the participants in a more global sense, in that they began to utilize this new perspective as a part of their overall decision-making process as educators. After taking this course, Nick discussed how collaboratively planning and building background knowledge around his topic had increased his confidence: "This has made me braver in the classroom, as it has also made me question how much to say and how much to remain silent." Through this, Nick saw his role as an advocate of anti-racism within the school system and was willing to push beyond the silent boundaries of the dominant ideology. Likewise, Derrick also wanted to advocate for those students who have been deemed "disadvantaged" by the educational system and suggested:

Attending this workshop and working on this unit has served to make me continuously conscious of the work that is needed to be done in education to improve our country for the disadvantaged. I am starting to frame every decision in my praxis from a perspective of race and power.

This evidence that teacher participants were acquiring a new lens attuned to issues of race and power suggests that the participants were beginning to take up the fifth tenet 
of TC, which encourages educators to utilize critical-thinking skills to deconstruct and reconstruct dominant knowledge and curricular paradigms. As seen above, the participants provided many examples of ways in which they were applying this type of critical thinking focused on power, race, and privilege in their own practice.

In the process of evaluating curriculum through an anti-racist lens, participants were also able to add to the curriculum and use the concepts of multiple points of view and counternarratives within their curriculum development. All of the participants incorporated curriculum that centrally featured narratives of people of color through fictional, informational, or historical content (counternarratives), suggesting that participants were beginning to take up the eighth tenet of TC, which calls for teachers to use counternarratives drawing on a variety of lived experiences and knowledge paradigms.

Summary. Under the theme of fostering a new lens, it was clear from the participants' statements that each was walking away from this project with a new filter for evaluating curriculum and the world around them. This allowed participants to employ critical-thinking skills to deconstruct and reconstruct dominant knowledge and curricular paradigms, and to utilize counternarratives that draw upon a variety of lived experiences and knowledge paradigms. What remains unclear is whether these participants will be able to hold onto their newly acquired lens and maintain their passion for anti-racist curriculum as they continue to work in the field of education.

\section{Participant Profile: Hazel's Story}


For the purpose of further illustrating the findings from this study, I chose to highlight one of the participant's experiences and comments. I selected Hazel, who represented a "typical" participant from this study as she identified as White and female, grew up in a mostly White context, had three years of experience in schools, and had experiences with cultures outside the United States.

Hazel was a pre-service teacher candidate working on attaining her teaching license in elementary education with an endorsement in ESOL. She had worked as an educational assistant in a variety of settings including in an ESOL program and in a selfcontained special education classroom, where she was employed at the time of data collection. Prior to such work, Hazel had completed a yearlong study program in Mexico and considered herself mostly fluent in Spanish. Additionally, she had worked overseas teaching English to native Korean students in a government-funded public school outside of Seoul, South Korea. Although Hazel came into this project with several years' worth of experience working in schools and with children, she appeared unsure of her ability to plan any sort of curriculum, let alone anti-racist curriculum. She clearly expressed a desire to teach for social justice but was unsure what that might look like in the classroom and in lesson plans.

Coming into this study, Hazel identified as White but—like her other White peers - had difficulty seeing herself as such because being White is often associated with White supremacy. She commented, 'I’ve had a hard time seeing myself as a White person because there's so many stereotypes with it that I feel like I don't fit in, but it's my racial identity." Hazel relayed how her family never discussed race or their racial 
heritage as she was growing up. She noted that at one point her dad decided to research their family lineage but that this search was limited due to her maternal grandfather's adoption and the fact that her paternal grandparents were deaf. Hazel also felt that her childhood left her ill prepared to understand race and racism. She explained:

My development and my understanding of racism and social inequities were limited. I think the community that I came from, that's what it meant when we're not racists is that you are told that you didn't see color, then you can't be racist.

Despite her trepidation with identifying as White and her limited experiences talking about race, Hazel demonstrated a desire to push through her discomfort and learn about anti-racist curriculum.

For Hazel, the idea of teaching for social justice meant having awareness and appreciation for the diverse experiences and funds of knowledge that all students and families hold. To date, Hazel's most memorable experience with the enactment of social justice practices occurred at a bilingual school where she was an assistant. She explained:

In this bilingual school, there were services that they were providing [for students and families] in the community, [that] was really powerful to me. I think as a form of social justice, we're providing these services. A lot of undocumented families wouldn't have felt comfortable reaching out to these community organizers that would provide services; this feels like it developed a sense of trust with them and they can provide what these families really need.

Hazel saw these actions by the school as true forms of inclusion and social justice. Instead of following a traditional model of family engagement where the school sets the agenda for how families are to interact with the school, they met the families where they were at and centered the families' needs above the schools'. She admired these actions and saw them as aspirational. 
Conversely, Hazel also mentioned that she had seen many examples of injustices in schools as well. Most notable for her, there was an incident in which a classroom teacher she was working with had been asked to write a letter of support for an undocumented father who was going to be deported due to his immigration status. Despite knowing that deportation would cause the student to be separated from his parent, the teacher refused to write the letter. Hazel explained:

And his classroom teacher refused to write it because she was like, it's the law. He deserves to be deported. So of course, we [other ESOL teachers and herself] wrote it for him, but that really stuck with me. Like, I can't believe someone would actually do that to a student.

Hazel described this experience as life changing; she saw the power and influence that a teacher could have in a child's life, beyond the classroom. She looked at this experience as a sort of calling for herself to advocate and fight for the humanity of children and their families.

In describing the planning process, Hazel expressed appreciation for the collaborative community and feedback. In our interview, she disclosed:

I really enjoyed the opportunity to collaborate, and part of that was I could 'just come as is' because we were all on different levels in that group. That's one thing I think that was huge, was that it was so small and that we could really get to know each other really well and discuss our process in depth, and then share our ideas and learn from each other. I think that was so different from any other course I've taken.

Hazel also mentioned that this experience helped her gain new insights and skills to inform her teaching practices. Hazel described developing a new understanding of the term color-blindness. Prior to this course, Hazel had thought that not seeing race meant that you weren't racist, as that was what she learned from her community growing up. 
Having the experience of learning about racial color-blindness and its impact on students' identity development was a poignant part of this project for Hazel. This new definition of racial color-blindness marked an evolution of thinking for Hazel, as she began to see the harm in not recognizing race and students' racial identities. Hazel also noted that this process provided her with a road map for fighting racial injustices in the classroom through curriculum. As she expressed:

You're just finding these authentic primary sources and then just having discussions about it. That has really changed my perspective on how I may be able to have this kind of content and discussions in my classrooms without creating controversial situations.

In this, Hazel seemed to acknowledge the tension between wanting to support her students in being seen and heard and the boundaries around topics deemed controversial.

Through this process, Hazel was able to recognize how curricular material, such as children's literature, can serve as an entry point for conversations with students about race, racism, and other inequities. She saw the benefits of utilizing curricular materials as the central source of classroom discussions rather than just a stand-alone topic within anti-racist lessons. All the while, Hazel recognized the lack of available materials, and yet she felt compelled to move forward with creating her own curriculum.

In addition, Hazel readily expressed awareness of the barriers and obstacles associated with creating anti-racist curriculum. To begin with, she-like the other participants - struggled to find quality, authentic, and age-appropriate materials for her lessons. For her anti-racist lessons on immigration, she ended up using a book that I provided her with: The Line Between Us: Teaching about the Border and Mexican Immigration by Bill Bigelow. With the help of this resource, written for high school 
students, she was able to duplicate several lesson structures and some content for her elementary-aged unit. More specifically, Hazel designed anti-racist curriculum for fifthgrade students around the history of immigration in the United States. This five-day unit featured lessons on (1) defining migration, immigration, emigration, and refugees; (2) why people move and possibly leave their countries; (3) separate but equal educational laws; (4) the history of Angel Island; and (5) the Universal Declaration of Human Rights. Another challenge Hazel encountered was working within the context of schools, with the scarcity of positive support amongst her peers. She noted the negative attitudes teachers held in her school: "I mean, teachers just straight up saying like, I don't see color and why are we focusing on equity? Why do we have to point out everyone's different ethnicity, and why can't we just be happy to help people?" Although Hazel observed a few teachers doing the work of implementing social justice in their classrooms, she explained that most of the teachers in her school have the opinion that the district is "taking its equity too far."

Lastly, Hazel was particularly fearful about how an anti-racist unit might land with the families in her community. For Hazel, both the lagging positive support from peers at her school and the fear of potential parental push-back appeared to intimidate her and caused her to pause and question her rationale for creating such lessons. In reflecting upon these fears, Hazel seemed to have a renewed determination for teaching for social justice, particularly when she considered the impact this work could have with students. Hazel often referred back to her experience with the teacher who would not write the letter of support. This story seemed to be a focal point to anchor Hazel's beliefs about 
what the role of a teacher should be and the powerful role a teacher can play in the lives of children. Hazel did not lose her fear but rather was willing to work in spite of her fear because of her commitment to advocate for the voices of students that are often left out of the educational curriculum.

Overall, many of Hazel's experiences were similar to those of her peers in the course. Not unlike the other participants, despite her lack of experience with planning anti-racist lessons and the fear she faced during the process, Hazel left with an excitement and a commitment to implement "curriculum that's actively and intentionally teaching to work against racism rather than not just being a racist or ignoring it." As a result of this process, Hazel experienced subtle shifts in her thinking around racial color-blindness and a willingness to push through the fear and discomfort to realize her goal of implementing anti-racist curriculum with students.

\section{Limitations of Study}

The findings of this research study answered my research questions, which were concerned with the experiences of educators designing anti-racist curriculum. In addition, the findings I put forth reaffirm much of the established research on racial colorblindness in education, Eurocentric curriculum, and the silence about race and racism in schools and curriculum. Further, the findings I presented offer new ideas to contribute to the research literature and also have implications for future research. Qualitative research is designed not to support broad claims of generalizability but to generate nuanced understandings of the meanings of phenomena for participants and of dynamic, contextualized processes. 
That being said, there are several potential limitations of this study. First, my study sought "willing" educators who were interested in creating anti-racist curriculum. To further substantiate the findings of this study, it might be advantageous to duplicate this research with a broader cross-section of educators who hold various degrees of knowledge about anti-racist curriculum.

Second, my role as the researcher and facilitator of the courses created power dynamics that could have influenced the participants' contributions and statements regarding the process. Even though I was not the instructor of record (which means I did not assign the grades for these courses), I was the "professor" of this graduate-level class. In the future, it may be beneficial to replicate this study as a workshop or professional development series outside the institution of higher education.

Third, although I took measures to increase the reliability of the study_including researcher reflexivity, collaboration, and peer debriefing - I feel that I could have strengthened these practices throughout the study. Specifically, after the completion of the data analysis, I asked the participants to review the transcripts from their interviews as a form of member-checking. In retrospect, I would have also had participants check the participant observation notes from class sessions and transcribed interviews prior to analysis. I would also have used member-checking with participants about my interpretations and findings.

Fourth, the main goal of this research was to understand the process in which the participants not only designed but implemented curriculum. However, by the time the participants were interviewed, only four of the seven had implemented their curriculum 
in their classrooms. For those who did implement their curriculum, the process of implementation was self-reported and not based on classroom observations or student interviews. In the future, I feel it would be advantageous to incorporate both observations of the curriculum implementation and student interviews to better contextualize and understand the experience of implementing anti-racist curriculum.

\section{Conclusion}

This study sought to generate new knowledge about the supports and obstacles teachers encounter as they work to develop anti-racist curriculum. As part of the study, the course on anti-racist curriculum construction attempted to disrupt the color-blind ideology and break the silence about race, racism, and racial inequities in education. My research questions sought to understand a collaborative process by which educators create and teach anti-racist curriculum. In this chapter, I presented the research findings I generated from my data collection and analysis, producing three main themes and five subthemes. Each of these themes was coupled with the most applicable research question and analyzed through the theoretical lens of transformative curriculum. The findings suggest that the participants valued the collaborative experience of constructing their independent anti-racist lessons in conjunction with feedback from their peers and a structured outline.

There were many challenges and obstacles for developing such curriculum, which caused fear and anxiety, and yet all of the participants managed to complete the task of creating anti-racist lesson plans. In the end, each of the participants described a "new lens" they had acquired as a result of this project and were returning to the field of 
education with new insights and a passion to continue the work. A profile of one participant (Hazel) illustrates the ways that the key themes and subthemes interconnected in the dynamic process of racial identity development and anti-racist curriculum construction. Chapter 5 will discuss these findings further and outline implications for further research and practice. 
Chapter V

Discussion

Education is our passport to the future, for tomorrow belongs to the people who prepare for it today. (Malcolm X, June 28, 1964).

By now, it should be firmly understood that, in the United States today, race remains a predictor of educational achievement for students (Bonilla-Silva, 2014;

Hilliard, 2014; Howard, 2010; Kozol, 1991; Ladson-Billings, 1994; Noguera, 2008; Tatum, 1997) as racial color-blindness continues to be the dominant stance toward race in educational institutions (Eaton, 2001; Gillborn, 1992; Lewis, 2001; Pollock, 2004; Schofield, 2006; Sleeter, 2004). Despite the negative consequences associated with the color-blind ideology (Hawley \& Nieto, 2010; Sleeter, 1996; Tatum, 1992), research has indicated that teachers - particularly White teachers - feel uncomfortable about and underprepared for talking with students about race, racism, and racial inequities (Bakari, 2003; Banks, 2006; Husband, 2016; Milner, 2010; Modica, 2015). As a countermeasure, anti-racist curriculum can be utilized to directly teach students about race and intentionally interrupt the color-blind ideology (Cheng \& Soudack, 1994; Kailin, 2002; Nieto \& Bode, 2012).

Through this qualitative research, I sought to understand how teachers attending a series of collaborative professional development sessions experience the process of designing and implementing anti-racist curriculum, while engaging teachers in challenging the color-blind ideology in education The data collected for this researchincluding participant observation notes, research artifacts, and semi-structured interviews - were analyzed through a multi-cycle process of coding. The coding, 
categorization, and thematic analysis of the transcribed data and corresponding data were compared to the research questions and evaluated through the lens of transformative curriculum. As a result, I cultivated research themes from contextual examples from the entire collection of data as a means for answering the following questions:

1. How do PK-12 teachers participating in a collaborative professional development experience describe the processes of planning and implementing anti-racist curriculum?

2. How do the teachers describe obstacles or challenges with planning and implementing anti-racist curriculum?

3. According to the teachers, how does participating in the collaborative sessions impact their teaching practices in anti-racist lessons?

In this final chapter, I synthesize and discuss the study's key findings and describe further implications of this research.

\section{Synthesis of Findings}

My investigation yielded several significant findings. To begin with, the cumulative experiences of the collaborative sessions - through which each participant successfully created anti-racist lesson plans-were regarded as positive amongst all of the participants. Further, irrespective of the useful outcomes of the collaborative sessions, all of the participants faced multiple challenges and obstacles when planning and attempting to teach such curriculum. Lastly, each of the White participants struggled to accept his or her own racial identity, which presented as an internal grappling fraught with ambivalence and uneasiness. In this forthcoming section, I describe each of these findings in more detail.

\section{Positive Experiences with Collaborative Planning}


First, the experiences of the participants confirm that creating anti-racist lessons through collaborative professional development is possible and that such experiences can positively impact teaching practices. The participants appeared to thrive in this community context and stated that the constructive feedback, shared resources, and structured planning guidelines were the most helpful aspects of the collaborative experiences. Several of the described benefits of the professional development sessions aligned with Spark's (2002) characteristics of high-quality professional development, including (1) a focus on deepening content knowledge and pedagogy; (2) time for practice, research, and reflection; (3) ongoing learning sustained over time; and (4) a sense of collegiality and collaboration with other educators focused on solving important problems related to teaching and learning.

As another indicator of the positive impact of these experiences, all of the participants expressed gratitude for the opportunities afforded to them through this project and appeared to leave the project with a new sense of purpose and a desire to continue engaging collaboratively to create more anti-racist lessons. Each of the participants expressed a desire for more time to engage in this work, as nearly all asked if I would be teaching the course again and indicated an interest in enrolling. Additionally, Hazel, Josie, and Cecilia all separately indicated that this course should be a required class for all pre-service teacher candidates. Also, several participants asked if I would continue to support them in designing future lessons. For instance, Gwen disclosed that it would be her last year teaching seventh and eighth grade because the next year she would 
be teaching third grade. She had already created a year-long theme of "injustice" for her third-graders and wanted my help collaborating on curriculum.

Furthermore, the collective experiences of this project—including collaborative sessions, topics presented, transformative knowledge, and writing anti-racist curriculum — seemed to foster the development of new skills and even an "anti-racist lens" for each of the participants. The combination of the safe and supportive collaborative environment, the focal topics of discussions, sharing of materials, background knowledge of the facilitator (myself), and willingness of the participants appeared to create optimal learning conditions for the participants to gain new analytical skills for evaluating curriculum. Several of the participants discussed how their new lenses were helping them evaluate their school's physical environment and curricular materials through their own racial representation inventory. Which racial groups were included in hallway posters, pictures, and bulletin boards? Who were the main characters featured in required literature? Whose histories were highlighted in curricular content? These new lenses seemed to be something that participants were going to take with them into their everyday teaching practices. But what remained unclear from this research study was how and if these participants were going to be able to sustain their newly acquired skills in the long term. This concept of the adaption of a "new lens" as part of teaching for social justice and/or planning anti-racist curriculum has not been discussed in research literature and warrants further investigation, research, and discussion.

\section{Challenges and Obstacles}


Beyond the positive experiences with the collaborative sessions, this study also highlighted another finding: The challenges and obstacles for creating and implementing anti-racist curriculum are not only pervasive but inescapable. To begin with, the participants were hindered by the lack of time and materials for planning such curriculum. While such a dilemma in not new in the practice of teaching, the participants reported that time and materials were particularly problematic factors when planning anti-racist curriculum. In fact, within this work, the lack of time and materials were interrelated phenomena, given that much of the participants' time was devoted to sourcing appropriate curricular materials for their units of study. As mentioned, very few race-related curricular materials exist within current school-adopted curriculum, as well as curriculum available for purchase from publishers or websites. Therefore, the participants spent a significant amount time creating and/or modifying existing curricular materials for the lessons plans they were developing.

As another challenge, most of the participants also bumped up against racial color-blindness in their school contexts, which often appeared in the form of resistance from their peers. This was not surprising given the pervasiveness of color-blindness embedded within schools (Eaton, 2001; Gillborn, 1992; Lewis, 2001; Pollock, 2004; Schofield, 2006; Sleeter, 2004) and the fact that many educators still believe it to be the most effective way to deal with race in schools (Bakari, 2003; Banks, 2006; Husband, 2016; Milner, 2010; Modica, 2015). Although their peers' negative comments and toxic gossip were not directed at the participants themselves, such hostility served as an intimidating factor for creating and teaching anti-racist curriculum. Those participants 
who implemented their curriculum were able to move past the negativity to implement their anti-racist lessons for this study, but what was not clear was how the participants will choose to handle or confront the color-blind mentality in their school environments in the future. Will they be able to continue the work of teaching anti-racist curriculum? Or will the color-blind ideology pervasive in most schools inhibit them from doing such work? Thus, further long-term research is warranted to explore the complexity of the larger context of the school community when anti-racist curriculum is being developed and taught.

At some point during the study, each of the participants grappled with another challenge: their own fears regarding the process of designing and implementing antiracist curriculum. While the participants' expressed fears differed, all of their emotionality appeared to derive from the process and/or the imagined or real context for implementing their curriculum. Their specific fears ranged from causing harm with not having "age-appropriate" materials, to looking foolish when representing perspectives, to the possibility of push-back from families and administrators. This universality of fear was a surprising finding for me, given the fact that I was working with willing participants who had elected to take the course to design curriculum. Yet, in my own reflection on the anti-racist lessons I have designed and implemented, I realized that I too faced moments of fear. Such findings suggest that fear may be an inevitable emotion of Whiteness when challenging or attempting to interrupt the Eurocentric ideology in schools. Although several scholars have investigated the emotionality of Whiteness (Leonardo, 2009; Matias, 2016; Matias \& Allen, 2013), more research into the emotions 
associated with the development and teaching of anti-racist curriculum would not only be valuable but necessary to understanding the complexities of this work.

\section{White Identity Development}

Throughout this study, the White participants consistently struggled with accepting their own White racial identity. This finding registered as significant due to the incongruence between the participants' internal uneasiness with their racial identity and their acceptance of systematic racism. More specifically, each of the participants readily understood and acknowledged the systems of oppression that are operationalized at the expense of people of color within society and education, yet these same participants could not seem to reconcile their own racial classification within a racialized society, as if to say that race is a social category for others in society but not for themselves.

While such racial incongruencies have been discussed within the research literature regarding Whiteness, these discrepant thoughts about race have not been addressed in research relative to White identity development. To date, most research on racial identity development — whether White racial identity (Helms, 1990; Tatum, 2017), Black racial identity (Cross, 1991), or Bi-racial identity (Poston, 1990)—incorporates linear progressive stages as indicators of an individual's racial evolution. These lock-step stages presume congruence between the individual's understanding of race in the larger societal context and their own racial identity.

My findings suggest a more complex reality of racialized understandings within society and the self, particularly for White people, which speaks to a gap in the literature wherein most of the White identity development research implies a harmony between 
societal understandings of racism and internal understandings of identity. Further exploration of the nuanced complexities of racial identity development is needed, along with additional research addressing both White racial identity development and the interplay of White racial identity within the development and implementation of antiracist curriculum.

Despite the positive collaborative experiences and the omnipresent challenges, a central question remains with regard to each participant's ability to sustain the practices of designing and teaching anti-racist curriculum. Leonardo (2016) uses the metaphor of a river to explain this phenomenon: Whiteness represents the natural downstream flow of the river, and anti-racism is the struggle to forge upstream. "Whites have swum downstream since the age of discovery, but as anti-racists they are forced to swim upstream and fight the currents of White domination" (p.11). With respect to the participants in this study, will they be able to hold onto their newly acquired skills and enthusiasm for cultivating anti-racist curriculum? For how long? Under what conditions?

Despite the positive experiences with regard to planning and implementing antiracist curriculum, this research may raise more questions than it answers. This study demonstrates that the development and implementation of anti-racist curriculum is possible but cannot corroborate whether such work is sustainable. Further, this research calls for the continued need to define and foster racial identity development, particularly for White educators.

\section{Implications}


This research offers insights for the field of education in the following areas: (1) the need for more research about anti-racist curriculum development, (2) the role of educational leaders in supporting anti-racist work, and (3) the call for more anti-racist curriculum and resources, particularly at the elementary level.

This initial exploration of the experiences of teachers developing and implementing anti-racist curriculum opens up a potentially viable area for future research. As previously discussed in Chapters 1 and 2, very few research studies have investigated the development and implementation of anti-racist curriculum (Cheng \& Soudack, 1994; Derman-Sparks, 2011; Kailin, 2002; Michael, 2015). As mentioned, in my search for relevant research to support my study, I found only three empirical studies that explored the implementation of anti-racist curriculum, only one of which was based in the United States. Therefore, further research is warranted with regard to the phenomenon of antiracist curriculum.

An appropriate next step would be to scale up this project by incorporating more educators, conducting the study over a longer period of time, and infusing classroom observations of the implementation of the curriculum to create a rich description of this process. As an application of the findings of the current study, a subsequent study would ideally be situated in a school building and conducted in partnership with administrators, teachers, and families. Because fear and lack of support for anti-racist work emerged as such important obstacles to developing and implementing explicitly anti-racist curriculum in this study, there is reason to believe that situating a similar study in a school and involving various stakeholders could facilitate more robust uptake of the 
course content and more sustainable implementation in classrooms than was possible in the context of the current study.

Another area for future research involves the role of educational leadersincluding school administrators, district leaders, and lead teachers - in the creation and implementation of anti-racist curriculum. Often, educational leaders are uniquely positioned to create professional development opportunities for teachers while providing the parameters and resources necessary to support the completion of this work. In turn, the findings of this research can offer guideposts for educational leaders in facilitating the time and conditions through which teachers can plan and implement anti-racist curriculum. Currently, there does not appear to be any research literature or empirical studies related to educational leaders' roles in the implementation of anti-racist curriculum. The findings of this study invite further investigation into the role educational leaders play with regard to anti-racist curriculum.

Finally, there is a significant void in available materials and curriculum that focus on societal injustices involving race and racism, particularly for elementary school students. Research has indicated that much of the curriculum used in the United States is Eurocentric, reflecting European-American experiences and worldviews (Asante, 1991; Au, 2009; Banks, 1991; Banks \& Banks, 2013; Delpit, 1988; Ladson-Billings, 2001; Nieto \& Bode, 2012; Zimmerman, 2004). Participants in the current study struggled to find existing anti-racist lessons and curricular materials that address race and racism. Therefore, this research reinforces the call for more anti-racist curriculum, particularly for the elementary grades. Not only does this curriculum need to be constructed but it 
needs to be made accessible to educators as well. Whether this curriculum is centralized on a website or published as a complete volume of curriculum, educators need reliable access to such materials. Again, the development of anti-racist curriculum is a phenomenon that has scarcely been researched, especially in the United States. This process of curriculum development is yet another line of inquiry that could be further investigated, whether the curriculum is constructed in collaboration (as in this study) or independently completed in the field by individual educators.

\section{Conclusion}

This research maintains the hope that disrupting the pervasive color-blind ideology in education is possible, yet more work is needed to create sustainable and lasting changes in education. This research highlights the journeys that those of us who are aspiring anti-racists have chosen to take. As Nick described, "We're all kind of unfolding...I feel like we're all waking up, it's just, you know, we're at different points on the path." 


\section{References}

Alridge, D. P. (2006). The limits of master narratives in history textbooks: An analysis of representations of Martin Luther King, Jr. Teachers College Record, 108(4), 662.

Ambady, N., Shih, M., Kim, A., \& Pittinsky, T. L. (2001). Stereotype susceptibility in children: Effects of identity activation on quantitative performance. Psychological science, 12(5), 385-390.

American Psychological Association Presidential Task Force on Preventing Discrimination and Promoting Diversity. (2012). Dual pathways to a better America: Preventing discrimination and promoting diversity. Washington, DC: American Psychological Association.

Apfelbaum, E. P., Pauker, K., Ambady, N., Sommers, S. R., \& Norton, M. I. (2008). Learning (not) to talk about race: When older children underperform in social categorization. Developmental Psychology, 44(5), 1513-1518.

Apfelbaum, E. P., Pauker, K., Sommers, S. R., \& Ambady, N. (2010). In blind pursuit of racial equality? Psychological Science, 21(11), 1587-1592.

Apfelbaum, E. P., Sommers, S. R., \& Norton, M. I. (2008). Seeing race and seeming racist? Evaluating strategic colorblindness in social interaction. Journal of Personality and Social Psychology, 95(4), 918.

Apple, M. W. (2004). Ideology and curriculum. New York, NY: Routledge.

Asante, M. K. (1991). The Afrocentric idea in education. The Journal of Negro Education, 60(2), 170-180.

$\mathrm{Au}, \mathrm{W}$. (2013). High-stakes testing and curriculum control: A qualitative metasynthesis. In D. J. Flinders \& S. J. Thornton (Eds.), The curriculum studies reader $\left(4^{\text {th }}\right.$ ed., pp. 235-251). New York, NY: Routledge.

$\mathrm{Au}, \mathrm{W}$. (2014). Rethinking multicultural education: Teaching for racial and cultural justice ( $2^{\text {nd }}$ ed.). Milwaukee, WI: Rethinking Schools.

Bakari, R. (2003). Preservice teachers' attitudes toward teaching African American students contemporary research. Urban Education, 38(6), 640-654.

Baldwin, B. (2009). Symposium: Defining race: Colorblind diversity: The changing significance of 'race' in the post-Bakke era. Alabama Law Review, 72, 863.

Banks, J. A. (1991). A curriculum for empowerment, action, and change. In C. Sleeter (Ed.), Empowerment through multicultural education (pp. 125-141). Albany, NY: State University of New York Press.

Banks, J. A. (1991). Teaching strategies for ethnic studies. Needham Heights, MA: Allyn and Bacon.

Banks, J. A. (1993). Multicultural education: Historical development, dimensions, and practice. Review of Research in Education, 19, 3-49. 
Banks, J. A. (1995). The historical reconstruction of knowledge about race: Implications for transformative teaching. Educational Researcher 24, 15-25.

Banks, J. A. (2001). Approaches to multicultural curriculum reform. Multicultural Education: Issues and Perspectives, 4, 225-246.

Banks, J. A. (2006). Race, culture, and education: The selected works of James A. Banks. New York, NY: Taylor \& Francis.

Banks, J. A., \& Banks, C. A. M. (2013). Multicultural education: Issues and perspectives ( $8^{\text {th }}$ ed.). Hoboken, NJ: John Wiley \& Sons.

Barndt, J. R. (2007). Understanding and dismantling racism: The twenty-first century challenge to White America. Minneapolis, MN: Augsberg Fortress.

Baxter, P., \& Jack, S. (2008). Qualitative case study methodology: Study design and implementation for novice researchers. The Qualitative Report, 13(4), 544-559.

Bean, T. W., Valerio, P. C., Senior, H. M., \& White, F. (1999). Secondary English students' engagement in reading and writing about a multicultural novel. The Journal of Educational Research, 93(1), 32-37.

Bell, D. (1992). Faces at the bottom of the well: The permanence of racism. New York, NY: Basic Books.

Bell, D. (2004). Silent covenants: Brown v. Board of Education and the unfulfilled hopes for racial reform. New York, NY: Oxford University Press.

Bigelow, B. (2008). A people's history for the classroom. Milwaukee, WI: Rethinking Schools.

Bigelow, B., \& Peterson, B. (1998). Rethinking Columbus: The next 500 years. Milwaukee, WI: Rethinking Schools.

Bobbitt, F. (2013). Scientific method in curriculum-making. In D. J. Flinders \& S. J. Thornton, (Eds.), The curriculum studies reader ( ${ }^{\text {th }}$ ed., pp. 11-18). New York, NY: Routledge.

Bobo, L., Kluegel, J. R., \& Smith, R. A. (1997). Laissez-faire racism: The crystallization of a kinder, gentler, antiBlack ideology. Racial Attitudes in the 1990s: Continuity and Change, 15, 23-25.

Bonilla-Silva, E. (1997). Rethinking racism: Toward a structural interpretation. American Sociological Review, 465-480.

Bonilla-Silva, E. (2001). White supremacy and racism in the post-civil rights era. Boulder, CO: Lynne Rienner Publishers.

Bonilla-Silva, E. (2014). Racism without racists: Color-blind racism and the persistence of racial inequality in America. Lanham, MD: Rowman \& Littlefield. 
Bonilla-Silva, E., \& Embrick, D. G. (2008). Recognizing the likelihood of reproducing racism. In M. Pollock (Ed.), Everyday antiracism: Getting real about race in school (pp. 334-336). New York, NY: The New Press.

Bonilla-Silva, E., \& Forman, T. A. (2000). "I am not a racist but...": Mapping White college students' racial ideology in the USA. Discourse \& Society, 11(1), 50-85.

Bonilla-Silva, E., Forman, T. A., Lewis, A. E., \& Embrick, D. G. (2003). It wasn't me: How will race and racism work in $21^{\text {st }}$ century America. Research in Political Sociology, 12(1), 111-134.

Broaded, C. M. (1997). The limits and possibilities of tracking: Some evidence from Taiwan. Sociology of Education, 36-53.

Brown, K. D., \& Brown, A. L. (2010). Silenced memories: An examination of the sociocultural knowledge on race and racial violence in official school curriculum. Equity \& Excellence in Education, 43(2), 139-154.

Brown-Jeffy, S., \& Cooper, J. E. (2011). Toward a conceptual framework of culturally relevant pedagogy: An overview of the conceptual and theoretical literature. Teacher Education Quarterly, 38(1), 65-84.

Casas, M. (2008). Designing an antiracist curriculum for middle school students in Texas via the Texas Essential Knowledge and Skills (TEKS) and Latino/Latina critical pedagogy. Journal of Border Educational Research, 7(1), 87-100.

Chen, D. W., Nimmo, J., \& Fraser, H. (2009). Becoming a culturally responsive early childhood educator: A tool to support reflection by teachers embarking on the anti-bias journey. Multicultural Perspectives, 11(2), 101-106.

Cheng, M., \& Soudack, A. (1994). Anti-racist education: A literature review. No. 206. Toronto, Ontario, Canada: Toronto Board of Education, Research Department.

Clark, K. B. (1988). Prejudice and your child. Middletown, CT: Wesleyan University Press.

Clark, K. B., \& Clark, M. P. (1950). Emotional factors in racial identification and preference in Negro children. The Journal of Negro Education, 19(3), 341-350.

Clarke, J. (1993). Christopher Columbus and the Afrikan holocaust: Slavery and the rise of European capitalism. New York, NY: A \& B Publishers Group.

Clawson, R. A. (2002). Poor people, Black faces: The portrayal of poverty in economics textbooks. Journal of Black Studies 32(3), 352-361.

Cochran-Smith, M. (1995). Color blindness and basket making are not the answers: Confronting the dilemmas of race, culture, and language diversity in teacher education. American Educational Research Journal, 32(3), 493-522.

Cochran-Smith, M. (2000). Blind vision: Unlearning racism in teacher education. Harvard Educational Review, 70(2), 157-190. 
Conley, D. (1999). Being Black, living in the red: Race, wealth, and social policy in America. Berkeley, CA: University of California Press.

Copenhaver, J. F. (2001). Silence in the classroom: Learning to talk about issues of race. The Dragon Lode, 18(2), 8-16.

Crabtree, B. F., \& Miller, W. L. (1999). Doing qualitative research. Thousand Oaks, CA: Sage.

Crenshaw, C. (1997). Resisting Whiteness' rhetorical silence. Western Journal of Communication (includes Communication Reports), 61(3), 253-278.

Crenshaw, K. W. (1997). Color-blind dreams and racial nightmares: Reconfiguring racism in the post-civil rights era. In T. Morrison \& C. Lacour (Eds.), Birth of a Nation'hood (pp. 97-168). New York: Pantheon Books.

Crenshaw, K. W. (2001). First decade: Critical reflections, or a foot in the closing door. The UCLA Law Review, 49, 1343.

Crenshaw, K., Gotanda, N., Peller, G., \& Thomas, K. (1995). Critical race theory: The key writings that formed the movement. New York, NY: New Press.

Creswell, J. W., Hanson, W. E., Plano, V. L. C., \& Morales, A. (2007). Qualitative research designs selection and implementation. The Counseling Psychologist, 35(2), 236-264.

Creswell, J. W., \& Miller, D. L. (2000). Determining validity in qualitative inquiry. Theory into Practice, 39(3), 124-130.

Cross, W. E., Jr. (1991). Shades of Black: Diversity in African-American identity. Philadelphia, PA: Temple University Press.

Darder, A. (2010). Schooling bodies: Critical pedagogy and urban youth. Urban Questions: Teaching in the City, 215(19), xiii-xxiv.

Darder, A. (2014). Freire and education. New York, NY: Routledge.

Darling-Hammond, L. (2007). Third annual Brown lecture in education research-The flat earth and education: How America's commitment to equity will determine our future. Educational Researcher, 36(6), 318-334.

Darling-Hammond, L., \& McLaughlin, M. W. (1995). Policies that support professional development in an era of reform. Phi Delta Kappan, 76(8), 597.

Darling-Hammond, L., Wei, R. C., Andree, A., Richardson, N., \& Orphanos, S. (2009). Professional learning in the learning profession. Washington, DC: National Staff Development Council, 12.

DeCuir, J. T. \& Dixson, A. D. (2004). So when it comes out, they aren't that surprised that it is there: Using critical race theory as a tool of analysis of race and racism in education. Educational Researcher, 33(5), 26-33. 
Dei, G. (1996). Basic principles of anti-racism education. In D. George (Ed.), Anti-racism education: Theory and practice. Halifax: Fernwood Pub.

Delgado, R., \& Stefancic, J. (2000). Critical race theory: The cutting edge. Philadelphia, PA: Temple University Press.

Delgado, R., \& Stefancic, J. (2012). Critical race theory: An introduction. New York, NY: NYU Press.

Delpit, L. D. (1988). The silenced dialogue: Power and pedagogy in educating other people's children. Harvard Educational Review, 58(3), 280-299.

Delpit, L. D. (2006). Other people's children: Cultural conflict in the classroom. New York, NY: The New Press.

Delpit, L. D. (2012). "Multiplication is for White people”: Raising expectations for other people's children. New York, NY: The New Press.

Delpit, L. D., \& Dowdy, J. K. (Eds.) (2002). The skin that we speak: Thoughts on language and culture in the classroom. New York: New York Press.

Derman-Sparks, L., \& Ramsey, P. G. (2011). What if all the kids are White?: Anti-bias multicultural education with young children and families. New York, NY: Teachers College Press.

Donner, J.K. (2013). Education as the property of Whites: African Americans continued quest for good schools. In M. Lynn \& A.D. Dixson (Eds.), Handbook of critical race theory in education (pp. 195-215). New York, NY: Routledge.

Dovidio, J. F., Gaertner, S. E., Kawakami, K., \& Hodson, G. (2002). Why can't we just get along? Interpersonal biases and interracial distrust. Cultural Diversity and Ethnic Minority Psychology, 8(2), 88.

DuBois, W. E. B. (1935). Black reconstruction in America, 1860-1880. New York: Atheneum.

DuBois, W. E. B., \& Edwards, B. H. (2007). The souls of Black folk. New York, NY: Oxford University Press.

Duran, B., Duran, E., \& Brave Heart, M.Y. H. (1998). The trauma of history. In R. Thornton (Ed.), Studying native America: Problems and perspectives (pp. 60-78). Madison, WI: The University of Wisconsin Press.

Dyson, A. H., \& Genishi, C. (2005). On the case: Approaches to language and literacy research. New York, NY: Teachers College Press.

Eaton, S. E. (2001). The other Boston busing story: What's won and lost across the boundary line. New Haven, CT: Yale University Press.

Eisner, E. W. (1985). The educational imagination. New York, NY: Macmillan.

Epstein, T. (2009). Interpreting national history. New York: Routledge. 
Feagin, J. R., \& Van Ausdale, D. (2001). The first R: How children learn race and racism. Lanham, Maryland: Rowman \& Littlefield Publishers.

Feistritzer, C.M. (2011). Profile of teachers in the U.S. Retrieved from http:/www.edweek.org/media/pot2011final-blog.pdf

Flinders, D. J., Noddings, N., \& Thornton, S. J. (1986). The null curriculum: Its theoretical basis and practical implications. Curriculum Inquiry, 16(1), 33-42.

Forman, T. A. (2004). Color-blind racism and racial indifference: The role of racial apathy in facilitating enduring inequalities. In M. Krysan, \& A. E. Lewis (Eds.), The changing terrain of race and ethnicity. New York, NY: Russell Sage Foundation.

Ford, D. Y., \& Grantham, T. C. (2003). Providing access for culturally diverse gifted students: From deficit to dynamic thinking. Theory into Practice, 42(3), 217-225.

Foster, S. J. (1999). The struggle for American identity: Treatment of ethnic groups in United States history textbooks. History of Education 28(3), 251-78.

Fowler, F. C. (2013). Policy studies for educational leaders $\left(4^{\text {th }}\right.$ ed.). Boston, MA: Pearson.

Frankenberg, R. (1993). White women, race matters. Minneapolis, MN: University of Minnesota Press.

Franklin, J.H. \& Higginbotham, E. (2010). From slavery to freedom: A history of African Americans (9th ed.). New York, NY: McGraw-Hill.

Freire, P. (1970). Cultural action for freedom. Harvard Educational Review, 476-521.

Freire, P. (2000). Pedagogy of the oppressed. New York, NY: Continuum.

Freire Institute. (2016). Concepts used by Paulo Freire. Retrieved from http://www.freire.org/paulo-freire/concepts-used-by-paulo-freire

Gay, G. (2000). Culturally responsive teaching: Theory, practice and research. New York, NY: Teachers College Press.

Gay, G. (2002). Preparing for culturally responsive teaching. Journal of Teacher Education 53(2), 106-116.

Gay, G. (2006). Connections between classroom management and culturally responsive teaching. In C.M. Evertson, \& C.S. Weinstein (Eds.), Handbook of classroom management: Research, practice, and contemporary issues (pp. 343-370). New York, NY: Routledge.

Gay, G. (2010). Acting on beliefs in teacher education for cultural diversity. Journal of Teacher Education, 61(1-2), 143-152.

Gay, G. (2015). Teachers' beliefs about cultural diversity: Problems and possibilities. In H. Five \& M .G. Gill (Eds.), International handbook of teachers' beliefs (pp. 436452). New York, NY: Routledge. 
Gay, G., \& Kirkland, K. (2003). Developing cultural critical consciousness and selfreflection in preservice teacher education. Theory into Practice, 42(3), 181-187.

Gillborn, D. (1992). Citizenship, 'race' and the hidden curriculum. International Studies in Sociology of Education, 2(1), 57-73.

Gillborn, D. (2009). Education policy as an act of White supremacy. In E. Taylor, D. Gillborn, \& G. Ladson-Billings (Eds.), Foundations of critical race theory in education (pp. 51-69). New York, NY: Taylor \& Francis.

Giroux, H. A. (1989). Critical pedagogy, the state, and cultural struggle. New York, NY: Suny Press.

Giroux, H. A. (1995). Critical pedagogy and predatory culture: Oppositional politics in a postmodern era. New York, NY: Psychology Press.

Giroux, H. A. (1997). Pedagogy and the politics of hope: Theory, culture, and schooling. Boulder, CO: Westview Press.

Giroux, H. A. (2015). Against the terror of neoliberalism: Politics beyond the age of greed. New York, NY: Routledge.

Given, L. M. (Ed.). (2008). The Sage encyclopedia of qualitative research methods. Thousand Oaks, CA: Sage.

Glazier, J. A. (2003). Moving closer to speaking the unspeakable: White teachers talking about race. Teacher Education Quarterly, 30(1), 73-94.

Glesne, C. (2016). Becoming qualitative researchers: An introduction (5 $\left.5^{\mathrm{h}} \mathrm{ed}.\right)$. Boston, MA: Pearson.

Goodman, M. E. (1952). Race awareness in young children. Cambridge, MA: AddisonWesley Press.

Goodman, A. H. (2008) Exposing race as an obsolete biological concept. In M. Pollock (Ed.), Everyday antiracism: Getting real about race in school (pp. 4-8). New York, NY: The New Press.

Gould, S. J. (1996). The mismeasure of man. New York, NY: W.W. Norton \& Company.

Graham, P. (2007). Improving teacher effectiveness through structured collaboration: A case study of a professional learning community. RMLE Online, 31(1), 1-17.

Grant, C. A., \& Sleeter, C. E. (2013). Race, class, gender, and disability in the classroom. In J.A. Banks \& C.A. McGee Banks (Eds), Multicultural education: Issues and perspectives ( $8^{\text {th }}$ ed.). Hoboken, NJ: John Wiley \& Sons.

Hancock, D. R., \& Algozzine, B. (2011). Doing case study research: A practical guide for beginning researchers. New York, NY: Teachers College Press.

Hargreaves, A., \& Dawe, R. (1990). Paths of professional development: Contrived collegiality, collaborative culture, and the case of peer coaching. Teaching and Teacher Education, 6(3), 227-241. 
Hatch, J. A. (2002). Doing qualitative research in education settings. Albany, NY: Suny Press.

Hawley, W. D., \& Nieto, S. (2010). Another inconvenient truth: Race and ethnicity matter. Educational Leadership, 68(3), 66-71.

Helms, J. E. (1990). Black and White racial identity: Theory, research, and practice. New York, NY: Greenwood Press.

Hilliard, A. G. (2014). What do we need to know now? In W. Au (Ed.), Rethinking multicultural education: Teaching for racial and cultural justice ( $2^{\text {nd }}$ ed., pp. 2538). Milwaukee, WI; Rethinking Schools.

Holzman, M. (2006). Public education and Black male students: The 2006 state report card. Quincy, MA: Schott Foundation for Public Education.

Horsford, S. D., \& Grosland, T. J. (2013). Badges of inferiority: The racialization of achievement in US education. In M. Lynn \& A. D. Dixson (Eds.), Handbook of critical race theory in education (pp. 153-166). New York, NY: Routledge.

Howard, T. C. (2010). Why race and culture matter in schools: Closing the achievement gap in America's classrooms. New York, NY: Teachers College Press.

Hughes, J. M., Bigler, R. S., \& Levy, S. R. (2007). Consequences of learning about historical racism among European American and African American children. Child Development, 78(6), 1689-1705.

Husband Jr, T. (2012). "I don't see color": Challenging assumptions about discussing race with young children. Early Childhood Education Journal, 39(6), 365-371.

Johnston, R. C. (2000, June). Federal data highlight disparities in discipline. Education Week, 19(41), 3.

Jones, J. M. (1999). Cultural racism: The intersection of race and culture in intergroup conflict. New York, NY: Russell Sage Foundation.

Kailin, J. (2002). Antiracist education: From theory to practice. New York, NY: Rowman \& Littlefield.

Kao, G., \& Thompson, J. S. (2003). Racial and ethnic stratification in educational achievement and attainment. Annual Review of Sociology, 29, 417-442.

Katz, J. H. (2003). White awareness: Handbook for anti-racism training. Norman, OK: University of Oklahoma Press.

Katz, P. A. (2013). The acquisition of racial attitudes in children. In P. A. Katz (Ed.), Towards the elimination of racism: Pergamon general psychology series (pp. 125-156). New York, NY: Pergamon Press.

Kindy, K., Fischer, M., Tate, J., \& Jenkins, J. (2015). A year of reckoning: Police fatally shoot nearly 1000. Washington Post. Retrieved from 
http://www.washingtonpost.com/sf/investigative/2015/12/26/a-year-of-reckoningpolice-fatally-shoot-nearly-1000/

Kozol, J. (2012). Savage inequalities: Children in America's schools. New York, NY: Broadway Books.

Krathwohl, D. R. (2009). Methods of educational and social science research: The logic of methods. Long Grove, IL: Waveland Press.

Ladson-Billings, G. (1995). Toward a theory of culturally relevant pedagogy. American Educational Research Journal, 32(3), 465-491.

Ladson-Billings, G. (2001). Crossing over to Canaan: The journey of new teachers in diverse classrooms. The Jossey-Bass education series. San Francisco, CA: JosseyBass, Inc.

Ladson-Billings, G. (2004). Landing on the wrong note: The price we paid for Brown. Educational Researcher, 33(7), 3-13.

Ladson-Billings, G. (2006). From the achievement gap to the education debt: Understanding achievement in US schools. Educational Researcher, 35(7), 3-12.

Ladson-Billings, G. (2009). Just what is critical race theory? In E. Taylor, D. Gillborn, \& G. Ladson-Billings (Eds.), Foundations of critical race theory in education (pp. 17-36). New York, NY: Taylor \& Francis.

Ladson-Billings, G. (2013). Critical race theory-What it is not! In M. Lynn \& A. D. Dixson (Eds.), Handbook of critical race theory in education (pp. 34-47). New York, NY: Routledge.

Ladson-Billings, G., \& Tate IV, W. (1995). Toward a critical race theory of education. The Teachers College Record, 97(1), 47-68.

Lather, P. (1992). Critical frames in educational research: Feminist and poststructural perspectives. Theory into Practice, 31(2), 87-99.

Leonardo, Z. (2009). Race, whiteness, and education. New York, NY: Routledge.

Leonardo, Z. (2016). Tropics of Whiteness: Metaphor and the literary turn in White studies. Whiteness and Education, 1(1), 3-14.

Leonardo, Z., \& Boas, E. (2013). Other kids' teachers: What children of color learn from White women and what this says about race, Whiteness, and gender. In M. Lynn \& A. D. Dixson (Eds), Handbook of critical race theory and education (pp. 313324). New York, NY: Routledge.

Levine-Rasky, C. (2000). Framing Whiteness: Working through the tensions in introducing Whiteness to educators. Race ethnicity and education, 3(3), 271-292.

Lewis, A. E. (2001). There is no "race" in the schoolyard: Color-blind ideology in an (almost) all-White school. American Educational Research Journal, 38(4), 781811. 
Lewis, A. E. (2004). What group? Studying Whites and Whiteness in the era of colorblindness. Sociological Theory, 22(4), 623-646.

Lewis, A. E., \& Diamond, J. B. (2015). Despite the best intentions: How racial inequality thrives in good schools. New York, NY: Oxford University Press.

Lipka, J., \& Adams, B. (2004). Culturally based math education as a way to improve Alaska Native students' math performance. Appalachian Collaborative Center for Learning, Working Paper 20.

Lipka, J., Hogan, M. P., Webster, J. P., Yanez, E., Adams, B., Clark, S., \& Lacy, D. (2005). Math in a cultural context: Two case studies of a successful culturally based math project. Anthropology \& Education Quarterly, 36(4), 367-385.

Lipka, J., Sharp, N., Adams, B., \& Sharp, F. (2007). Creating a third space for authentic biculturalism: Examples from math in a cultural context. Journal of American Indian Education, 46(3), 94-115.

Loewen, J. W. (1995). Lies my teacher told me. New York, NY: The New Press.

Lucas, S. R. (2008). Constructing colorblind classrooms. In M. Pollock (Ed.), Everyday antiracism: Getting real about race in school (pp. 62-66). New York, NY: The New Press.

Marable, M. (2003). The great wells of democracy: The meaning of race in American life. Cambridge, MA: Basic Books.

Maslak, M. A. (2009). Using enrollment and attainment in formal education to understand the case of India. In D. B. Holsinger \& W. J. Jacob (Eds.), Inequality in education: Comparative and international perspectives. Hong Kong, China: Springer.

Matias, C. E. (2016). Feeling white: Whiteness, emotionality, and education. Rotterdam, Netherlands: Sense Publishers.

Matias, C. E., \& Allen, R. L. (2013). Loving Whiteness to Death: Sadomasochism, Emotionality, and the Possibility of Humanizing Love. Berkeley Review of Education, 4(2), 285-309.

Maxwell, J. A. (2013). Qualitative research design: An interactive approach $\left(3^{\text {rd }} \mathrm{ed}\right.$.). Thousand Oaks, CA: Sage.

McIntosh, P. (1988). White privilege: Unpacking the invisible knapsack. Race, Class, and Gender in the United States: An Integrated Study, 4, 165-169.

McIntosh, P. (2010). White privilege and male privilege: A personal account of coming to see correspondence through work in women's studies. In E. F. Provenzo, Jr. (Ed.), The Teacher in American Society: A Critical Anthology (pp. 121-134). Thousand Oaks, CA: Sage.

McIntyre, A. (1997). Making meaning of Whiteness: Exploring racial identity with White teachers. Albany, NY: Suny Press. 
McLaren, P. (2000). Paulo Freire's pedagogy of possibility. In S. Steiner, H. Frank, P. McLaren, \& R. Bahruth (Eds.), Freirean pedagogy, praxis and possibilities: Projects for the new millennium (pp. 1-21). New York, NY: Falmer Press.

McLaren, P. (2015). Life in schools: An introduction to critical pedagogy in the foundations of education ( $6^{\text {th }}$ ed.). New York, NY: Routledge.

Mezirow, J. (1997). Transformative learning: Theory to practice. New directions for adult and continuing education, 1997(74), 5-12.

Michael, A. (2015). Raising race questions: Whiteness and inquiry in education. New York, NY: Teachers College Press.

Milner, B. (2014). Taking multicultural, anti-racist education seriously: An interview with Enid Lee. In W. Au (Ed.), Rethinking multicultural education: Teaching for racial and cultural justice ( $2^{\text {nd }}$ ed.). Milwaukee, WI: Rethinking Schools.

Milner IV, H. R. (2010). Start where you are, but don't stay there: Understanding diversity, opportunity gaps, and teaching in today's classrooms. Cambridge, MA: Harvard Education Press.

Milner IV, H. R., Pearman III, F. A., \& McGee, E. O. (2013). Critical race theory, interest convergence, and teacher education. In M. Lynn \& A. D. Dixson (Eds.), Handbook of critical race theory in education (pp. 339-354). New York, NY: Routledge.

Modica, M. (2015). Unpacking the 'colorblind approach': Accusations of racism at a friendly, mixed-race school. Race Ethnicity and Education, 18(3), 396-418.

Mondale, S., Patton, S. B., \& Streep, M. (2001). School: The story of American public education. Boston, MA: Beacon Press.

Monroe, C. R. (2005). Why are "bad boys" always Black?: Causes of disproportionality in school discipline and recommendations for change. The Clearing House: A Journal of Educational Strategies, Issues and Ideas, 79(1), 45-50.

Mukhopadhyay, C., \& Henze, R. C. (2003). How real is race? Using anthropology to make sense of human diversity. Phi Delta Kappan, 84(9), 669.

National Governors' Association. (2005). Closing the achievement gap. Retrieved from http://www.subnet.nga.org/educlear/achievement/

Neville, H. A., Awad, G. H., Brooks, J. E., Flores, M. P., \& Bluemel, J. (2013). Colorblind racial ideology: Theory, training, and measurement implications in psychology. American Psychologist, 68(6), 455.

Neville, H. A., Lilly, R. L., Duran, G., Lee, R. M., \& Browne, L. (2000). Construction and initial validation of the Color-Blind Racial Attitudes Scale (CoBRAS). Journal of Counseling Psychology, 47(1), 59.

Nieto, S. (1994). Moving beyond tolerance in multicultural education. Multicultural Education, 1(4), 9-12, 35-38. 
Nieto, S. (1996). Affirming diversity: The sociopolitical context of multicultural education. White Plains, NY: Longman.

Nieto, S., \& Bode, P. (2012). Affirming diversity: The sociopolitical context of multicultural education $\left(6^{\text {th }}\right.$ ed.). Boston, MA: Allyn \& Bacon.

Nunan, D. (1989). Toward a collaborative approach to curriculum development: A case study. TESOL Quarterly, 23(1), 9-25.

Orfield, G., Losen, D., Wald, J., \& Swanson, C. B. (2004). Losing our future: How minority youth are being left behind by the graduation rate crisis. Cambridge, MA: The Civil Rights Project at Harvard University.

Paris, D. (2012). Culturally sustaining pedagogy: A needed change in stance, terminology, and practice. Educational Researcher, 41(3), 93-97.

Pauker, K., Apfelbaum, E. P., \& Spitzer, B. (2015). When societal norms and social identity collide: The race talk dilemma for racial minority children. Social, Psychological, and Personality Science, 6(8), 887-895.

Perry, P. (2002). Shades of White: White kids and racial identities in high school. Durham, NC: Duke University Press.

Peters, M., \& Lankshear, C. (1996). Critical literacy and digital texts. Educational Theory, 46(1), 51-70.

Pilgrim, D. (September 2000). What was Jim Crow? (Web log comment). Retrieved from http://www.ferris.edu/jimcrow/what.htm

Plaut, V. C. (2014). Diversity science and institutional design. Policy Insights from the Behavioral and Brain Sciences, 1(1), 72-80.

Plaut, V. C., Thomas, K. M., \& Goren, M. J. (2009). Is multiculturalism or colorblindness better for minorities? Psychological Science, 20(4), 444-446.

Pollock, M. (2001). How the question we ask most about race in education is the very question we most suppress. Educational Researcher, 30(9), 2-11.

Pollock, M. (2004). Colormute: Race talk dilemmas in an American school. Princeton, NJ: Princeton University Press.

Pollock, M. (2008). Everyday antiracism: Getting real about race in school. New York, NY: The New Press.

Poston, W. C. (1990). The biracial identity development model: A needed addition. Journal of Counseling \& Development, 69(2), 152-155.

Proshansky, H. (1966). The Development of Intergroup. Review of Child Development Research, 2(2), 311.

Richeson, J. A., \& Nussbaum, R. J. (2004). The impact of multiculturalism versus colorblindness on racial bias. Journal of Experimental Social Psychology, 40(3), 417423. 
Rickford, A. (2001). The effect of cultural congruence and higher order questioning on the reading enjoyment and comprehension of ethnic minority students. Journal of Education for Students Placed at Risk, 6(4), 357-387.

Rosenberg, P. M. (2004). Color blindness in teacher education: An optical delusion. In M. Fine, L. Weis, L. Powell Pruitt, \& A. Burns (Eds.), Off White: Readings on power, privilege, and resistance (pp. 257-272). New York, NY: Routledge.

Saldaña, J. (2015). The coding manual for qualitative researchers. Thousand Oaks, CA: Sage.

Sargrad, S., Marchitello, M., \& Hanna, R. (2015). Invisible by design: How Congress risks hiding the performance of disadvantaged students. Retrieved from https://www.americanprogress.org/issues/education/report/2015/10/29/124421/inv isible-by-design/

Schofield, J. W. (1989). Black and White in school: Trust, tension, or tolerance? New York, NY: Teachers College Press.

Schofield, J. W. (2006). The colorblind perspective in school: Causes and consequences. In J. Banks, \& C. A. McGee Banks (Eds.), Multicultural education: Issues and perspectives (pp. 271-295). Hoboken, NJ: Wiley \& Sons.

Schuman, H. (1997). Racial attitudes in America: Trends and interpretations. Cambridge, MA: Harvard University Press.

Schultz, E. L., Neyhart, T. K., Reck, U. M., \& Easter, L. M. (1996). Uphill all the way: An investigation of attitudinal predispositions of preservice teachers toward diversity in urban classrooms. The Teacher Educator, 32(1), 22-36.

Seidman, I. (1998). Interviewing as qualitative research: A guide for researchers in education and the social sciences ( $2^{\text {nd }}$ ed.). New York, NY: Teachers College Press.

Seidman, I. (2013). Interviewing as qualitative research: A guide for researchers in education and the social sciences ( ${ }^{\text {th }}$ ed.). New York, NY: Teachers College Press.

Short, G., \& Carrington, B. (1987). 14 Towards an anti-racist initiative in the all White primary school: A case study. In A. Pollard (Ed)., Children and their primary schools: A new perspective (pp. 220-235). Philadelphia, PA: Falmer Press.

Skiba, R. J., Horner, R. H., Chung, C. G., Rausch, M. K., May, S. L., \& Tobin, T. (2011). Race is not neutral: A national investigation of African American and Latino disproportionality in school discipline. School Psychology Review, 40(1), 85.

Skiba, R. J., Michael, R. S., Nardo, A. C., \& Peterson, R. L. (2002). The color of discipline: Sources of racial and gender disproportionality in school punishment. The Urban Review, 34(4), 317-342. 
Sleeter, C. E. (1995). Multicultural education, critical pedagogy, and the politics of difference. Albany, NY: SUNY Press.

Sleeter, C. E. (1996). Multicultural education as social activism. Albany, NY: SUNY Press.

Sleeter, C. E. (2001). Preparing teachers for culturally diverse schools: Research and the overwhelming presence of Whiteness. Journal of Teacher Education, 52(2), 94106.

Sleeter, C. E. (2004). How White teachers construct race. In G. Ladson-Billings \& D. Gillborn (Eds.), The RoutledgeFalmer reader in multicultural education (pp. 163178). New York, NY: Routledge Falmer.

Sleeter, C. E. (2008). Preparing White teachers for diverse students. In M. CochranSmith, S. Feiman-Nemser, D. J. McIntyre, \& K. E. Demers (Eds.), Handbook of research on teacher education: Enduring questions in changing contexts ( $3^{\text {rd }}$ ed., pp. 559-582). New York, NY: Routledge.

Sleeter, C. E. (2011). The academic and social value of ethnic studies: A research review. Washington, DC: National Education Association Research Department.

Sleeter, C., \& Carmona, J. F. (2016). Un-standardizing curriculum: Multicultural teaching in the standards-based classroom. New York, NY: Teachers College Press.

Sleeter, C. E. \& Grant, C. A. (1991). Race, class, gender and disability in current textbooks. In M. W. Apple \& L. Christian-Smith (Eds.), Politics of the textbook (pp. 78-110). New York, NY: Routledge.

Sleeter, C., \& Stillman, J. (2013). Standardizing knowledge in a multicultural society. In D. J. Flinders \& S. J. Thornton (Eds.), The curriculum studies reader $\left(4^{\text {th }}\right.$ ed., pp. 253-287). New York, NY: Routledge.

Smedley, A., \& Smedley, B. D. (2005). Race as biology is fiction, racism as a social problem is real: Anthropological and historical perspectives on the social construction of race. American Psychologist, 60(1), 16.

Solórzano, D. G. (1997). Images and words that wound: Critical race theory, racial stereotyping, and teacher education. Teacher Education Quarterly, 24(3), 5-19.

Solórzano, D. G., Villalpando, O., \& Oseguera, L. (2005). Educational inequities and Latina/o undergraduate students in the United States: A critical race analysis of their educational progress. Journal of Hispanic Higher Education, 4(3), 272-294.

Solórzano, D. G., \& Yosso, T. J. (2001). Critical race and LatCrit theory and method: Counter-storytelling. International Journal of Qualitative Studies in Education, 14(4), 471-495.

Stake, R. E. (1995). The art of case study research. Thousand Oaks, CA: Sage. 
Stanton, C. R. (2015). Beyond the margins: Evaluating the support for multicultural education within teachers' editions of U.S. history textbooks. Multicultural Perspectives, 17(4), 180-189.

Stovall, D. O. (2013). Fightin' the devil 24/7: Community, and critical race praxis in education. In M. Lynn \& A.D. Dixson (Eds.), Handbook of critical race theory in education (pp. 289-301). New York, NY: Routledge.

Sue, D. W. (2004). Whiteness and ethnocentric monoculturalism: Making the "invisible" visible. American Psychologist, 59(8), 761-769.

Sue, D. W. (2005). Racism and the conspiracy of silence: Presidential address. The Counseling Psychologist, 33(1), 100-114.

Sue, D. W. (2015). Race talk and the conspiracy of silence: Understanding and facilitating difficult dialogues on race. Hoboken, NJ: John Wiley \& Sons.

Tatum, B. D. (1992). Talking about race, learning about racism: The application of racial identity development theory in the classroom. Harvard Educational Review, 62(1), 1-25.

Tatum, B. D. (2004a). Defining racism: Can we talk? In P. Rothenberg (Ed.), Race, class, and gender in the United States: An integrated study (6 ${ }^{\text {th }}$ ed., pp. 124-131). New York, NY: Worth Publishers.

Tatum, B. D. (2004b). Talking about race, learning about racism. In J. Bobo, C. Hudley, \& C. Michel (Eds.), The Black studies reader (pp. 389-412). New York, NY: Routledge.

Tatum, B. D. (2007). Can we talk about race?: And other conversations in an era of school resegregation. Boston, MA: Beacon Press.

Tatum, B. D. (2017). Why are all the Black kids sitting together in the cafeteria?: And other conversations about race. New York, NY: Basic Books.

Thornton, S. J. (2013). Silence on gays and lesbians in social studies curriculum. In D. J. Flinders \& S. J. Thornton (Eds.), The curriculum studies reader $\left(4^{\text {th }}\right.$ ed., pp. 331337). New York, NY: Routledge.

Townsend, B. L. (2000). The disproportionate discipline of African American learners: Reducing school suspensions and expulsions. Exceptional Children, 66(3), 381391.

Turner, M. A., Ross, S. L., Galster, G. C., \& Yinger, J. (2002). Discrimination in metropolitan housing markets: National results from Phase I HDS 2000. Washington, DC: US Department of Housing and Urban Development.

Tyson, K. (2003). Notes from the back of the room: Problems and paradoxes in the schooling of young Black students. Sociology of Education, 76(4), 326-343. 
Ullucci, K., \& Battey, D. (2011). Exposing color blindness/grounding color consciousness challenges for teacher education. Urban Education, 46(6), 11951225 .

University of Pittsburgh School of Education Race and Early Childhood Collaborative. (2016). Positive racial identity development in early education: Understanding PRIDE in Pittsburgh. Pittsburgh, PA: University of Pittsburgh.

Unzueta, M. M., \& Lowery, B. S. (2008). Defining racism safely: The role of self-image maintenance on White Americans' conceptions of racism. Journal of Experimental Social Psychology, 44(6), 1491-1497.

U.S. Census Bureau (2010). Census interactive population search. Retrieved from http://www.census.gov/2010census/popmap/ipmtext.php?fl=06

U.S. Census Bureau (2010). Quick Facts: California. Retrieved from https://www.census.gov/quickfacts/fact/table/ca/POP010210\#POP010210

U.S. Department of Education, Institute of Education Science, National Center for Educational Statistics (2013). National Assessment of Educational Progress (NAEP) reading assessment. Retrieved from http://nces.ed.gov/nationsreportcard/

U.S. Department of Education, Institute of Education Science, National Center for Educational Statistics (2013). National Assessment of Educational Progress (NAEP) reading assessment. Retrieved from http://dashboard.ed.gov/statedetail.aspx?i $=\mathrm{c} 8 \& \mathrm{id}=0 \& w \mathrm{wt}=40$

U.S. Department of Education, Institute of Education Science, National Center for Educational Statistics (2015). Racial/ethnic enrollment in public schools. Retrieved from http://nces.ed.gov/programs/coe/indicator_cge.asp

U.S. Department of Education, Office for Civil Rights. (2014). Civil rights data collection: Data snapshot (school discipline). Retrieved from http://www2.ed.gov/about/offices/list/ocr/index.html

U.S. Government Accountability Office (2016). PK-12 education: Better use of information could help agencies identify disparities and address racial discrimination. Retrieved from http://www.gao.gov/products/GAO-16-345

Valencia, R. R. (1997). The evolution of deficit thinking: Educational thought and practice. London, England: Routledge.

Vavrus, M. (2008). Culturally responsive teaching. 21st Century Education: A Reference Handbook, 2, 49-57.

Verkuyten, M. (2005). Ethnic group identification and group evaluation among minority and majority groups: Testing the multiculturalism hypothesis. Journal of Personality and Social Psychology, 88(1), 121.

Villegas, A. M. (2007). Dispositions in teacher education: A look at social justice. Journal of Teacher Education 58(5), 370-380. 
Weiss, R. S. (1994). Learning from strangers: The art and method of qualitative interview studies. New York, NY: Free Press Inc.

Wiggins, G. P., \& McTighe, J. (2011). The understanding by design guide to creating high-quality units. Alexandria, VA: ASCD.

Wills, J. S. (1994). Popular culture, curriculum, and historical representation: The situation of Native Americans in American history and the perpetuation of stereotypes. Journal of Narrative and Life History, 4(4), 277-294.

Willis, A. I. (2003). Parallax: Addressing race in preservice literacy education. In S. Greene \& D. Abt-Perkins (Eds.), Making race visible: Literacy research for cultural understanding (pp. 51-70). New York, NY: Teachers College Press.

Wolfe, P. (2006). Settler colonialism and the elimination of the native. Journal of Genocide Research, 8(4), 387-409.

Wood, J. (2016). Enacting culturally restorative and anti-racist education in a kindergarten classroom. In T. Husband (Ed.), But I don't see color (pp. 49-62). Rotterdam, Netherlands: Sense Publishers.

Yin, R. K. (2003). Case study research: Design and methods ( $3^{\text {rd }}$ ed.). Thousand Oaks, CA: Sage.

Yin, R. K. (2014). Case study research: Design and methods $\left(5^{\text {th }}\right.$ ed.). Thousand Oaks, CA: Sage.

Yosso, T. J. (2002). Toward a critical race curriculum. Equity \& Excellence in Education, 35(2), 93-107.

Yosso, T. J. (2005). Whose culture has capital? A critical race theory discussion of community cultural wealth. Race Ethnicity and Education, 8(1), 69-91.

Zimmerman, J. (2004). Brown-ing the American textbook: History, psychology and origins of modern multiculturalism. History of Education Quarterly, 44(1), 4669.

Zinn, H. (2004). A people's history of the United States ( $2^{\text {nd }}$ ed.). New York, NY: Seven Stories Press. 


\section{Appendix A \\ Written Informed Consent}

\section{Dear Educators,}

My name is Kelly Cutler and I am currently a doctoral candidate in the Graduate School of Education (GSE) at Portland State University (PSU). For the purposes of completing my doctorate in education, I will be investigating the process in which teachers plan and implement curriculum focused on teaching about equity and social justice. You have been selected because you expressed interest in developing multicultural curriculum.

You are invited to participate in my research study through the Graduate School of Education (GSE) at Portland State University (PSU). The primary goals of the study are to learn about how teachers describe the process of designing and implementing antiracist curriculum, the obstacles or challenges experienced during this process, and how the collaborative sessions of this study impact their teaching practices with anti-racist lessons.

Should you decide to participate, you will be asked to complete a short survey, participate in individual interviews, participate in planning sessions, keep a reflective journal, and share the lesson plans you produce during the planning sessions with the researcher. The interviews will be audio-taped and only the research team will have access to the recordings. The interviews can be conducted at your school site, at Portland State University, or another location at your suggestion. To maintain confidentiality, I will use the following procedures: identify participants only by a coded identifier (pseudonyms) and maintain records in password-protected computer and external hard drive which will remain in a locked file cabinet. Your identity will not be used for publication or publicity purposes.

You may not receive any direct benefit from taking part in this study, but the study may help to increase your knowledge and strengthen your professional practice. Through this research, I hope to gain an understanding of teachers' experiences and perspectives as they design and implement anti-racist curriculum. The findings from this study could help inform other teachers, as well as district personnel, about the process by which such curriculum could be created, including the benefits, challenges and obstacles. Your participation may benefit others by contributing to these goals.

Your participation is completely voluntary. If you choose to participate, and decide at some point that you do not feel comfortable with the interviews, focus groups, 
observations or the use of your artifacts (e.g., reflective journal and lesson plans), you may withdraw from the study at any time.

If you have concerns about your rights as a research subject, please contact the PSU Office of Research Integrity, 1600 SW 4th Ave., Market Center Building, Ste. 620, Portland, OR 97201: phone (503) 725-2227, email hrssc@pdx.edu. If you have questions about the study itself or your participation in this study, please contact me or my advisor.

Kelly J. Cutler, (503) 730-8682, kcutler@pdx.edu, Doctoral Candidate

Dr. Dot McElhone, (503) 725-8993, mcelhone@pdx.edu, Associate Professor and Academic Advisor

Your signature indicates that you have read and understand the above information and agree to take part in this study. The researcher will provide you with a copy of this form for your own records.

Signature

Date 


\section{Appendix B}

Participant Survey

1. Why did you become a teacher? Tell me about the values and beliefs that guide your teaching.

2. Please describe your educational background, including schools attended, major, and teacher preparation program.

3. Tell me about where you are currently teaching. What is your job assignment? Describe the student population.

4. What do you believe "teaching for social justice" means?

5. What might teaching for social justice look like in practice? Describe an example.

a. What experience, course, person, text, film, etc. has been the greatest influence on your understanding of teaching for social justice?

b. To what degree does teaching for social justice actually happen in the school settings? Why?

6. Have you taught lessons that has an anti-bias and/or social justice focus?

a. If yes, tell me about it.

b. If no, would you like to teach a lesson with this focus?

7. Have you taught lessons about race or racism with students?

a. If yes, tell me about them.

b. If no, would you like to teach a lesson with this focus?

8. What role do you think race plays in the lives of children?

9. What does the term "anti-racist" mean to you?

10. When you think about your racial identity, what comes to mind?

11. Have you ever participated in racial equity trainings, courses, or book clubs? If so, please describe these experiences.

12. Is there anything else you would like to tell me, or anything else that I need to know? 


\section{Appendix C \\ Semi-Structured Interview}

NOTE: The questions listed below are the same questions found on the participant survey. Interviews were conducted after the participants have completed the professional development series. First, I posed follow-up questions to probe for further information about the items on the survey. In addition, listed below each question are potential follow-up or probing questions. Second, I wanted to get a really good sense of how you are experiencing the process of planning and implementing curriculum, including obstacles and challenges, as well as the impact of the collaborative sessions on your teaching (as related to the research questions).

\section{INTRODUCTION}

Thank you so for coming to talk with me about your experiences as part of this project. I really appreciate it. For this interview, I want to start by getting a really good sense of your experiences and background. In review, these are the research questions that I aim to address in this study:

Q1: How do PK-12 teachers participating in a collaborative professional development experience describe the processes of planning and implementing anti-racist curriculum?

Q2: How do the teachers describe obstacles or challenges with planning and implementing anti-racist curriculum?

Q3: According to the teachers, how does participating in the collaborative sessions impact their teaching practices in anti-racist lessons?

\section{CONFIDENTIALITY}

I will be recording our conversation so I can accurately document your words. Later, I will have the recordings transcribed by a professional and you will have a chance to review the transcriptions. No one else will listen to the recordings and I won't use your name on any part of the study. Is it okay with you for me to record? Do you have any questions before I start recording?

\section{OPENING}

1. Why did you become a teacher? Tell me about the values and beliefs that guide your teaching.

- Do you have a particular teaching philosophy or pedagogy that you subscribe to? If so, describe.

- Do you belong to any professional organizations in education? If so, describe. 
- Name some of the professional literature or text that you rely on as part of your educational practice.

2. Please describe your educational background, including schools attended, major, and teacher preparation program.

- Tell me about the community you grew up in and the schools you attended during your PK-12 experience.

- What (if any) experiences in your upbringing, inform your teaching practice?

- Describe any influential teachers you have had during your educational experiences.

- Are you currently or have you recently taken education related classes, workshops, and/or conferences? If so, describe.

3. Tell me about where you are currently teaching. What is your job assignment? Describe the student population.

- What other grade levels have you taught?

- Have you worked at other schools or other educational settings?

- Describe those student populations.

- Have you had other roles in education, besides being a classroom teacher?

- Do you hold any additional endorsements to your teaching license? Which ones?

- What other roles or leadership positions do you hold in your school? In your district? In your community?

4. What do you believe "teaching for social justice" means?

- What does teaching for social justice mean to you?

- Do you read or subscribe to social justice-oriented literature? If so, describe.

- Have you taken or attended social justice-oriented classes, workshops, and/or conferences? If so, describe.

5. What might teaching for social justice look like in practice? Describe an example.

- Have you seen teaching for social justice first hand? If so, describe.

- What experience, course, person, text, film, etc. has been the greatest influence on your understanding of teaching for social justice?

- If not the "greatest influence," can you name some experiences with courses, people, text, film etc.? Describe.

- What stands out about this/these experiences?

- To what degree does teaching for social justice actually happen in the school settings? Why? 
- Have you seen specific lessons teaching social justice in your school setting? If so, describe.

- What are some of the limitations or challenges with teaching for social justice?

6. Have you taught lessons that had an anti-bias and/or social justice focus?

a If yes, tell me about them.

b If no, would you like to teach a lesson with this focus?

- What does the term anti-bias mean to you?

- Have you seen others in your educational setting teach an anti-bias lesson? If so, describe.

- What are some of your reservations about teaching an anti-bias or social justice lesson?

7. Have you taught lessons about race and racism with students? NOTE: Participants may indicated that they answered this questions already (questions \#6). If so, ask a follow-up question about the relationship between social justice and racism, as well as perceived differences.

a If yes, tell me about them.

b If no, would you like to teach a lesson with this focus?

- What do the terms race and racism mean to you?

- Have you seen others in your educational setting teach lessons about race and racism? If so, describe.

- What are some of your reservations about teaching lessons about race and racism lesson?

8. What role do you think race plays in the lives of children?

- Have you heard or witnessed any experiences where race has impacted students that you know or have worked with? If so, describe.

- Has race and/or racism been a topic that you have discussed with your colleagues? Your students in PK-12? With families? If so, describe.

9. What does the term "anti-racist" mean to you?

- Have you heard of this term before? If so, describe when and in what context.

- What does the term "anti-racist" curriculum mean to you?

- What might "anti-racist" curriculum look like in a classroom? Can you think of examples you have seen? If so, describe.

- Do you see the current literacy adoption as anti-racist? How so/not? 
- What changes do you think would need to be made to the current adoption to make it anti-racist?

10. When you think about your racial identity, what comes to mind?

- Have you ever explored your racial identity on your own, through a workshop or class, or by reading a book? If so, describe what you learned/realized.

- Specifically, how do describe your racial identity?

- Do you know your family's ethnic and racial background? If so, describe.

11. Have you ever participated in racial equity trainings, courses, or book clubs? If so, please describe these experiences.

- Describe the trainings, courses, and/or book clubs and books.

- If yes, describe what these experiences were like for you.

- Describe what you learned/realized from the experience(s).

- What was positive/beneficial about these experiences?

- What was challenging about this/these experience(s)?

- How did these experiences change your teaching practice? (If at all).

12. Is there anything else you would like to tell me, or anything else that I need to know?

\section{COLLABORATIVE PROFESSIONAL DEVELOPMENT SESSIONS}

Grand Tour (overview question): We have had X number of planning sessions, would you briefly walk me through those as though I was a teaching colleague that had not attended the sessions? (Look for follow-up questions, regarding specific memories or critical events.)

13. How would you describe the overall experience?

14. Describe what worked for you in this process of collaboration and planning.

- What are some things you learned through the collaborative professional development sessions?

- What was the most helpful? For planning lessons? For implementing lessons?

15. Describe what was challenging for you about this process of collaboration and planning. For planning lessons? For implementing lessons?

16. What are some things you learned through the collaborative professional development sessions? What has been the most helpful? What has been the most challenging?

17. What are some things that you learned through the collaborative professional development sessions about your own racial identity? 
18. Are there some other supports/resources or information that were helpful during the collaborative professional development sessions? If so, what?

19. Describe the emotions have you experience throughout this process.

20. How have the collaborative professional development sessions impacted your teaching practices around anti-racist lessons?

\section{PLANNING \& IMPLEMENTING ANTI-RACIST CURRICULUM}

21. One of the intended outcomes of this process is to plan anti-racist lesson plans. Tell me about the lessons that you are planning and walk me through your planning process for designing these particular lessons.

22. What resources did you used to write anti-racist lessons? What did you have to gather for writing the lessons?

23. Are there other supports/resources or information that would be helpful in planning anti-racist lessons? If so, what?

24. What have you learned about anti-racist curriculum? If you had to teach colleagues at your school about planning anti-racists lessons, where would you start?

- What would you include? How would you distinguish anti-racist lessons from lessons on other topics like kindness?

- What has been the most helpful? What has been the most challenging?

\section{If the teacher has taught the lessons...}

- Walk me through how the lesson unfolded. (Probe about student responses, teacher thinking and decision making, etc.)

- Tell me about the experience of teaching the lessons with your students. What was that like for you? (Think about probes across a range of possibility dimensions - emotional, cognitive, etc.)

- What did you change or need to change in the lessons?

- What would you do same/differently the next time they taught the lesson?

- Would you teach this lesson again? Why or why not?

- How did the students react to the lessons?

\section{CHALLENGES \& OBSTACLES}

26. Describe some of the challenges or obstacles around planning anti-racist lesson plans.

27. Do you have support in their education community to help you teach anti-racist curriculum? From administrators? Fellow teachers? How does that support unfold for you? 
28. Did you experience resistance or challenges in teaching anti-racist curriculum? From whom? What did that resistance or challenge look like/sound like?

29. What kind of feedback did you hear from families about your anti-racist instruction?

30. Do administrators inquire about the work? Do other teachers? What does that look/sound like? How does it make you feel? Does it affect your practice?

31. What kind of comments have you heard regarding this work? From administrators? Other teachers? Staff? Families? Other? What does that look/sound like? How does it make you feel? Does it affect your practice?

32. Describe the emotions have you experienced you have had with support and/or resistance, hearing feedback, comments, or inquiries.

\section{STIMULATED RECALL}

NOTE: During the collaborative professional development sessions, I will be taking participant observation notes. One thing I will be looking for is "critical events," which I describe as moments, conversations, or visible/observable ah-ha's that participants may have specifically related to race, racism, and anti-racist teaching. This would be a time for me to follow up with questions regarding "critical events." In addition, teacher participants will also be writing journal reflections throughout this process. I may also use journal entries to prompt follow up questions.

33. During the collaborative professional development session...X happened/I saw $\mathrm{X}$...tell me what that was like on your end, how did it feel, what were you thinking?

34. In your journal entry on $X$, you noted $X$...tell me what that was like on your end, how did it feel, what were you thinking?

\section{CLOSING}

35. Is there anything else you'd like to tell me regarding this project?

THANK YOU so much for talking to me. Your answers were really helpful for me. I really appreciate your help! 


\author{
Appendix D \\ Participant Observation Protocol
}

\title{
Overall Observation Guides:
}

Adopted from Creswell, J. W. (2002). Educational research: Planning, conducting, and evaluating quantitative and qualitative research. Upper Saddle River, NJ: Prentice Hall.
a. Participants and setting
b. Time, place, and length of observation
c. Descriptive observations (individual, setting descriptors)
d. Reflections (experiences, hypotheses, guidance)
e. Role of the observer (participant, nonparticipant, other)

\section{Participatory Observation Related to Research Questions:}

1. Quotes, words, descriptions, and explanations that have a tone of urgency or emotion

2. How the teachers describe the processes of planning

3. Challenges in implementation and teaching

4. Benefits or positive statements related to teacher

5. Narratives and counternarratives 


\section{Appendix E \\ Participant Reflective Journal Prompts}

This study will address the following research questions:

Q1: How do PK-12 teachers participating in a collaborative professional development experience describe the processes of planning and implementing anti-racist curriculum?

Q2: How do the teachers describe obstacles or challenges with planning and implementing anti-racist curriculum?

Q3: According to the teachers, how does participating in the collaborative sessions impact their teaching practices in anti-racist lessons?

Describe what the collaborative professional development sessions have been like for you.

- How would you describe the overall experience?

- What was the experience like planning with other teachers?

- What was helpful about this process?

- What was not helpful about this process?

Describe where you are at in the planning process for your lessons.

- What resources have you used to write anti-racist lessons?

- What materials or resources have you needed to gather?

Describe some of the challenges with this work of planning and implementing antiracist lessons.

- Are there limiting factors interfering with this work?

- Other obstacles or challenges not named?

- What kind of emotions have you experienced throughout this process?

Describe how this process has impacted or influenced your teaching.

- How did this experience impact your teaching practice?

- What are your takeaways from this experience? 